busich

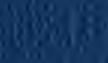

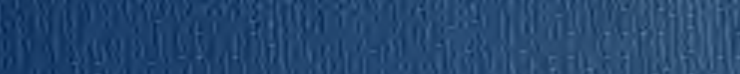

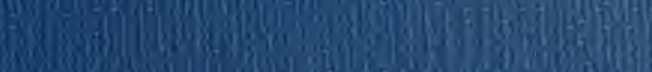
Wo.

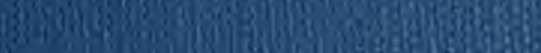
A s.2.

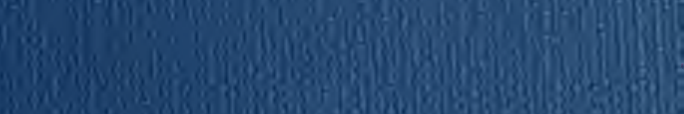

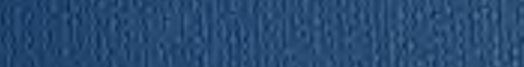

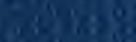

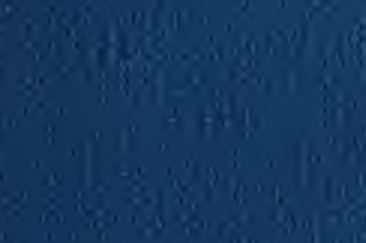

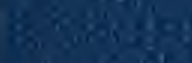

P. 3.5.

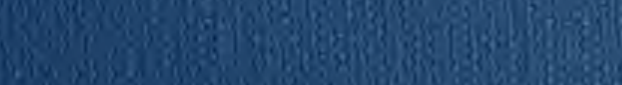

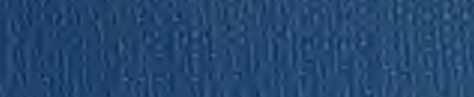

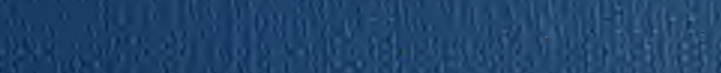

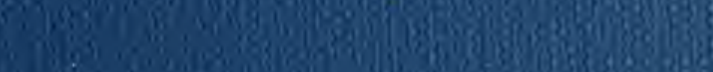
Si

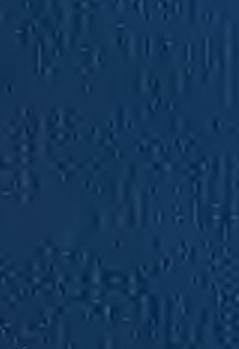

3016 4) 15\%

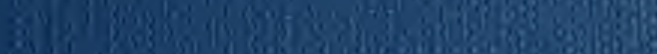
F. 1858 g.

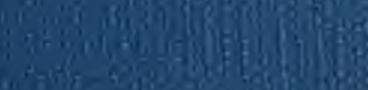

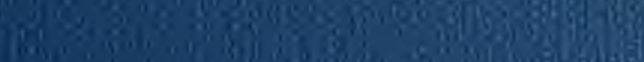

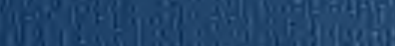
and

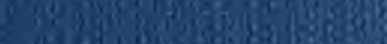

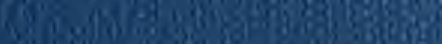
50\%

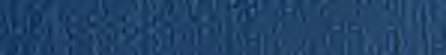
(1)

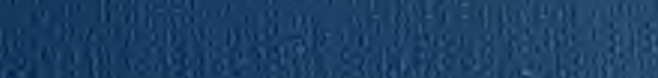

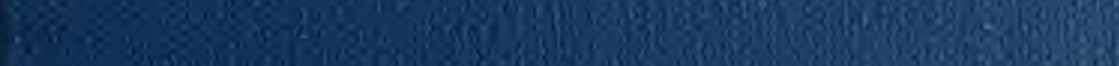



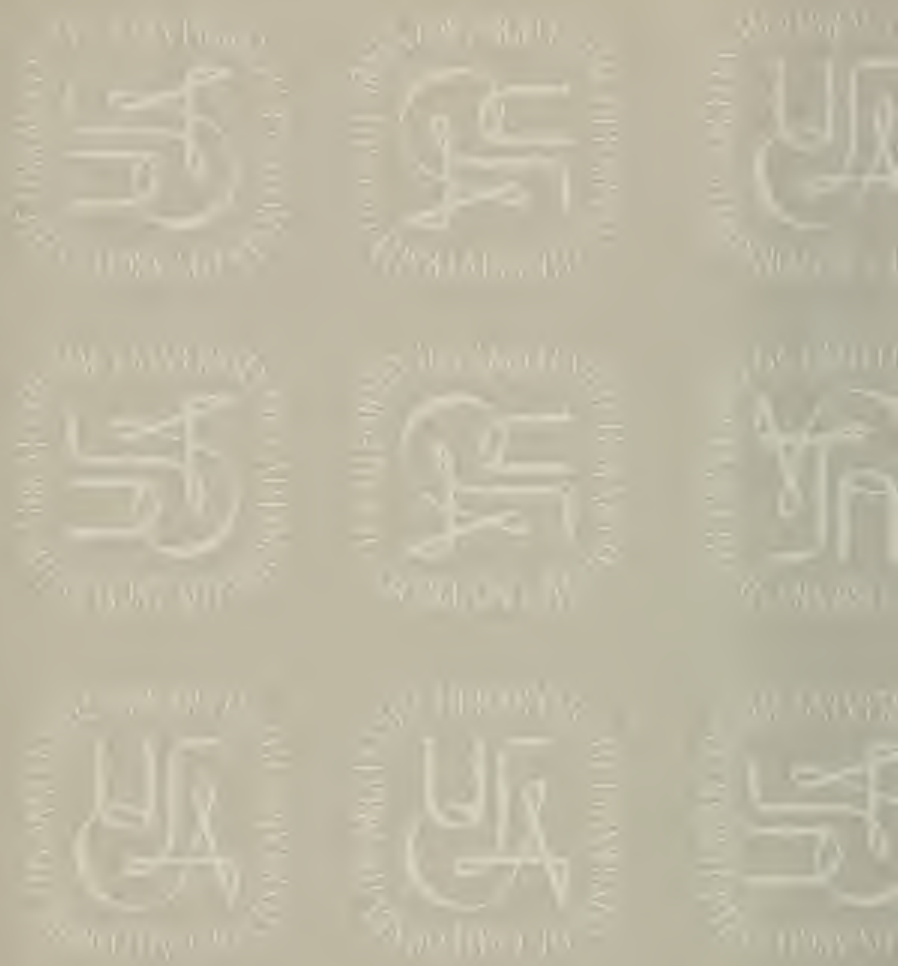

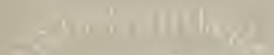
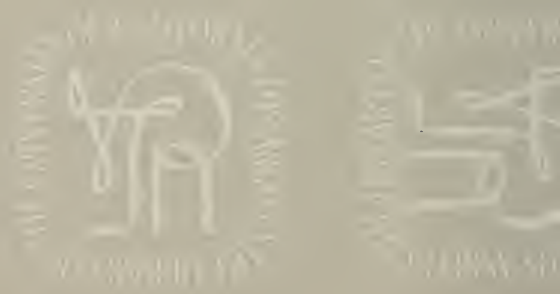

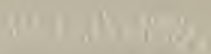

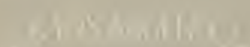

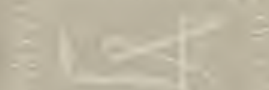

$=8\left(\frac{10}{2}=\right.$

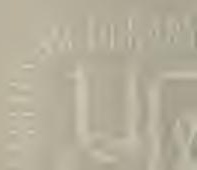







\section{BIRDS' NESTS}




\section{PUBLISHER'S ANNOUNCEMENT}

\section{TO-DAY WITH NATURE}

BY

\section{E. KAY ROBINSON}

Crown 8vo, Cloth Gilt, 6s.

"The work of an observer with eyes, and love to sharpen them. . . . Seldom indeed can you open a page without happening on something you did not know before and are glad to learn now. A quite charming book to keep by you and dip into."-The Academy.

"The book will be read with pleasure by all lovers of country life and natural history." -Outlook.

"As a faithful chronicler of wild life $M$ r. Robinson has nothing to fear from living competitors."-Daily Mail.

"Full of really fresh observation, especially about the habits of birds, ... the author is a real lover, and a really close student, of wild life, and we have read his book with the greatest enjoyment."-Literature.

\section{LON DON \\ GRANT RICHARDS}





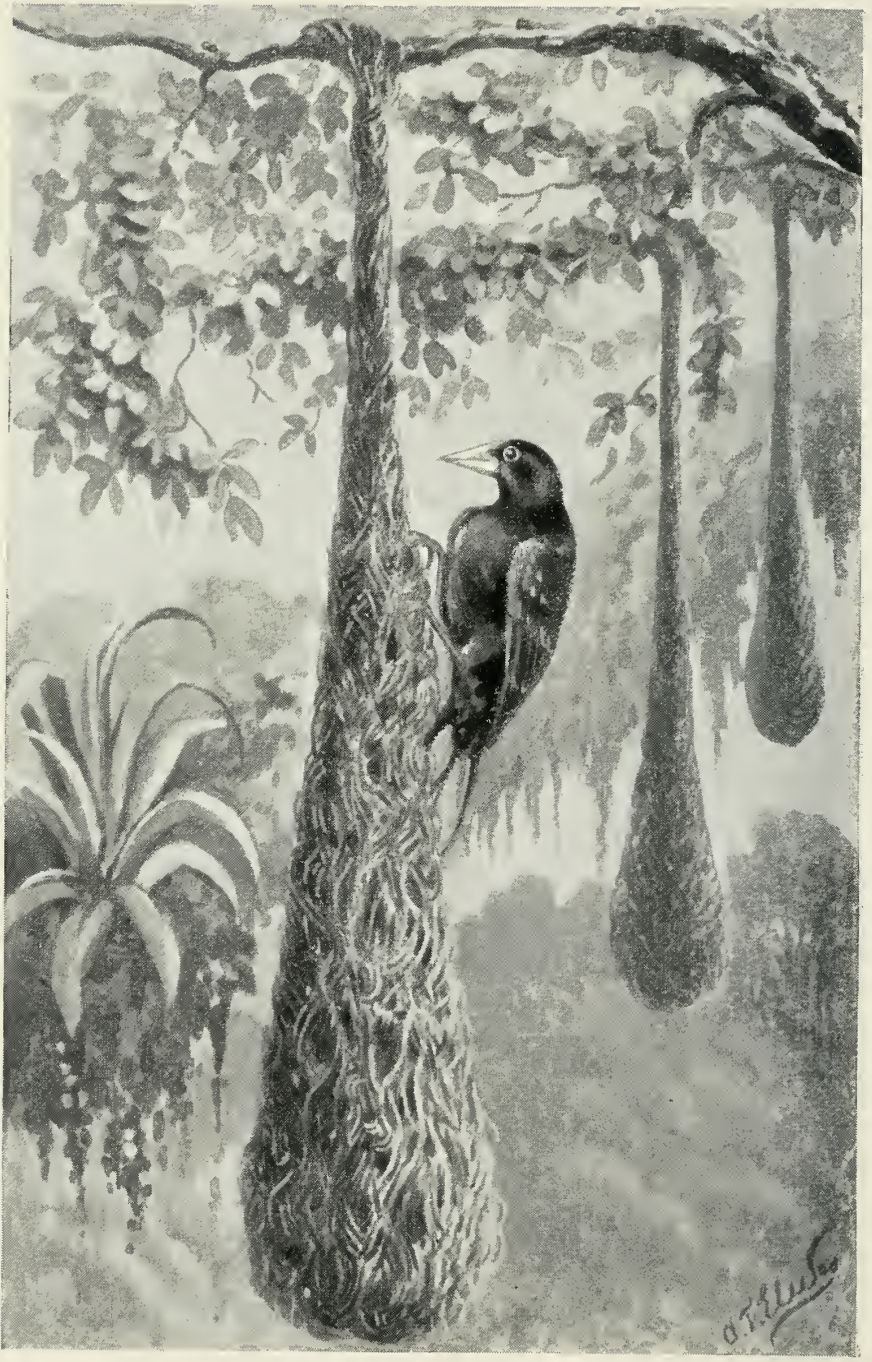

NESTS OF THE CASSIQUE (Page 266). 


\title{
BIRDS' NESTS
}

AN INTRODUCTION

TO THE SCIENCE OF CALIOLOGY

BY

\section{CHARLES DIXON}

AUTHOR OF

RURAL BIRD-LIFE," "THE GAME BIRDS AND WILD FOIVL OF THE BRITISH ISLANDS," "BRITISH SEA BIRDS," "CURIOSITIES OF BIRD LIFE,"

"THE MIGRATION OF BIRDS," "AMIONG THE BIRDS IN NORTHERN SHIRES," "THE STORY OF THE BIRDS," ETC., ETC.

WITH ILLUSTRATIONS BY A. T. ELWES

\author{
LONDON \\ GRANT RICHARDS
}

NEW YORK

FREDERICK A. STOKES COMPANY

I $9 \circ 2$ 



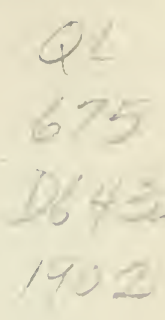

\section{PREFACE}

IT is a somewhat remarkable fact that notwithstanding the extreme popularity of the subject of Birds' Nests, no book has yet been published entirely devoted to these beautiful and curious objects. And yet their study - the science of Caliology-is one of the most fascinating branches of Ornithology, perhaps more intimately connected with those difficult problems and questions relating to the mental attributes of what man in his ignorance is pleased to consider the "lower animals," than any other. Indeed, there are many of us who would fain deny the existence of any reasoning faculties whatever in birds, classing their expression in a thousand different ways, all under the vague, meaningless and ridiculous term "Instinct."

A bird's nest is the most graphic mirror of a bird's mind. It is the most palpable example of those reasoning, thinking qualities with which these creatures are unquestionably very highly endowed. Evidence of this reasoning power confronts the student of Birds' Nests as he gazes upon each procreant cradle, no matter how crude on the one hand, or how elaborate on the other it may chance 
to be; for each type of home represents the best possible harmony with the conditions under which reproduction may take place.

Unfortunately, Birds' Nests have been little studied in relation to those important scientific questions with which they are so inseparably involved. Alas, too often the despoiling oologist carries off the coveted eggs without even a glance at the cradle which holds them, or with no thought to the philosophy of the architectural arrangements (or to the want of them) before him. Then on the other hand there is the observer who views such structures as objects of beauty only, ignoring all evidence of purely utilitarian significance. For him, a pretty nest is one to be admired for its beauty alone; but the neatest and most elaborate and beautiful bird cradle ever put together, is no more woven for beauty's sake, than the crudest nest-form is provided with any view to the lack of it. Birds' Nests are purely utilitarian structures; their beauty or their ugliness, their elaborate finish, or their crude workmanship are matters of human sentiment only, and play no part in the general plan of avine architecture. Upon such a foundation the science of Caliology alone must rest, and its philosophy must be woven round a utilitarian motive, not one in any sense of beauty for its own sake.

The opportunities for the scientific study of Birds' Nests are well-nigh endless; for almost every nest 
presents special features and is an example of individual intelligence. At present our lack of information relating to the manner in which a nest is made in the majority of species is almost complete. The building sex-the part played by the male bird, the various stages through which a nest must pass before completion, and a hundred other items require the most patient observation. Even our lack of knowledge is vast concerning the nests of British birds alone; and when we come to exotic species, information is much more meagre still.

The present little volume has been written with the object of guiding the student to an acquisition of a scientific knowledge of Birds' Nests. It has been necessarily a brief one, but many lines of original research have been indicated, and some sort of plan promulgated upon which the science of Caliology may, at all events, provisionally be based.

Charles Dixon.

Paignton, S. Devon, 1901. 



\section{CONTENTS}

\section{CHAPTER I}

\section{INTRODUCTORY}

Absence of literature relating to Birds' Nests-Difficulty of classifying Nests-The Philosophy of Birds' Nests-Nests regarded as Utilitarian Structures-Intelligence of Birds in Nest-buildingThe Theory of Instinct-Changed Nesting Habits and TypesEvidence against the Theory of Instinct-Variation in Nestbuilding Skill-Wallace's Theory of Birds' Nests-Faculties Employed by Birds in Nest-building-Retention of Old Habits by Various Birds-Nest-building Tools-Differences in Nest-typeAmongst Nearly Allied Birds-Abnormal Nest Materials-Abnormal Nest sites-The Nest-building Sex-Instructions for Collecting and Preserving Nests-Necessity for Recording Certain Facts-Preservative for Nests-Storage of Nests

\section{CHAPTER II}

\section{Nestless Birds, Annexers, and Parasites}

Conditions of a nestless state-Occasional lapses in the Nest-building Habit-Nestless Birds-Tropic Birds and Vultures-Ringed Plover - Coursers and Pratincoles-Stone Curlew-Gulls and Terns-Auks -Nestless Petrels-Goatsuckers-Origin of the Nestless HabitNumber of Eggs laid by nestless species-Annexing Birds-Birds of Prey and Owls-The Kestrel-The Hobby-Honey BuzzardOrange-legged Hobby-Iceland Jer.Falcon-The annexing habit not always universal in the same species-Egyptian Vulture-Turkey Vulture-Cooper's Hawk-Tawny Owl-Long-eared Owl-Tengmalm's Owl-Hawk Owl-Eagle Owl-American Parred Owl-Sawwhet Owl-Green Sandpiper-Wood Sandpiper-Swallows-Birds building in nests of other species-Great Titmouse-House Sparrow -Purple Grackle-Spanish Sparrow in nest of Stork-Return of Birds to old Nests-Parasitic Birds-Origin of the habit of Parasitism -Coloration of Eggs of Parasitic Birds-Cow Bird-Birds laying astray-Birds evicted by other species-Benevolent characteristics in Birds-Origin of Parasitism through the young 


\section{CHAPTER III}

\section{The Crudest Nest.Forms}

Apparent development of nest-building art-Illustrated by nest of Bullfinch-By nests of Crows-By nests of "Willow Wrens"-Importance of nesting conditions-The most skilful nest-builders-Crude nest-forms of Ratita Birds-Nidification of the Ostrich-Of the Falcons-Of certain Owls-Of the Coraciiformes-Of the Psittaciformes-Of the Cuculiformes-Of certain Cuckoos-Of the Columbiformes-Peculiarity in nests of Pigeons-Of certain Tyrant Birds-Of the Pediophli or Sand Grouse-Of the Game Birds or Galliformes-Similarity of architecture in this order-Nests of the Charadriiformes-Of the Bustards-Of the Oystercatchers-Of the Stilts-Of the Woodcocks-Of the Jacanas-Of the Crab PloverCrude nest-forms of the Divers-Of the Penguins-Of the Procellariiformes-Of the Lariformes-Nests of the Noddy Tern-Of the Skuas-Of the typical Gulls-Of the Black-headed Gull-Of the Ducks and allied Birds-Of the Mergansers-Uses of down in these Nests-Number of crude nest-builders-The State of the young when hatched

\section{CHAPTER IV}

\section{Concealed or Covered Nests}

Nests made in earth tunnels-Sand Martins-Tunnel-boring Wood Hewers-Nest of Sclerurus umbretta-Of the Kingfishers-Of the Jacamars, Todys and Bee-eaters-Of certain Parrakeets-Of the Burrowing Owl-Of the Puffins-Of the Petrels-Stormy PetrelFork-tailed Petrel-Spectacled Petrel-Of the Whale Birds-Of the Shearwaters-Cave-building Birds-The Jackdaw-The ChoughsThe Rock Dove-The Shag-Cock of the rock-Oil Bird-Edible Swifts-Alpine Swift-Cave-building Swallows-Nests under stones and in holes and fissures of rocks-Various Petrels-Little AukHorned Puffin-Little Owl-Certain Parrots-Various Chats-Redstarts and Accentors-Wall Creeper-Rose-coloured StarlingBuntings and Swallows and Pipits-Timber-building Birds-Woodpeckers and Wrynecks-Hornbills - Toucans and Trogons-Barbets and Honey Guides-Parrots-Certain Cockatoos-Hoopoes-Rollers -Titmice-Nuthatches-Certain Flycatchers-Sparrows-Nest of Phylloscopus occipitalis-Scops Owl-Certain Ducks-Nests in holes, in banks, or under tussocks of vegetation-Robins and Buntings-Twite and Ring Ousel-Mound Birds-The Philosophy of Concealed Nests 


\section{CHAPTER V}

\section{Open Nests}

Open Nests a widely prevailing type-Nests of certain Geese-Nest of the Screamer-Nests of Curassows, Guans and the Hoatzin-Of Bonaparte's Gull-Classification of "Open" Nests-Nests of the Albatrosses-Of the Herons and Bitterns-Of the Spoonbills and Ibises - Of the Storks - Nests of the Pelecaniformes-Of the Gannets-Of the Cormorants-Of the Darters-Of the PelicansOf the Frigate Birds-Of the Flamingoes-Of the Cranes-Of the Rails and Finfoots-Nests of various Falconiformes-Of the Vultures-Of certain Eagles-Of the Kites-Of the Hawks and Harriers - Of the Ospreys - Nests of the Humming Birds - Of certain Swifts-Of the Colies-Nests of the Passeriformes-Of Crows and allied Birds-Of the Birds of Paradise-Of the Drongos -Of the Orioles-Open Nest of a Hangnest-Of the TanagersOf the Finches and allied Birds-Of the Larks-Of the Wagtails and Pipits-Of the American Wood Warblers-Of the Honey-eaters -Of the White-eyes-Of certain Flower-peckers-Of the Goldcrests -Of the Bearded Titmouse-Of the Shrikes-Of the WaxwingsOf the Vireos-Of the Thrushes-Of the Whinchat-Of the Warblers - Of the Mocking Birds-Of the Timeliidæ-Of the Tailor Birds -Of the Laughing Thrushes-Of the Bulbuls-Of the Cuckoo Shrikes - Of certain Flycatchers-Of certain Swallows - Of the Tyrant Birds-Of the Chatterers-Of the Ant Thrushes-Of the Pteroptochidæ-General Remarks on the Open or Cup-shaped Type of Nest-Mimicry in Nest-building . . . . .

\section{CHAPTER VI}

\section{Domed AND Roofed Nests}

Nest of the Hammer-head-Domed Nests of the Rails-Of certain Swifts -Of various Parrots-Of the Lark-heeled Cuckoos-Nests of the Broad-bills-Of the Lyre Birds-Domed type a dominant one in the Order Passeriformes-Of the Magpies-Of certain Starlings-Of the Meadow Starling-Of the Weaver Birds-Domed Nests of certain Tanagers-Of the Sugar Birds-Of certain Sparrows-Other domed. building Finches-Of the Bush Larks-Of certain American Wood Warblers-Of the Sun Birds-Nests of the Sun Birds resembling those of the Social Spiders-Nests of the Flower-peckers-Of certain Titmice-Of the American Bush Tits-Of the Hill Tits-Of the Rock Nuthatches-Of the "Palm Sparrow"-Of the Willow Warblers-Of the Fantail Warblers-Of the Dippers-Of Origma rubricata-Of the Wrens-Of the Timeliidæ-Of various Pomatorhini-Of various species of Pellorneum-Triple types of Nest- 
Nests of certain Flycatchers - Of various Swallows - Of certain Tyrant Birds-Of certain Chatterers-Of the Pittas-Of various Wood Hewers-Of the Oven Bird-Of certain species of Pteroptochidæ-General Remarks . . . . . . .

\section{CHAPTER VII}

\section{Pendulous Nests}

Erroneous opinions respecting Pendulous Nests-Definition of Pendulous Nests-Rarity of this type in Avine Architecture-Variation in shape of Nest in same species-Nests of the Penduline Tits-Of various Flower-peckers - Of certain Honey-eaters - Of various species of Gerygone-Of the Glossy Starlings-Of the Weaver-birds -Of the Indian Weaver-bird-Extraordinary Nest of this SpeciesOf the Vellow-crowned Weaver-Various shapes of Weaver-birds' Nests - Method of building adopted by Weaver-birds - Weaverbirds a striking feature of Eastern Bird Life-Nests of the Hangnests-Shape and dimensions of Nests-Changes in Materials used according to locality occupied by species-Nest of Baltimore Oriole -Reason displayed by Birds in Nest-building - Most typical Pendulous Nests-Of various Cassiques-Nests of the Cassiques a feature in tropical American scenery-The Cow Birds-Parasites -Various facts relating to Pendulous Nests-Enemies to Birds and Eggs-Resumé of previous chapters and conclusion . 


\section{LIST OF ILLUSTRATIONS}

Nests of the Cassiques .

Frontispiece

Abnormal Nest of the Chaffinch . . Face page 13

The Ringed Plover and Eggs . . . " , 43

Eggs of Green Sandpiper in Old Nest of

FIELDFARE . . . . . . , 50

Nest of 'The Ring Dove. . . . . . " 70

Nest and Eggs of the Mallard . . . . ,, 83

Nest of the Edible Siwift . . . . . $\quad 104$

TyPiCal Nest of a WOOdPECkER . . . , , 115

Flamingo and Nest . . . . . . $\quad$, 152

Nest of Calliope Huming Bird . $\quad$, 164

Golden Oriole and Nest . . . . "

Nest of the ChafFincii . . . . . "

Magpies ANd Nest . . . . . . . $\quad 214$

Nest of Magnificent Sun Bird . . . , 223

Nest of The Longtailed Tit . . • " 226

Nest of A Weaver Bird . . . . , 260 

CHAPTER I

INTRODUCTORY 



\title{
BIRDS' NESTS
}

\author{
CHAPTER I \\ INTRODUCTORY
}

Absence of Literature relating to Birds' Nests-Difficulty of Classifying Nests - The Philosophy of Pirds' Nests - Nests regarded as Utilitarian Structures-Intelligence of Birds in Nest-building-The Theory of InstinctChanged Nesting Habits and Types-Evidence against the Theory of Instinct-Variation in Nest-building Skill-Wallace's Theory of Birds' Nests -Faculties Enployed by Birds in Nest-building-Retention of old Habits by Various Birds-Nest-building Tools-Differences in Nest-type-Amongst Nearly Allied Birds-Abnormal Nest Materials-Abnormal Nest Sites-The Nest-building Sex-Instructions for Collecting and Preserving Nests-Necessity for Recording Certain Facts-Precervative for Nests-Storage of Nests.

Although birds are by no means the only creatures that make nests, either to shelter themselves or for the purpose of reproduction, they are unquestionably by far the most closely associated in the popular mind with such structures. Popularly speaking a bird and a nest are inseparable terms, one invariably suggesting the other. Among insects, fishes, and animals, for instance, there are many elaborate and cunning nest-builders, but we have little hesitation in stating that birds will still continue to furnish the one popular example of Nature's architects. There must be few persons indeed, nowadays, unfamiliar with a bird's nest of some species or another; on 
the other hand the elaborate and wonderful homes of the hornet, the sticklebat, and the dormouse (to quote but three of the commonest examples) are rarely seen and even less frequently examined by ordinary observers.

It is a somewhat remarkable fact, that notwithstanding the great and increasing popularity with which nests are regarded as objects of admiration, no work has within the past seventy years been written entirely devoted to them; whilst little less extraordinary, down to comparatively recent times they have been almost entirely discarded by the biologist, and their scientific study has been almost completely ignored. This is all the more remarkable when we bear in mind that their investigation not only involves a study of the mental attributes of the birds that build them, but is very intimately associated with the habits and structure of their feathered builders. Seventy years ago Rennie published a book about nests, entitled The Architecture of Birds; whilst in $1868 \mathrm{Dr}$ Wallace promulgated his celebrated "Theory of Birds' Nests," by far the most scientific contribution to the subject which had then been published. Darwin and one or two other naturalists have briefly touched upon the subject; whilst the late J. G. Woods' popular treatment of birds' nests, in his Homes without Hands, practically exhausts the special literature of caliology. There are of course many memoirs and 
so forth (amongst which we may allude to those of the present writer, with criticisms thereon by Allen, the American ornithologist) relating to nests, scattered over various books and periodicals of a natural history character; whilst the nests of a very large proportion of the twelve thousand (in round numbers) species of known birds have been described in numerous ornithological works. Nests, however, have never yet received that special treatment which we intend to devote to them in the present little volume.

The arrangement of the subject matter, so that it may be at once comprehensive and intelligible, in a work of this character, is attended by no little difficulty. Nests do not admit of the same methods of classification as the birds that build them. The various types of nests are by no means peculiar to groups or even genera, because we find most wonderful exceptions in what are obviously closely allied species. Neither can we classify nests by materials, for we are confronted by a still more bewildering similarity on the one hand, or an equal diversity on the other-remotely related species employing the same fabrics, closely allied birds, even the same species, selecting vastly different ones. It seems, therefore, the most satisfactory way to divide nests into various grades and types quite irrespective of their ownership, and as far as possible to deal with the crudest nest forms first, 
passing on to the more elaborate structures. First of all, however, as nests are such an avine characteristic, it seems desirable to glance at those birds that do not make a nest at all.

Before doing so, and in order better to understand the study of our subject, it becomes necessary to enter at some length upon the more philosophical side of it. There are, perhaps, few things in nature more exquisitely pretty than the nests of certain birds; not only do these structures appeal to us through their beauty, but still more so through the creative mind of the little architects that build them. But mere admiration of these complex structures can lead to nothing more; their beauty, great as it is, is by no means the end and purpose for which they were so deftly woven; we must discard their attractiveness in this direction and ever keep prominently in view their utilitarian purpose, should we desire to gain an insight into their philosophy. We may almost safely say that birds are not influenced by any sense of the beautiful in making their nests. If they are we have no direct proof of it, and the evidence that we at present possess is purely of a negative kind. Apparent instances of nest decoration from motives of beauty rather than utility are presented by such nests as the Chaffinch and the Long-tailed Titmouse, the outer walls of which are generally garnished with showy lichens, scraps of paper, bits of decayed wood, and so forth. Gould, with a totally erroneous con- 
ception of the facts, has stated that certain Humming Birds decorate the outside of their nests with the utmost taste, instinctively fastening upon them beautiful pieces of flat lichen, or now and then attaching a pretty feather in the same way. Darwin, in the Descent of Man, unfortunately quotes Gould's deductions, and has thus been misled, like so many other compilers before him, in giving as evidence of a taste for the beautiful in birds, what in reality is nothing of the sort. We believe that in every case of nest decoration apparently prompted by a taste for the beautiful, it will invariably and without exception be found that the primary, we may even say the exclusive, motive is that of concealment; an effort to evade discovery by harmonising the exterior of the nest with surrounding objects, either by an assimilation or blending of colour, or a collection of similar material to that near which the nest is built. Let it be clearly understood, however, that these remarks are in no way intended to convey the idea that birds have no taste for the beautiful. On the contrary, birds as a group have perhaps this xsthetic taste more highly developed than any other living creatures, man alone excepted. Some of the most convincing evidence of this is furnished by the Bower Birds, which are known to decorate their bowers or places of courtship in a highly elaborate and often gaudy manner. But these "bowers" have nothing to do with the nests, and are apparently intimately 
associated with that love of display, ornate and otherwise, which forms such a special feature in the courtship of so many birds. The direct evidence in support of the possession of this taste in birds would fill a volume, but is of course quite beyond the subject of Nests.

The nest of a bird then, apart from whatever natural beauty the special conditions of environment or the wants of the species may demand, must always be regarded as an utilitarian structure. It is the receptacle which nest-building birds provide for the purpose of containing their eggs during the period of incubation, and afterwards the young until they are sufficiently matured to follow a more volant existence. When once these purposes are served, the nest, no matter how elaborate or beautiful it may be, or the immense amount of labour it may have cost its owners, is forthwith deserted, either for ever (and in the case of not a few elaborate builders, such as the Long-tailed Titmouse and the Chaffinch, this is invariably the case), or only used again when the recurring necessities of reproduction require it. Like the gaudy chrysalis or cocoon, and notwithstanding its beauty, which has served but a secondary and quite unappreciated purpose, it is discarded and left to inevitable decay, its owners taking no further interest in it whatever. The leafless hedges in autumn disclose to us in large numbers these deserted nests, whose beauty is 
seen and appreciated by the human observer alone.

But if birds display no taste for the beautiful in their nests, their Intelligence in constructing them is beyond the slightest question. This intelligenceor perhaps reason is a better term-is abundantly manifest from the selection of the site up to the moment the last scrap of material is worked into the structure. In dealing with this part of the subject we reach a point in which it becomes necessary to decide whether a bird builds its nest by the guidance of blind instinct or by the exercise of its mental powers. On the one hand there are not a few able naturalists who believe that a bird builds by instinct; that a young bird is born with the power to make a nest typical of its species when the time comes for it to exert its inherited power in this direction. This opinion, we need scarcely say, is almost universally shared by the popular lover of birds, although very little thought, reasoning or experiment would be required to show that it is as untenable as it is unreasonable. On the other hand, a small but increasing number of naturalists, at the head of which we must in fairness place Alfred Russel Wallace, have sought to show that the nest-building capabilities of birds may be satisfactorily explained by the exertion of a reasoning faculty.

Now Instinct, which we may define as Inherited Habit, in a young bird is by no means sufficient to 
explain the act of building a first nest. If such were really the case, a young bird hatched in a nest of some other species should be able when the time arrives for it to require a nest to set to work and build one on the exact model prevailing with its particular species, and formed of similar materials to those selected by its own kind. This must consequently attribute to a bird an inborn inherited faculty for performing a most complex action, and endows that bird with powers that animals on a much higher plane of intelligence are incapable of accomplishing; for not even man himself can build a shelter resembling in its architecture that of his own tribe or race, without some model to copy or the instructions of his more experienced fellows. Then again, instinct or inherited habit being a power transmitted from parent to offspring in one unchanging order of descent, must necessarily be a constant power in the sense of never varying. We must assume it to be a stationary power, as perfect and unerring in the new-born chick as in the adult bird. Birds hatched with this instinctive power to make a nest without imitation, tuition, or experience must be able to exert it successfully under any circumstances; whilst the ancestral type of nest must resemble in every particular that which is constructed now, or that will be constructed unnumbered centuries hence. But unfortunately for this very attractive supposition, it is not supported by a single particle of fact; whilst 
the evidence against it (if at present somewhat meagre) is quite sufficiently conclusive and unanswerable. Like many other popular beliefs, it is founded upon tradition and myth. The theory of an unchanging instinct or unvarying inherited habit is disproved by the fact that birds do very frequently choose a site for their nest which differs in many respects from the one usually selected by the species, instances of which must be familiar to every observer; and by persistence in it, if found to be advantageous or in no way injurious an entirely new nesting habit may result. Then again, although the fact is perhaps not so generally known, many birds have not only changed their habits of nesting, but in some cases have completely altered the type of their nest. Such a change is entirely at variance with any inherited habit, and shows that birds are constantly exercising their mental powers in adapting themselves to changing conditions of life. Even in the British Islands no less than five species can be named which are known to have changed their mode of nest-building considerably during a comparatively short lapse of time. The House Martin there can be little doubt before the dawn of civilisation in this area attached its nest to maritime and inland cliffs. But with the prevalence of a more elaborate form of human architecture, the Martin, with an ever alert sense of adaptiveness, acquired the habit of attaching its nest to the most suitable portions of the new and 
artificial sites. By this means, we may incidentally state, the Martin has been enabled to extend its range into new districts, and has doubtless increased accordingly. The Swallow at a similarly remote period must have bred in caves and hollow trees, just as so many kindred species do at the present time in wild uncivilised countries. Like the Martin it has not failed to profit by the changed conditions afforded by modern architecture, and nowadays attaches its nest to rafters and other convenient ledges and projections about houses, barns, and so forth. The Starling has shown a very similar power of adaptiveness, whilst the Jackdaw is perhaps quite as familiar and interesting an instance. Lastly we may mention the House Sparrow, a bird possessed of exceptional intelligence and sagacity, and one which has not only changed its nesting habits within historic time, but also its building materials to an extent unequalled by any other known bird. A still more extraordinary instance of changed methods of nesting in this species in New Zealand (to which country the bird has been introduced) has been recorded in Nature (1888) by Mr G. L. Grant. He writes as follows: "In many of the deep cuttings in our roads, and on the cliffs upon our river banks, where the formation is a light pumiceous sand, these birds are in the habit of burrowing holes similar to those of the Sand Martin. In some cases I have found these burrows by measurement to be as much as six feet in depth." Instances are also on record 



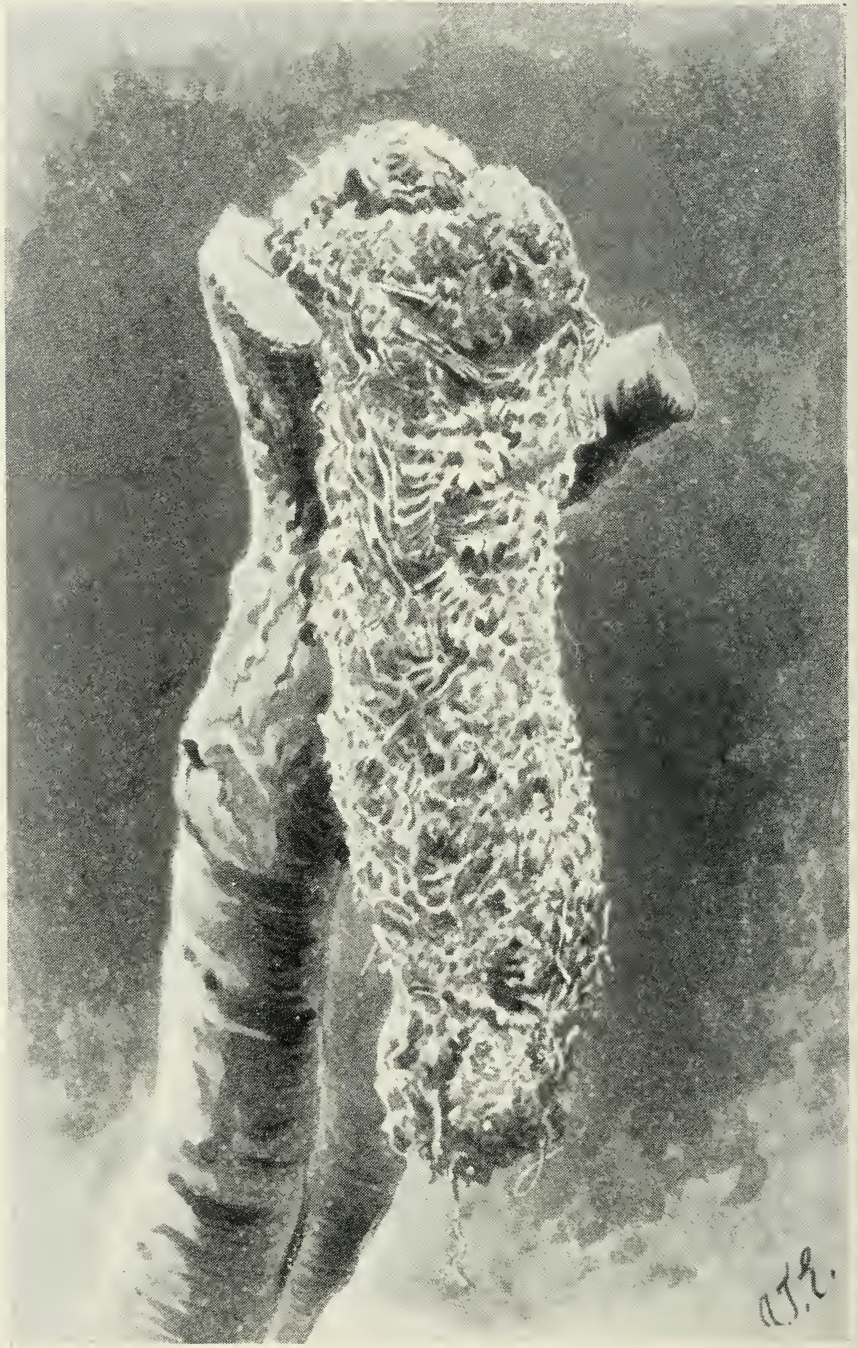

ABNORMAL NEST OF THE CHAFFINCH (FRINGILLA CELEBS). 
where species have completely changed their method of nesting when threatened by some new danger. The Penguins of Tristan d'Acunha have since the introduction of pigs into the islands sought safety for their eggs and young by changing the site of the nest from an open to a covered one. Other instances of avine intelligence as opposed to fixed inherited habit are the departures from the general rule in the method of reproduction, so remarkable in not a few species. Herons will nest indiscriminately upon cliffs or trees or upon the ground in fens and marshes. Eagles in some countries nest upon trees and cliffs; elsewhere on the ground. The Cormorant is as much at home when nesting in a tree as upon a maritime cliff or a low rocky reef; whilst the Moorhen and some other ground-breeding birds have been known to make their nests in trees, in districts subject to sudden floods-another interesting proof of avine intelligence and reasoning power.

Lastly, we have the most important evidence of all against the theory of blind instinct or inherited habit in the now absolutely proved fact that birds are incapable of building a nest typical of their species without the aid of imitation or experience. Although we have recorded the facts in Nature and elsewhere, they are sufficiently important and interesting to be fully repeated in a work dealing exclusively with nests. The striking illustration here given is from an actual photograph of a nest made by a pair of 
Chaffinches that had been taken out to New Zealand. They were young birds, and had had no experience of nest-building in England before their departure; turned out in their new home to forage for themselves, and in every way in a state of nature. This nest is built in a fork of a branch, and shows none of that wonderful neatness of fabrication for which the Chaffinch is so justly famed in England. The cup of the nest is small and loosely put together, and the walls of the structure are prolonged for about eighteen inches, hanging down the side of the supporting branch. Indeed it more resembles in its structure the nests of the American Hangnests (Icteridæ), with the exception that the cavity containing the eggs is situated on the top. Clearly these New Zealand Chaffinches were at a loss for a design when fabricating their nest. They had no standard to work by, no nests of their own kind to copy, no older birds to give them any instruction. Possibly these Chaffinches imitated in some degree the nest of a New Zealand species; or it may be that the few resemblances this extraordinary structure bears to the typical nest of the Palæarctic Chaffinch are the results of memory-the dim remembrance of the nest in which they were hatched, but which had almost been effaced by novel surroundings and changed conditions of life. There can be little or no doubt that had these young Chaffinches been hatched in an alien nest in England, 
and never allowed to see a nest typical of their species, or have any communication with old and experienced birds, the results would have been still more startling and strange.

There is just one more point we ought to mention before finally dismissing the subject of Instinct. We have already seen that the great range of variation in site and materials amongst the individuals of the same species is a most serious and fatal objection to any theory of inherited habit. We have also the no less important fact that the nests of birds of the same species are by no means all of the same excellence of construction. In other words, nests are sometimes very indifferently made, some being much more perfectly constructed than others. The supporters of the theory of instinct assert that the first nest a bird makes is as perfect as that which it will construct after years of experience. This is a bold assertion, but after all it is no more than the theory inexorably demands, because if the habit is inherited it must be as perfect at the beginning of a bird's life as at the end of it. Unfortunately, however, it is quite at variance with the actual facts. My own observations, as well as those of many other naturalists, do not in the least tend to confirm its accuracy. From a lifelong experience of birds' nests in many localities, I can assert without hesitation that at least five per cent. of the nests of any one species selected for comparison are carelessly 
made, and evidently the work of inexperienced birds. This is all the more remarkable in species that make fairly elaborate nests, being specially observable in such nests as those of the Chaffinch, Goldfinch, Longtailed Titmouse, and Song Thrush. But when we begin to quote examples we might name almost every nest-building species, and we know that the experience is a common one amongst naturalists and collectors. That the fact is widely known is proved by a note contributed to the Leisure Hour some years ago by a correspondent at Petersfield. My readers may possibly like to have the extract in full. "About eight years ago a Blackbird built near a well in our garden. It was evidently a novice at building, for it put such a large lump of clay in the nest it could not tread it down into the proper layer, though it tried hard to do so for several days. At length it built another nest about a hundred yards from the first, and that it filled so full of leaves it could not make a comfortable nest, and eventually relinquished it. I do not know what the bird did in the end, but a village boy who was working in the garden told my children that the first nest was built by a young bird who had not learnt to build properly. I doubted that being true, and when the bird made a second failure the boy again pointed out that he was right as to its being a bird which had never made a nest and had not gained experience; and that he and other boys often found nests badly 
built and forsaken, and that it was a well known thing that young birds only built a proper nest after several experiments. I doubt if old and experienced birds ever show the inexperienced; I think it is a matter of experience solely. It is a belief in this village that Wrens build several nests a year which they do not inhabit, and one of my sons says he has proved that is so." Another instance coming very recently within my own experience may also be given. During the past spring (1900) a pair of Song Thrushes took up their quarters in my garden for nesting purposes, and I had every opportunity of observing the preliminary operations of the female bird which from a minute examination within a few feet, aided by a field-glass, had every appearance of being a bird of the previous year, the buff spots on the wing coverts being very large and bright. No less than three nests were commenced in as many different sites (laurel bushes) and abandoned after a mere heap of dry grass had been collected, which I may say the hen bird was most assiduous in gathering, especially in early morning and again at evening. A pair of older Thrushes were also nesting in the same garden, and in their case the nest was begun and finished without any abortive attempts. The young bird eventually made an indifferent nest with scarcely any mud or decayed wood for lining, in which she laid three eggs which for some reason unknown to me both birds deserted. Again, there is more local variation in avine architec- 
ture than is generally supposed. I have repeatedly remarked during my birds'-nesting wanderings not only over many parts of the British Islands, but in foreign lands, that the nests of some of the commoner species present a very marked diversity. For instance, the Chaffinch, generally speaking, I have found builds a much less finished nest in Devonshire than in other parts of England, whilst on the other hand the finest nests of the Long-tailed Titmouse I have ever seen were from that county. I was also much struck with the local differences of some of the birds' nests I found in Algeria, belonging to species that also breed in our islands. Doubtless other observers have remarked very similar facts.

Having thus discarded the theory of instinct or inherited habit, the reader may justly ask what we would offer as a substitute for it? We may here repeat in substance the matter most closely bearing upon this subject which is contained in a paper written by us and read before a scientific society in Yorkshire some years ago. Mr Wallace's theory that birds do not make their nests instinctively, but by imitating the nests in which they were reared-that if they never saw or were not brought up in a nest peculiar to their species they would be unable to construct one for themselves similar in position, form, and materials is, after the absolute confirmation supplied by the instance of the New Zealand Chaffinches just given, probably the true solution of this interesting problem. The 
question, therefore, arises, How do birds build their nest, and especially their first nest. To credit birds with instinct which because it seems so self-evident is taken to be matter of fact, is to admit that they possess intellectual powers infinitely superior to those of man; whilst the evidence that can be gathered on the subject all tends to show that their intellectual powers are of precisely the same kind as man's, but some of them, of course, are much inferior in degree, whilst others are unquestionably superior. Reason, comparatively speaking, in birds can only be regarded as rudimentary, though, as we have already seen, there is undoubted evidence of its existence. The faculties a bird brings into play in nest building are probably Imitation, to which we would assign the most important part, whilst the next most important faculty of the mind is Memory, Reason and Hereditary Habit playing the minor parts. All these powers are found in man, but, with the exception of reason, in a much less pronounced degree, especially in civilised man in whom they have a tendency to become abortive through disuse or non-employment. Therefore to credit birds with such a marvellous power as blind and infallible instinct is to place them on a vastly higher plane of intelligence than man, nay more, to allot to them a faculty which can only be classed as superhuman. As we have already shown, the evidence all tends to disprove the possession of such a power. Birds brought up in confine- 
ment do not make a nest typical of their species, and in most cases content themselves with forming the merest rudiments of a nest, merely heaping a lot of material together upon which to lay their eggs; and in some cases they do not make even this slight provision. This may be instinct or hereditary habit, the blind impulse to make a nest; but without tuition, or some standard to work by, it is a failure. The same remarks apply to man; for with all his boasted reason he is equally incapable of building a habitation peculiar to his race, if he has not seen one or been initiated in the secrets of its construction. Savage man neither alters nor improves any more than the birds, and each of his great races possesses a peculiar style of architecture. The Arab and the American Indian dwell in tents, the negro builds a hut, and the bushman lives in caves, whilst the Malay erects his house on posts. Now transfer an infant of any one of these races of men, say, to a civilised land like Europe, and is it conceivable that when grown up to manhood he would set to work to build a tent, a hut, or a house on posts according to the particular race to which he belongs, instinctively and with no instruction? If man is so helpless in such a case, why should not a bird be the same? Why should a creature infinitely below man in so many of its intellectual attributes be so far in advance of him in this particular respect? The same remarks apply equally to a bird's song and to the language of man- 
kind-each, be it understood, have to be learnt. Now a bird's intellectual porrers advance to maturity much more quickly than in the human race. A young bird three or four days old is capable of considerable powers of memory and observation, and during the time that elapses in which it is in the nest it has ample opportunity of gaining an insight into the architecture peculiar to its species. It sees the position of the nest, it notes the materials, and when it requires one for itself, is it so very extraordinary that, profiting by such experience, it builds one on the same plan? Again, birds often return to the place of their birth the following season, and possibly see the old home many times ere they want one for themselves. This aided by the strong hereditary impulse to build a nest similar to the one in which they first saw the light, and aptitude to work up certain special materials, the collective and inherited or transmitted result of many generations, aid them in their task. Further, we know that some birds do not breed for several seasons after they are hatched, and consequently must often see older birds at work and profit by the experience. Then, again, many birds breed in companies, and the young may watch and imitate the work of older and more experienced nest-builders around them. Young birds may also often pair with older and more experienced mates. The nests these young birds build may, and often do vary from the original type in many slight particulars; and it is by 
these slight variations which, when beneficial, are preserved by natural selection, that birds adapt themselves to any changed conditions of life. I have, for instance, several times remarked a complete absence of feathers from the lining or interior of the nest of the Common Wren; also considerable variation in the lining of the nest of the Magpie; whilst every observer must have remarked the great amount of difference in the nests in a large rookery; whilst, lastly, as a case in point there are many Puffins that never collect any material at all, whilst others make quite a warm nest of dry grass and feathers. I noted similar variation in the nest arrangements of the Fulmar Petrel, some individuals making quite an elaborate nest, others contenting themselves with little or no artificial resting-place for the egg.

As Dr. Wallace most forcibly says, with birds as with man, "when once a particular mode of building has been adopted and has been confirmed by habit and by hereditary custom, it will be long retained, even when its utility has been lost through changed conditions." Now, we know that although many habits have long since ceased to be of any service, they are retained. We have, for instance, the case of hole-building Ducks covering their eggs like their congeners nesting in open situations; Jackdaws making a most elaborate nest in a position where one even of the slightest description is of small necessity; Swans adding to their nest (undoubtedly a habit origin- 
ally acquired for its protection from sudden rises in the water level or the wash of the waves), when that nest may be made at some considerable distance trom any water whatever. The direct results of a bird's reasoning faculties in respect to nest-making may be seen in many directions. The wonderful way that so many species copy surrounding objects, and thus by assimilating their nest materials most cunningly conceal their home, or the equally amazing forethought of others that suspend their nests from tapering branches often over water, or of others yet again (the Tailor Birds) that knot the threads by which the leaf is drawn into a cone in which the nest is built-may be given as appropriate examples. An entire chapter of the present book would not by any means exhaust the specially prominent instances of a reasoning power employed in avine architecture; to the birds'nesting student of birds it becomes manifest, wherever his observations and searches may lead him.

It now becomes interesting to enquire what relation exists between the tools or appliances that a bird may have at its command and the quality or style of the nest it is able to produce with them. Is the architectural skill subservient to the tools, or to what other influences are the endless types of nests otherwise due? Now I think we should be very careful in imputing the various apparent imperfections on the one hand, or the amazing skill on the other, in the architectural qualities of birds' nests to the appliances or 
tools with which those nests are constructed. Dr Wallace suggests that this may be due to the physical structure of the builder; but I believe the many and wide differences in the structure of nests may be safely attributed to far more important and deeply rooted influences. Instead, therefore, of viewing the Swift's rude nest, or the Ring Dove's wicker cradle as the inevitable results of imperfect natural appliances, they should be considered as structures made perfect for the transient purpose they serve, and completely in harmony with the requirements of their builders. On the other hand, instead of regarding the nest of the Chaffinch and the Wren merely as structures the paragon of perfection and architectural skill, the results of perfect natural tools, they should be looked upon as nests, the only object their beauty and perfection serves being a utilitarian one. A bird's beak and its legs and feet are the tools with which its nest is made; perhaps we might also include the breast, for many species make considerable use of that part of the body in working some of the materials. Yet, as I hope shortly to demonstrate, neither on the form, the length, nor any other peculiarity of these parts does the comparative beauty and perfection of the nest depend. Now we all know that the Wren has a finely-pointed bill and long legs. With these tools she builds a well-made nest which seems to owe its perfect form and well-woven walls to the little creature's nest-building appliances. But how 
wrong we should be in such an assumption is proved by the Chaffinch, which, with her comparatively clumsy bill and short legs, also makes a nest equally well woven, and even rivalling in its external appearance the Wren's globular dwelling! Then, again, the Titmice, with their short bills and well-developed legs, build nests in holes in trees and walls-structures so loosely made that it is impossible to remove them entire. But we know the Long-tailed Tit and its several allies with similar tools (indeed, the bill is proportionately shorter than in other Titmice) build nests in the branches the paragon of beauty and well-woven perfection. The Penduline Titmice and the Dipper may be quoted as very similar instances. The Swift, with its weak bill and abnormally short legs, seems totally unable to make an elaborate nest; but we know that it seeks a hole for its purpose from other motives than its seeming inability to make one, and, as is the case with almost all hole-building species, irrespective of their natural tools or physical peculiarities, it is poorly made. Some of the Swifts, however, make more elaborate and remarkable nests, as we shall find in a future chapter (conf. p. 104). Against the Swifts we have the case of the Humming-birds, which, with their almost functionless legs, build some of the most beautiful cradles in all the wide and varied range of avine life. Then, again, the Swallows and the HouseMartins possess similar tools to those of the Swifts, yet they build well-made structures either fastened to 
the eaves of buildings, or placed on beams and ledges in sheds; whilst the Sand Martins of various species, with their short, weak bills, burrow into banks with as much ease as the Kingfishers, with weak legs and feet (in many genera) construct their subterranean abodes. The delicate Warblers (as for instance, the Blackcap, the Whitethroat and the Garden Warbler), all with appliances similar to those of the Wren, make slight net-like nests; whilst the Finches (as for instance, the Goldfinch, the Bullfinch, the Redpole and the Chaffinch), with clumsy beaks and somewhat short legs, weave nests well and elaborately made, and most beautifully adapted to the purposes they serve. The Hedge Accentor felts its nest materials together most cunningly and skilfully; whilst the Whitethroat makes a nest so flimsy that the wonder is it does not fall to pieces under the weight of its nestling tenants. Some of the other Warblers, with almost precisely the same appliances, succeed in fabricating most elaborate and beautiful homes. We allude to such nests as those of the Willow Wrens, the Reed and Marsh Warblers, and the Tree Warblers. Then the Jay and most birds of the Crow tribe, particularly the Magpie (its well-made and intricatelywoven nest is a masterpiece of avine architecture), have powerful and somewhat clumsy bills and feet; yet we know their nests can compare favourably with those of any other class of birds. Many of the clumsybilled Gulls with webbed feet make well-made nests; as 
also do certain Raptores, Herons, Coots, Moor-hens, Grebes, Ducks and Swans-nests that exhibit the same principles as those of the smaller birds, but, of course, carried out on a much larger scale. Again, what difference is there between the nest-building tools of the Kestrel and the Sparrow-Hawk? Yet the latter builds a fairly made nest, and the other never makes a nest at all and rears its young in the deserted nests of other birds, or on the ledges of cliffs, on no other resting-place than the bare rocks or the refuse of its food. In fact, in no other group of birds are the tools of more equal merit and the architectural results so various, for we have species most elaborate and clever nest-builders, species that make nests on the trees and the cliffs and on the bare ground, whilst the nests of others are slight, often crudely made, and in not a few cases are dispensed with altogether (as in many of the Falcons), or some deserted home of another and very different species is annexed for the purpose. The Woodpeckers, the Kingfisher, the Starling, and sometimes the Jackdaw, well provided with the requisite appliances for building an elaborate nest, rear their young in structures poorly fabricated in the holes of trees, rocks, banks, or buildings, or do not make a nest at all. In some entire groups (as in the Parrots and certain Picarian species) we find an utter absence of architecture, notwithstanding the fact that the birds seem in every way adapted for making elaborate nests. From all these interesting facts I think that 
we are perfectly justified in coming to the conclusion that birds are in no way influenced by the appliances they possess in building their nests. The whole evidence is too contradictory to prevent us taking any other view of the question. We have now seen that birds are capable, quite irrespective of the form of their bills and feet, of making elaborate nests of matchless beauty, or poorly fabricated and very plain in appearance respectively and according to circumstances; and I think, therefore, that we may safely rest assured that the nest-building capabilities of birds are not in any way subordinate to their natural appliances or tools for making their nests, but are regulated by and subordinate to the various conditions under which their young are produced, and especially by the colour of the eggs. ${ }^{1}$

When we come to consider the question, Why so many species of bird build a different kind or type of nest (often great divergency is displayed by species obviously very closely allied), we come to a matter which is immeasurably more difficult of explanation. We have not only to take into consideration the general type of nest, but the infinite diversity of materials. Dr Wallace seeks an explanation by suggesting that birds select those materials which are nearest to hand and easiest to obtain. But in opposition to this we are confronted by the fact that

${ }^{1}$ For information bearing upon this portion of the subject the reacler may be referred to my Story of the Birds and other works. 
very differently constructed nests are very common in the same localities, almost one might say, side by side; whilst birds are frequently known to wander far and wide, sometimes going long distances, in quest of some special substance. That each type of nest is admirably adapted to its special purpose is unquestionable, although in numberless cases it would be inpossible to demonstrate the fact. This fact is confirmed by another equally suggestive, and that is the extraordinary amount of variation between the nests of obviously closely allied species so frequently remarled. I may give as examples the nest of the Willow Wren, warmly lined with feathers, in comparison with that of the Wood Wren (another globular structure) in which such lining is entirely absent; or the still more curious variation in the lining of the nest of the Song Thrush and that of the Redwing-or yet again in that of some of the Buntings' nests. Perhaps we might say that the more uniform the conditions of life of the species forming any group, family or order may be, the more uniform will be the nest type prevailing. This is specially illustrated by the species composing such a large and natural order as the Plovers and Sandpipers and their allies. Throughout this large group the nests are remarkably uniform, the young being hatched in relatively slight nests upon the ground. There are, of course, one or two notable exceptions, but these only go to prove the rule. The Herons form another group 
remarkable for the uniformity of the nest type; the Ducks another. With regard to the determining factors in the selection of materials we are as yet almost in complete ignorance. Many things have to be taken into consideration, such as temperature of breeding grounds, special methods of concealing the nest, and so forth. In not a few cases abnormal materials, often of a very curious character, have been known to be selected. Indeed instances of this are repeatedly coming within the experience even of the most ordinary birds'-nester. I have not space to quote many of these instances, much as I should have liked to have done so, but one or two may be mentioned in passing. The abnormal materials worked into the nest of the House Sparrow, string, paper, rags, the wire from lemonade bottles, to mention but a few, is a very familiar instance. Then in some parts of Lancashire and Yorkshire I have known cotton and other waste worked into nests of the Chaffinch and some other species. The late J. G. Wood has recorded that at Soleure, in Switzerland, certain Wagtails made their nests out of broken watch-springs. Another very remarkable case of abnormal nest materials was that of the Spotted Flycatcher which made a nest (I believe) in Hyde Park, London, largely from the remains of wax vestas which smokers in "the Row" had thrown down; whilst still more extraordinary was the nest of a Dove-cote Pigeon placed on the roof of the Crystal 
Palace, and made of hairpins and wire. The most remarkable instances of abnormal sites occur amongst species perhaps that make their nests in covered situations; and in such cases we generally find that the selected place somewhat closely resembles the ordinary site in its most "salient characteristics. As might naturally be expected, the most frequently abnormal species are such homely birds as Robins, Sparrows, Titmice, Wagtails, Flycatchers, and so on. Discarded cans, crockery, flower-pots, saucepans, kettles, and other domestic utensils left lying about hedgerows or in tall grass and weeds seldom fail to prove an irresistible attraction to the Robin; whilst even such less likely receptacles as old hats, bags hanging on walls, and battered baskets, are occasionally chosen. In most cases the typical nest of the species is made in these curious artificial sites. The House Sparrow is another species apparently ever on the alert to pop a nest into every niche at all capable of holding it. A nest of this bird has been known inside a large gong which was in constant use; I have seen nests of this species amongst the ornamental ironwork of gasometers, behind advertisement placards at railway stations, in the crevices amongst statuary, and in signal posts. The partiality of Titmice for pumps, boxes, water jugs, and other utensils is well known, whilst the disused nest of some other and larger bird is not unfrequently selected. Wagtails are little less familiar; and the Spotted Flycatcher 
by no means rarely selects some most unlikely spot near or on man's dwelling for a nesting place. There is in the Natural History Museum at South Kensington a nest of this bird built in the hollow hoof of a horse. At Chatsworth, in Derbyshire, several pairs of Sand Martins used regularly to nest in the breech of the small cannons placed near the hunting tower. This abnormal selection of a nesting site is by no means confined to birds in civilised countries, for the Snow Bunting has been known to make its nest in the breast of a dead Esquimaux, the Cape Wagtail's nest has been discovered in the skull of some unfortunate Caffir; whilst another Wren (Troglodytes furvus) inhabiting South America is said habitually to nest in skulls, doubtless of cattle, so plentiful in the Argentine; whilst the Hoopoe so frequently uses a hole in a coffin in China for a nesting place that the Celestials name it the "Coffin Bird." Finally we may draw attention to the fact that in not a few instances some of the shyest birds most unaccountably build their nests in the most unlikely and frequented spots, and in some species the habit is a perfectly normal one, as for instance in the Misselthrush and the Eider Duck.

A few words now become necessary on the nestbuilding sex. There is no universal rule in this matter, but, broadly speaking, I should say the female is the predominant architect. This is certainly the case in not a few instances, where the nest is excep- 
tionally elaborate. In many cases the male bird conveys much of the material to the female, the latter working it into the nest; in other cases both sexes work at the structure with almost equal industry. In not a few cases the male never comes near the nest at all, and therefore can take no share in the task of building it. This is especially the case with polygamous birds and certain Ducks. On the other hand there are species in which both sexes seem to be equally gifted in the matter of architectural skill. The male Little Grebe and Moorhen may often be observed to build a complete nest unaided by its mate; and popular supposition, at any rate, credits the male Wren with amusing himself by nestbuilding.

Perhaps it may be as well to devote the concluding pages of the present chapter to a few remarks relating to the collecting and preserving of birds' nests. For various reasons these objects, exceptionally interesting as they may be, are somewhat unsatisfactory ones to collect. Not only do they occupy a large amount of space, but they are very fragile, and even with the most careful usage are apt soon to lose their shape. Then the materials of which they are composed not only wither but their colours fade, and thus a large portion of their beauty vanishes. Moths and some other insects are also very troublesome, and have ever to be carefully guarded against. These 
are serious objections to the forming of a private collection of birds' nests especially, but to those students who may be ambitious to do so, the following hints may probably prove of some service. The utility of forming a representative collection of nests cannot be over-estimated. In accumulating such a collection the student will not fail largely to increase his knowledge of the ways and methods of the little architects themselves; nor will he fail to realise much that has been said already in the present chapter, or to gather fresh evidence in support of the views here propounded. In the first place I would advise the collector to confine his efforts to the nests of the smaller birds. Large nests are unmanageable. Whatever may strike the observer as peculiar about them, therefore, must be committed to the note-book, as also full and detailed descriptions of all the larger and rarer structures that he may meet with. I would strongly recommend a collector of nests with but limited space at his disposal to confine his efforts to the various types, never duplicating these in the various closely allied species except for some special reason. All the smaller nests should be removed with the supporting branches or twigs as far as possible; nests in other situations must be removed with great care and transferred to boxes without delay. Nests in holes are the most difficult to secure in a perfect condition, being often so very loosely fabricated that removal entire is impossible. 
It will be found a good plan to secure those loosely made nests with a needle and thread, making stitches here and there which will strengthen the nest, and yet remain practically invisible. As soon as a nest is taken a label should be attached. This need not contain anything beyond a reference number to the note-book, in which all particulars must be fully entered at the time. Leave nothing to memory. In the case of a nest that is under observation whilst building, minute details can be recorded as the work progresses; and let the student bear in mind that it is this detailed observation that is specially required, even relating to common and familiar species. Concerning the nest-building habits of vast numbers of exotic birds we know literally nothing, and in this direction lies some of the most fascinating work open to the caliologist. The facts to be observed are almost endless: the peculiarities of the site, any special display of intelligence on the part of the architects, such as in its concealment or in the materials selected, the building sex, the time of building, the duration of the work, and the methods of putting the materials together so far as can be observed, may be given as a few of the more salient ones. Nests should be taken for the collection as soon as the eggs are deposited, for they are then at their best. As nests are as much liable to the attacks of insects as skins or furs it becomes absolutely necessary to apply a preservative of some kind. 
Many nests contain feathers, wool, and hair, and these, of course, are more liable to the attacks of insects than such nests as are made exclusively of vegetable fibres. I have found a solution of corrosive sublimate dissolved in alcohol or spirits of wine to be the best preventative, the nests being dipped in this. Care must be taken that the solution reaches every part of such densely felted and warmly lined nests as those of the Willow Wren and the Long-tailed Titmouse, for instance, otherwise in a few months they will be entirely destroyed. After the nests have been thoroughly well soaked and preserved the question of their final disposal in the collection has to be solved. There are several excellent ways of keeping nests. They should, however, never be crowded into boxes, in fact never be permitted to touch each other, or speedy ruin will come to them. Perhaps the best method is to place each nest in a separate cardboard box with a glass top. These boxes are then arranged in drawers in the cabinet. Each nest may then be easily inspected, and what is of more importance each is kept absolutely isolated from its neighbour. Another method, which I have seen adopted by collectors both in India and China, is neatly to enclose each nest with strong paper, leaving the top of the nest exposed, the bag being fitted as closely as possible without interfering with the normal shape of the nest. This method has economy of space to recommend it, for with a little judicious selection and 
management quite a large number of nests can be got into a single glass-topped box. The encircling paper also serves to keep the nests in their proper shape. By this plan numbers of nests may be arranged close together, which for a collector or working naturalist is a matter of no small importance. Of course the most elaborate method of preserving nests is that adopted by the authorities at South Kensington. Here the nests may be seen practically in situ, but to display even a moderate number of nest types on this principle would soon exhaust even the space available at the Natural History Museum. 

CHAPTER II

NESTLESS BIRDS, ANNEXERS

AND PARASITES 



\section{NESTLESS BIRDS, ANNEXERS AND PARASITES}

Conditions of a nestless state-Occasional lapses in the Nest-building HabitNestless Birds-Tropic Birds and Vultures-Ringed Plover-Coursers and Pratincoles-Stone-Curlew-Gulls and Terns-Auks-Nestless Petrels-Goatsuckers-Origin of the Nestless Habit-Number of eggs laid by nestless species -Annexing Birds-Birds of Prey and Owls-The Kestrel-The Hobby-Honey Buzzard-Orange-Legged Hobby-Iceland Jer Falcon-The annexing habit not always universal in the same species-Egyptian Vulture-Turkey VultureCooper's Hawk-Tawny Owl-Long-Eared Owl-Tengmalm's Owl-Hawk Owl-Eagle Owl-American Barred Owl-Saw-whet Owl-Green SandpiperWood Sandpiper-Swallows-Birds building in nests of other species-Great Titmouse-House Sparrow-Purple Grackle-Spanish Sparrow in nest of Stork-Return of Birds to old Nests-Parasitic Birds-Origin of the habit of Parasitism-Coloration of Eggs of Parasitic Birds-Cow-Bird-Birds laying astray-Birds evicted by other species-Benevolent characteristics in BirdsOrigin of Parasitism through the young.

Notwithstanding the fact that birds are so intimately associated with nests, there are a good many species that never make a nest at all, or that profit by the architectural exertions of more industrious birds, whilst some few there are that shirk all parental duties, make no nest, and leave all care of their young to others. The absence of any nest-building inclination or propensity is by no means an indication of a low stage of development in birds, or of any lack of intelligence, but is most probably entirely due to the conditions under which their eggs are hatched and their young brought to maturity. 
Indeed, from a human point of view, we might justly ascribe the habit of annexing some readymade nest, or that of relegating all responsibility of the offspring to foster parents, to an exceptional intelligence rather than to any want of it. Now, it is a remarkable and interesting fact, and one going far to prove the truth of the contention that nests are purely and simply utilitarian structures, subservient in every respect to the conditions under which the young are produced, that we find nestless species in so many of the great groups into which birds are divided by systematists. Not only are some of the most archaic avine forms devoid of any nest-building propensity, but some of the species in the more highly specialised groups are in an exactly similar condition, whilst in not a few instances we have nest-building as well as nestless species belonging to the same family or even genus. In some cases the general habits of the birds are almost the same, yet some small divergence in the way the young are produced determines whether there shall be a nest or not. By common consent the Ratitæ (comprising the Rheas, Cassowaries, Emus, Kiwis and Ostriches) is regarded as the most archaic order of surviving birds, and yet none of the members of it can be said to be nestless, as will be shown in the following chapter. It is also a curious fact that in some nest-building species individuals are occasionally known to forego the habit and to omit making any 



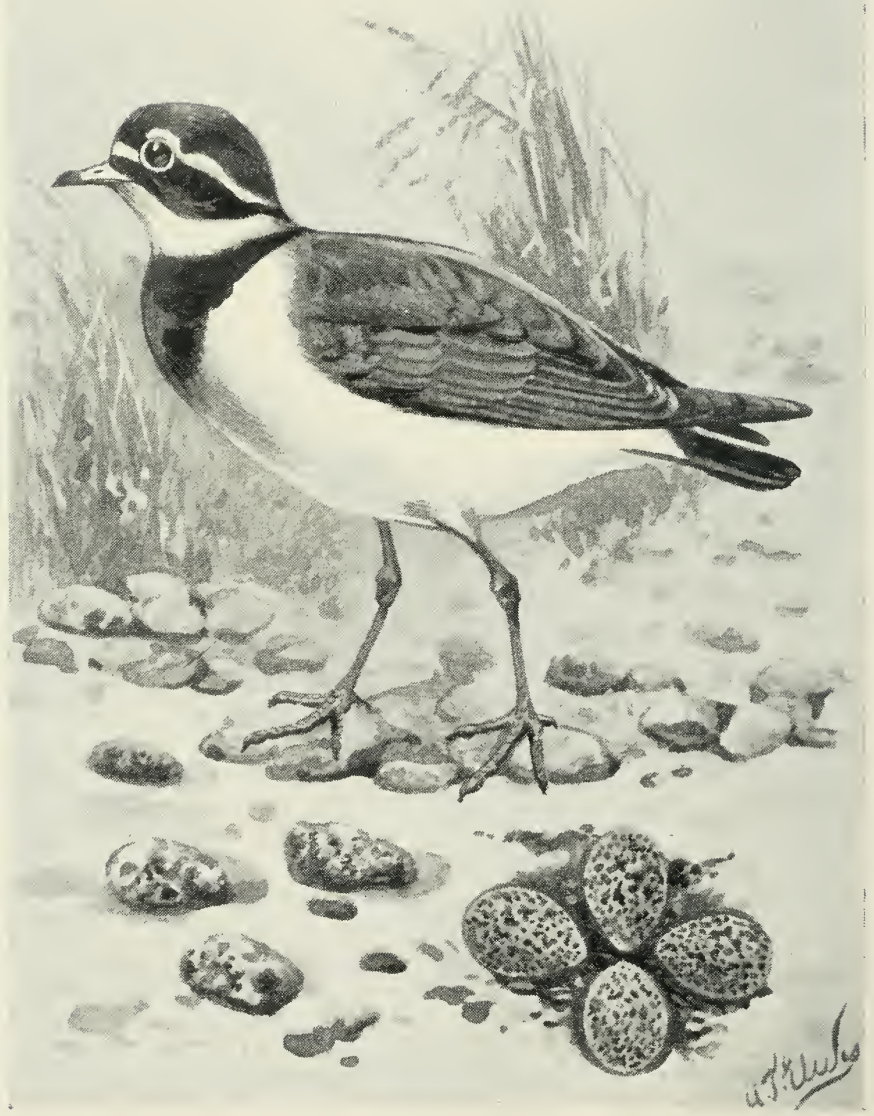

THE RINGED PLOVER AND EGGS. 
provision for incubation. This I have found especially frequent in the Fulmar Petrel, the Puffin, some of the Gulls and the Plovers. Amongst the species that are absolutely non-nest-building we may mention the Tropic Birds, comprising the family Phæthontidæ. Some of the Vultures are practically nestless. The American Black Vulture (Catharista atrata) is said never to make the slightest attempt at a nest, not even scraping a hollow, laying its eggs on the ground in cane brakes, under bushes or logs, or even in more exposed situations still. Then some of the birds in the important group Charadriiformes are nestless, a fact which is all the more remarkable when we bear in mind that others in the same assemblage of species are very fair if not actually elaborate nestbuilders, and one that incontestably proves my assertion that the conditions under which the eggs are incubated determine whether artificial provision be made for them or not. The Ringed Plovers, for example, can by no stretch of imagination be regarded as nest-builders. They deposit their eggs on the bare sands and shingles, often with not even the semblance of a hollow to contain them. A moment's reflection and we find that a nest in such a bare and open situation would be an absolute danger, and serve no useful purpose. It would be readily seen, and the eggs can be incubated with greater safety and absolute certainty without a nest of any kind. The Coursers and Pratincoles both breed upon open 
ground, and in each family the species make no actual nest, but incubate their eggs on the deserts and marshes where such a structure would only court discovery. Incidentally I may also mention that in a great many instances the Lapwing makes no nest whatever, depositing its eggs upon the bare pastures; but at other times it will be found to make a slight but perfect receptacle for its spotted treasures, the peculiarities of the ground apparently being the sole determining influence. If a nest would be conspicuous it is omitted, if the nature of the ground admits of such a structure it is generally made. The Stone Curlew furnishes yet another instance of a nestless species from this order of birds, and its peculiar method of nidification fully warrants this omission from its domestic arrangements. As most readers may know, it dwells upon open heaths and deposits its eggs usually on some stone-strewn patch of ground where their tints closely harmonise with surrounding objects, and where a nest would only assist in betraying their whereabouts to enemies. Some of the Gulls often refrain from making any nest whatever; whilst Terns of many species are absolutely nestless-the Lesser Tern for example-whilst others make more or less finished homes-the Common Tern for instance-the peculiarities of the site apparently being the determining factor. Thus the Lesser Tern delights to breed on shingly beaches where a nest would be decidedly conspicuous, 
whilst the Common Tern prefers places where herbage is abundant and where a nest can be hidden amongst it. No birds, however, are more absolutely nestless than the Auks, of which the Guillemot and the Razorbill are typical species. These birds lay their eggs upon the bare rocks, either exposed to the light of day on the ledges or flat table-like summits, or concealed from view in nooks and crevices. Singularly enough the Puffins-the nearest surviving relations of the Auks-are elaborate nest-makers, spending much time in excavating burrows at the end of which a rude bed is formed. Other nestless birds are to be found amongst the Petrels, although here again we have a group of birds in which some make more or less elaborate provision for their eggs. Bulwer's Petrel and Wilson's Petrel, for example, make no nest whatever, laying their single egg under rocks and stones, whilst the Fork-tailed Petrel and the Shearwater incubate their egg in burrows upon a nest of grass and twigs and leaves, etc. Lastly we have the Goatsuckers, which make no provision for their eggs, but lay them and incubate them upon the bare ground. It seems difficult at present to account for the nestless condition of the Nightjar, more especially when we bear in mind the bird's singular attachment to certain spots, often returning to them year by year and depositing the eggs in exactly the same place. It is interesting to speculate how these speciesrepresentatives being found in so many widely diver- 
gent groups-became nestless. That it is an exception to the general habit of birds is unquestionablea deviation from almost universal custom, rather than a retention of an archaic trait. Possibly the habit may have arisen through individuals accidentally depositing their eggs on the ground before any nest had been prepared for them, just as we often find nest-building species do in our own time. I have known the Starling especially to drop its eggs very frequently about the fields, the Song-Thrush and Blackbird, Bunting and Robin occasionally, but never to attempt to incubate them, however, in such a novel position. It is somewhat significant, too, that the most thorough nestless species lay but a very small number of eggs for a sitting-from one to two or three. If the eggs were as readily hatched under nestless conditions, and possibly received additional safety by the absence of a perhaps conspicuous nest, then we can understand how natural selection would preserve such new conditions of incubation and the habit consequently have a tendency to increase.

From the absolutely nestless birds we now pass to a consideration of those species which we have designated "Annexers"; that is to say, birds that do not under any circumstances make a nest for themselves, but select the disused or unoccupied home of some other species in which to lay their eggs and bring up their young. So far as is known, this singular habit, with few exceptions, occurs only in 
two groups, the Birds of Prey and the Owls, and of course it is by no means a universal one in these. Here again we are confronted by widely differing methods of nidification amongst what are obviously closely allied birds. We find species failing to make any provision of their own for their eggs, notwithstanding the fact that so far as we can judge they are just as well able to build a nest as their more thoughtful or industrious relations. One or two instances selected from well-known species must here suffice to illustrate this peculiar trait. One of the most familiar of these is the Kestrel. It has been stated by more than one writer that this pretty little Hawk occasionally makes its own nest, but this I do not for one moment believe. If it cannot find a suitable deserted tenement it lays its eggs upon the bare earth or rock in some crevice of the cliffs, or even in a hole in a building or a tree trunk. Indeed there can be no doubt that many pairs make such a selection from choice and not from necessity. In such a spot no nest is ever constructed, but as the breeding season progresses numbers of pellets or castings accumulate in the place and often surround the eggs. But it is as an annexing species that we are now considering the Kestrel. The bird generally selects the deserted home of a Crow, a Magpie, or a Sparrow Hawk, less frequently the old nest of a Ring Dove or even the drey of a squirrel. The Hobby is another annexing species. Unfortunately the British 
naturalist rarely meets with this Falcon nowadays, and the time may come when it will cease to breed within our limits at all. The old nest of a Crow, a Magpie or a Ring Dove appears to be the favourite selection, and here without alteration of any lind the eggs are incubated. Another British species (although we regret that it will soon no longer be one, if indeed it has not already disappeared) is the Honey Buzzard. This handsome bird selects the deserted home of a Crow, Magpie, Buzzard, or Kite; but in this case the old abode is furbished up a little by the addition of a lining of green leaves, which is renewed from time to time as incubation progresses. The Orange-legged Hobby, perhaps equally well known as the Red-legged Falcon, is yet another annexer, bringing up its young in the old nest of a Crow, a Magpie, or a Rook, when in the latter numbers of pairs sometimes breeding in company. The Iceland Jer Falcon is also said never to make a nest, but sometimes to select a disused Raven's abode for its purpose; more frequently perhaps depositing its eggs on the bare ground on a ledge of the cliffs. Incidentally I may state that the habit of annexing is not universal in some species. The Egyptian Vulture, for instance, sometimes builds a nest for itself, and sometimes selects the deserted home of a Short-toed Eagle, a Bearded Vulture, or a Raven - a fact which seems to suggest that the habit of annexing is gradually being acquired. Similarly the 
Turkey Vulture (an American species) has been known to make use of an old nest of a Heron or a Hawk. Again, Cooper's Hawk (another New World species) sometimes makes a nest for itself, but more generally selects the deserted home of a Crow, a Hawk, or a squirrel. The Short-tailed Hawk (the Buteo brachyurus of Vieillot) is another instance. Among the Owls we have many instances of this annexing habit. In a great many cases these birds rear their young in their usual day retreat or roosting place, making little or no nest. This retreat may sometimes be the deserted nest of another bird; possibly the situation is chosen for the purpose of incubation only. Thus the Tawny Owl not unfrequently breeds in an old nest of a Hawk, Magpie, or Crow ; the Long-eared Owl almost invariably selects a deserted nest of a Magpie, Crow, Ring Dove, or Heron; Tengmalm's Owl as frequently annexes the nest hole made by a Black Woodpecker, as also does the Hawk Owl; whilst the Eagle Owl takes possession of the old home of an Eagle or some other large bird. The American Barred Owl similarly secures the old nest of a Crow or Hawk for its procreant cradle; whilst its relation, the Sawwhet Owl of the same region, chooses a squirrel's drey or more frequently the deserted hole of a Woodpecker, as also does the Screech Owl in the same locality. A very remarkable exception of an annexing species occurring in a group which follows 
the normal conditions of nidification is furnished by the Green Sandpiper. This species, deserting the ground upon which its congeners habitually breed, selects the old nest of a Thrush, a Jay, a Ring Dove, or a Crow, in which to deposit its four eggs. Its close ally, the Wood Sandpiper, has also been recently detected breeding in similar situations, a fact which seems to suggest not only that the bird is changing its method of nesting, but also the manner in which the habit may have arisen in such species where it now more generally prevails. This is yet another instance of the intelligence-reason-displayed by birds in the matter of nesting, as opposed to the theory of an unchanging and unvarying instinct. Some of the Swallows (Tachycincta) make their nests in the deserted holes or nests of other birds.

Before leaving this particular branch of the subject, it may be as well to refer to the peculiar habit which some birds possess of making their nests inside the structures belonging to other species. Some of these are what may facetiously be termed the guests of larger birds. The Great Titmouse (Parus major), for instance, not unfrequently makes a domed nest in the interior of the disused abode of a Crow or a Magpie; whilst I have known it to build its nest amongst the sticks in the foundation of a Rook's nest, whilst the latter was occupied. The House Sparrow will also sometimes select a similar situation; whilst in North America both this species 


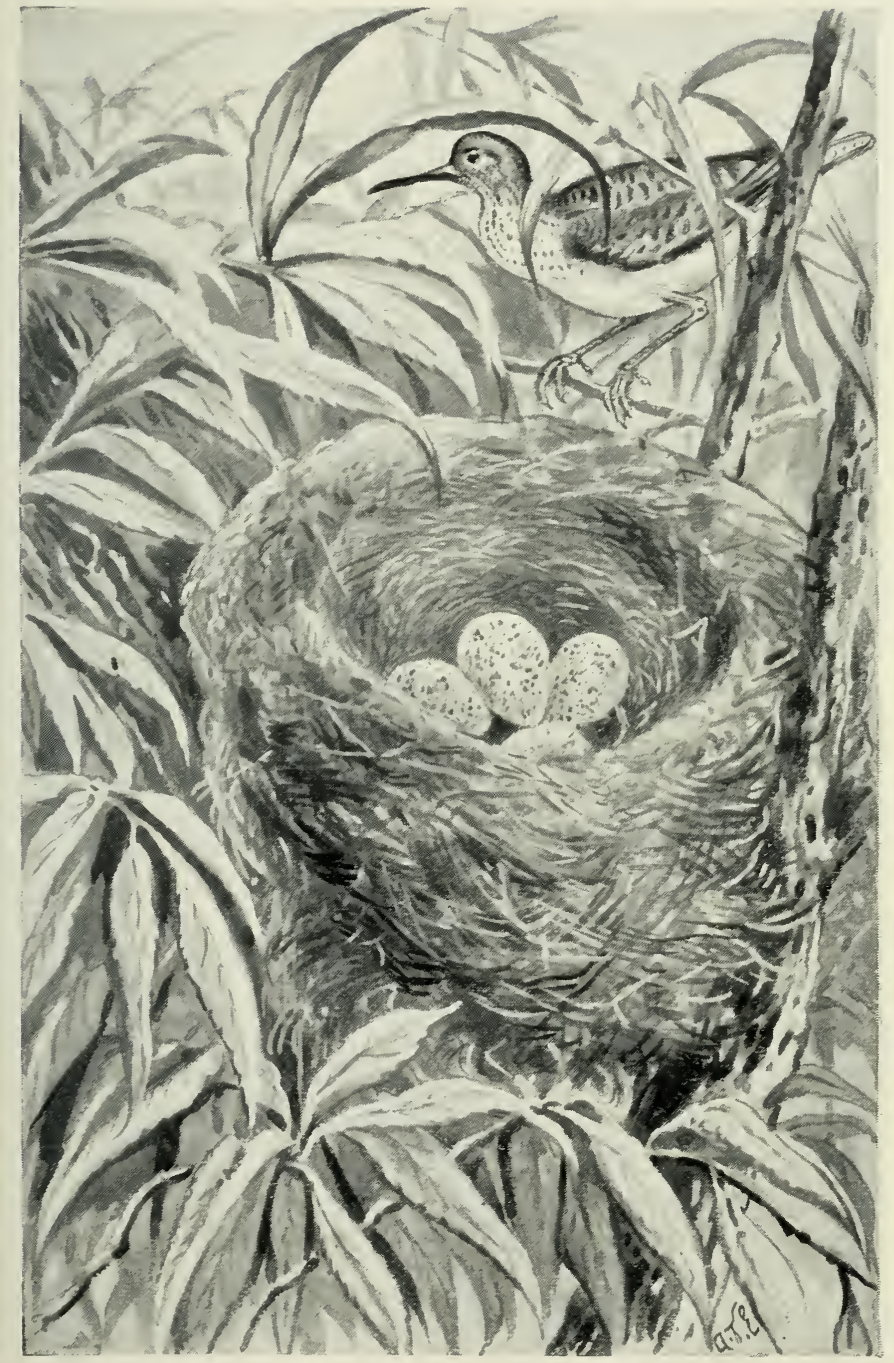

EGGS OF GREEN SANDPIPER IN OLD NEST OF FIELDFARE. 

and the Purple Grackle have been known to build amongst the sticks of an Osprey's nest. In Asia Minor colonies of Spanish Sparrows (Passer salicicola) have been observed in Storks' nests, almost every interstice in the great stick-built nest of the Stork containing one of the Sparrows, some fifty nests of the latter being accommodated amongst the material of each one of the former. It seems fitting here also to allude to the fact that some birds are in the habit of returning to the old nest season by season, and using it annually for purposes of reproduction. No more familiar instances could be given than those of the Rook, the Starling, and the House Sparrow. Here, again, we are confronted by another of those as yet inexplicable facts relating to the science of nests. Why, we may naturally ask, do some species retain an unquenchable love and affection for the old nest, returning to it each season of reproduction, patching, repairing, and adding to the structure as the time for its use comes round anew, whilst the majority of others desert it for ever as soon as it has served its purpose? I may, however, state that the species that so return are mostly gregarious during the season of reproduction; whilst the fact must not be overlooked that the majority of birds show a considerable amount of affection for the locality in which they rear their young. Every observer of birds must have had some experience of the manner 
in which certain individuals of a species will return each season, not only to the same locality, but in many cases to the same precise spot for nesting duties. Birds that pair for life appear to have this nostalgic impulse very highly developed, and this applies not only to sedentary species but to migratory ones as well. The Magpie, for instance, is no more deeply attached to its old nest, that it visits from time to time all the year round, than is the House Martin to its mud-built cradle beneath the eaves, to which it unerringly returns after a journey of many thousands of miles and a continuous absence of seven months. Both these species pair for life, and the nest seems to be a home centre, a trysting place of an irresistibly attractive kind.

We now pass to the consideration of another class of non-nest-building birds, what we have ventured to call "parasites." These we can scarcely describe as nestless birds, for their young are hatched and reared in nests-not the discarded homes of other speciesthe eggs being surreptitiously inserted during the absence of the rightful owners, the latter incubating them and rearing the chicks with every care. The Cuckoo, of course, is the most familiar instance to British naturalists of these bird parasites, but the curious habit is by no means confined to that species, not only prevailing widely in the family to which "the Messenger of spring" belongs, but in another group as well. There can be little doubt that the parasitic 
habit is, comparatively speaking, a recent one, as it only prevails in one or two families of highly specialised birds. Whether the habit will become more widely prevalent it is, of course, impossible to say. Should birds, however, follow human example in the growing tendency to shirk the responsibilities of offspring, then we may safely say that such will be the case. The manner in which this very exceptional habit amongst birds has arisen is a very fascinating question for ornithologists to solve, and notwithstanding the many plausible explanations of the phenomenon that have been suggested, it is still largely enshrouded in mystery. We can of course presume that parasitism may be the retained habit of some ancestral form of the species practising it at the present time, and acquired during conditions of existence of which we can have no possible conception nowadays. We can also suggest in its explanation that the habit may have prevailed more widely during earlier epochs of avine existence. The fact that every detail and condition of the habit is so marvellously perfect seems to suggest its long continued duration. The choice of nest is not the least important condition of success, for a species must be selected capable of bringing the alien young bird to maturity. Then the coloration of the eggs of parasitic birds is another important factor, this varying much or little according to the number of species selected by the parasites and the degree of variation reached by their eggs. 
Possibly the Common Cuckoo (Cuculus canorus) has the widest range of selection in this respect, a fact which is confirmed by the exceptional amount of variation presented by its eggs. Other species of Cuckoos in the same genus ranging over a wide expanse of country tenanted by vast numbers of suitable foster parents may exhibit a similarly large amount of variation in the coloration of their eggs, but unfortunately our information is extremely scanty. On the other hand such parasitic species as the Great Spotted Cuckoo (Coccyzus glandarius), which confines its unwelcome attentions practically to birds of the Crow tribe dwelling in the localities it frequents, lays eggs remarkably uniform in tint, and somewhat resembling those of the Magpie. Outside the Cuckoo family the only bird parasites at present known to exist are certain species of American Icteridæ, of which the Cowbird (Molobrus pecoris) is by far the best known (conf. p. 58). Whether the invading Cuckoo breaks any or all of the eggs of the rightful owner of the nest when paying her clandestine visits seems not to be definitely known; but with regard to the Cowbird and its allies Mr Hudson definitely states concerning the South American species that both male and female do actually destroy many of the eggs of their dupes. Another very remarkable fact is that one species of South American Cowbird (Molobrus rufaxillaris) is actually parasitic upon another species (M. badius), the latter making its own nest. 
But to return to the question of the origin of this parasitic habit. Parasitism in birds may have had its origin either through the parent or the offspring. At the present day instances are by no means rare not only of birds laying an odd egg in the nest of some other, and it may be very distantly related species, but of birds taking possession of a nest and driving away the rightful owners often when it contained eggs which have been hatched in due course with those of the invader. Partridge eggs, for instance, are frequently found in the nest of the Pheasant, whilst those of the latter are perhaps as commonly discovered in the home of the Partridge. The eggs of Gulls and Eider Ducks have also been found in each other's nests; whilst Stevenson records that he had frequently known Moorhen's eggs to be laid in the nests of Coots. A Pochard's egg has been found in the nest of a Tufted Duck; and even more curious still a Moorhen has been known to lay an egg in the unfinished nest of a Blackbird! Starlings are known frequently to turn Woodpeckers out of their nesting holes; House Sparrows still more commonly take possession of nests of the Martin. Many similar instances might be given, although it will be remarked that perhaps the majority of them refer to hole-building or domed-nest-building species. We can now understand how the accidental dropping of an egg into an alien nest might gradually become a fixed habit, natural selection having a tendency to 
preserve and extend the practice of such an action if beneficial, or at least not harmful, to the species concerned. We can also understand how a species might derive sufficient benefit from being ousted from its home by some invading form, being thus relieved of the duties of incubation and rearing a brood, that in time, by a similar process of selection, it might entirely relinquish all inclination to perform them. On the other hand, parasitism may have arisen through the actions of young birds in the following manner. In the first place we have the very interesting and significant fact that some at anyrate of these bird parasites are very voracious feeders. Then we have the equally well-known fact that certain species especially show a strong desire to feed any deserted or helpless nestling that may chance to come in their way-the drooping, fluttering wings, open mouth, and pleading notes of such outcasts apparently exciting parental instincts in the older birds, and irresistibly prompting such birds to respond to them. Many instances might be given of birds adopting and feeding the deserted or orphaned and helpless young of other species, and the significant result of such a combination of facts is at once palpable. There would also probably be a synchronous development of a strong tendency in the young birds brought up under such circumstances to consort with the species that had befriended them, and we can then understand the origin of the habit of seeking the nests of 
their foster parents and depositing their own eggs in them. Of course the parents of these deserted young birds might simultaneously assist in the development of the parasitic habit; for it is quite conceivable that with a brood of voracious young to provide for, they might readily desert some or even all of them, and more especially if they chanced to observe the readiness of other species to share their labours. So in both directions would the domestic instinct or habit gradually become weaker and finally disappear, whilst parasitism would as surely take its place. By tracing the origin of this avine parasitism through the young rather than through the adult, we are better able to understand that marvellous perfection of choice of foster parent now exhibited by all parasitic birds, the species selected being those that are in every way best adapted to secure its ultimate success. We believe that $\mathrm{Dr}$ Baldamus (a naturalist who has studied this habit of the Cuckoo perhaps more thoroughly than any other) attributes parasitism to the fact that the Cuckoo produces its eggs at such long intervals that one general incubation would be impossible; but on the other hand we must take into consideration that other species of non-parasitic birds lay at intervals, and begin to sit as soon as the first egg is produced; whilst it is much more probable to assume that intermittent egg-production in the cuckoo is a direct result of the bird's parasitic habits. Incidentally I may mention that a most interesting 
memoir on the Cowbirds, especially in relation to their parasitic habits, has been compiled by the late Major Bendire (conf. Report; U.S. National Museum, 1893, pp. 586-624, Pls. 1-3). A list of no fewer than ninety species is given, in which eggs of the Cowbird have been discovered. 


\section{CHAPTER III}

\section{THE CRUDEST NEST FORMS}





\section{THE CRUDEST NEST FORMS}

Apparent development of nest-building art-Illustrated by nest of Bullfinch -By nests of Crows-By nests of "Willow Wrens"-Importance of nesting conditions-The most skilful nest-builders-Crude nest-forms of Ratitæ Birds -Nidification of the Ostrich-Of the Falcons-Of certain Owls-Of the Coraciiformes - Of the Psittaciformes - Of the Cuculiformes - Of certain Cuckoos-Of the Columbiformes-Peculiarity in nests of Pigeons-Of certain Tyrant Birds-Of the Pediophli or Sand Grouse-Of the Game Birds or Galliformes-Similarity of architecture in this order-Nests of the Charadriiformes - Of the Bustards-Of the Oyster-catchers-Of the Stilts-Of the WoodcocksOf the Jacanas-Of the Crab Plover-Crude nest-forms of the Divers-Of the Penguins-Of the Procellariiformes-Of the Lariformes-Nests of the Noddy Tern-Of the Skuas-Of the typical Gulls-Of the Black-headed Gull-Of the Ducks aud allied Birds-Of the Mergansers-Uses of down in these nestsNumber of crude nest-builders-The state of the young when hatched.

As we pointed out in the previous chapter, a nestless state must not in any way be taken as an indication of any lack of intelligence, so may we also here insist that the crudest nest-builders are not necessarily wanting in that special quality of mental development. Neither must we assume that every type of nest, from the crudest to the most elaborate structure, represents, or is any indication of a gradual development of mental powers applied to avine architecture. Nests, we may again assert, are purely and simply utilitarian structures, and their plan and degree of elaborateness are controlled by the special conditions under which 
the young of each species are brought to maturity. This fact must never be neglected by the student of birds' nests, for it is one of the fundamental principles upon which the science of caliology is based. It is true, if we analyse the construction of certain nests, we are confronted by facts that seem to suggest a gradual development from a crude and simple to an elaborate model; but after a prolonged study of the subject, extending over many years, I am convinced that such is not really the case. For instance, we might endeavour to build up a theory of the gradual evolution of a Nest in this manner. In the first place, take for the sake of our argument the nest of a Bullfinch. In this structure we find a recapitulation of various cruder nest types before the elaborate and beautiful home is completed. We have the few twigs as a foundation, which represent the full and complete nest of such a simple architect as a Pigeon, for instance; and then we may gradually trace the more and more elaborate nest through each successive stage of its construction from the roots and bits of dry grass until we reach the final lining of hair, wool and feathers, the whole combined representing the perfect model of a nest of this particular type. So again we might illustrate the theory of nest evolution by a comparative study of the nests of various species of Crows. First, as the crudest type, we have the nest of such a species as the Chough and the Jackdaw built in holes and fissures, the materials 
often being scanty and generally arranged in a loose and slovenly manner. The Crows and Rooks, although employing much the same materials, are more careful and elaborate builders; whilst the Jay is an even better architect, its nest being to some extent a recapitulation of and improvement on those of the species already instanced. Last and most perfect nest-builder of all we have the Magpie. The nest of this bird is a masterpiece of its special type, an example of avine intelligence and skill that it would be hard to beat, embodying all the principles of those of its kindred, from the mere platform of sticks to the neatly-lined structure, and finally crowned with a roof of basketwork that renders it almost impregnable. Lastly, we may mention the group of Warblers, known more familiarly as "Willow Wrens," as furnishing instances of progressive types of nest-building. So far as is known, these birds all build nests of a very similar type, more or less domed, but the degree of finish varies considerably. Some of the species build nests of dry grass with little or no lining; others add a little hair (as in the Wood Wren), whilst the most elaborate architects finish off theirs with a warm and plentiful bed of feathers, as for instance the Willow Wren and the Chiffchaff. Now, looked at from one point of view, all this gradation of nest in certain groups (and many other instances might have been given) seems to suggest a gradual development of nest-building capabilities-improvements upon certain primitive types, 
until a more complicated and perfect system of architecture has been reached. It requires, however, but a small amount of reasoning to demonstrate the fallacy of such a supposition, or an even less amount of observation in the haunts of birds where nests can be studied in relation to the habits and requirements of their builders. The crude nest of the Ring Dove is as admirably suited for the purpose it serves as is that of the Chaffinch or the Long-tailed Titmouse. The loosely-formed nest of the Jackdaw and the Chough answers the purpose for which they are intended just as effectually as the more elaborate and highlyfinished nests of the Jay or the Magpie; whilst we may equally rest assured that the hair-lined home of the Wood Wren is just as admirably suited to the requirements of that species as the feather-carpeted abodes of the Willow Wren and the Chiffchaff are to the special conditions of existence of those species. Nesting conditions are too vitally important to the species to be in any way imperfect. It is just as vitally essential for the Tern or the Nightjar to hatch their eggs nestless on the bare ground as for the Magpie to produce its young in an elaborate roofed-in nest, the procreant cradle (or even the want of it) harmonising in every way with the special conditions of reproduction. Our study in the present chapter of the crudest forms of nests must not therefore in any sense be taken as indicative of a low nest-building capacity on the part of the birds that make them. 
We must also bear in mind that from a caliological point of view these crude nests are in a certain sense as interesting and important as those of more elaborate structure. On the other hand, it must, however, be conceded that the highest degree of architectural skill is reached in a group of birds universally acknowledged by systematic ornithologists to be the most specialised. These birds are the Passeres, and as we shall eventually learn in our general review of birds' nests, it is in this order, composed of the most highly specialised of avine forms, that we find the greatest intelligence and skill brought into play in forming the procreant cradle.

Let us now return more particularly to the subject of the present chapter-the crudest forms of nest. Amongst these we may first glance at the primitive homes made by what are almost by common consent considered to be the most archaic of all existing birds and classed as the Ratitr. This division is composed entirely of flightless birds, and includes the Rheas, Cassowaries and Emus, the Kiwis and the Ostriches. The nests of all these birds are of the crudest, and consist of hollows excavated in the ground (or, in the case of the Kiwis, amongst the roots of a tree fern), and almost entirely devoid of lining. In these rude hollows the females deposit their eggs. Both male and female Ostriches are said to prepare the crude "nest." According to Mr Crawston (Ostrich Farming in California), the male bird rests 
his breast-bone on the ground and kicks the sand behind. When one side is sufficiently deep he turns round and repeats the same operation, until a round hole about three feet in diameter and one foot deep is formed. According to this writer the eggs are covered with sand to protect them from the fierce rays of the sun, but there can be no doubt that many eggs are incubated in part by solar warmth. It has been frequently stated that the male bird alone in this group (Ratitx) incubates the eggs, but this is denied by Mr Crawston, who asserts that the male and female ostrich share the labour, the male sitting during the evening and night. It should be remarked, however, that equally trustworthy observers maintain that incubation is performed by the males alone. Then again the Tinamous (Crypturi), a Neotropical group, are very crude nest-builders, their procreant cradle consisting of a mere hollow scraped in the ground, in which a few feathers are strewn as likely as not by accident rather than by design. Many of the Falcons must also be classed as builders of the crudest forms of nest. The Jer Falcon (in its several representative or geographical forms), the most typical of the group, prepares no more than a mere hollow on the ledges of the cliffs in which to deposit her eggs. The Peregrine is equally unsolicitous; in fact, all the world over the typical Falcons are satisfied with the crudest provision for their eggs. Some of the smaller species, however, either annex the 
home of another bird, as we have already seen, or, as is the case with the Merlin, for example, build a slightly more elaborate nest. This latter bird surrounds the usual hollow with a ring of twigs. It is worthy of remark that nearly without exception the other groups (such as Vultures, Eagles, Hawks, Buzzards, Kites, etc.) contain species that build more or less elaborate nests, some of them, be it remarked, of enormous size and strength. Then, again, the nests of many of the Owls are crude in the extreme. As we have already pointed out, not a few species in this group are either entirely nestless, or annex the deserted homes of other birds. In the majority of the remaining instances, the nest is crude in the extreme, a mere hollow lined with food refuse. Even such species as the Snowy Owl that breed in the open make no elaborate provision for their eggs, laying them in hollows, trampled down in the soil or moss on the ledges of cliffs, or on some convenient hillock upon the wide expanse of tundra. The great Eagle Owls make a very similar provision if they do not annex the deserted nest of some other bird. In fact, throughout the entire group of Owls (numbering, broadly speaking, about two hundred species), we find the same conditions prevailing-all being either nestless, annexers, or builders of some of the very crudest forms of nest. Not only do these remarks apply to the Owls (Striges), but they are equally appropriate to the species in several 
other sub-orders and families in the extensive order of birds scientifically termed Coraciiformes. We have, for instance, already seen that the Goatsuckers are nestless; others, the Owlet Nightjars of Australia (Egotheles) lay their eggs in holes in trees; whilst another family of birds in the same sub-order Caprimulgi, the Frogmouths, Podargidæ, make a crude flat nest of sticks. Many other birds in this order make little or no nest, in the sense of an absolute bed for their eggs or young, but as they usually tunnel or burrow in the ground or in timber we shall have occasion to enter more fully into their domestic arrangements in a later chapter (conf. chap iv.). Another large and important assemblage of birds that make little or no provision for their eggs contains the Parrots or Psittaciformes, but as these birds again breed in holes we must also reserve a description of their "nests." Then, again, the Cuckoos and Plantain-eaters associated in the order Cuculiformes are representatives of a very low type of avine architecture. Many of the former birds are parasitic, and have already been dealt with in the previous chapter. Other Cuckoos make nests in the ordinary way, crude in type, and some of which may here be briefly described. The nests of the Yellow-billed Cuckoo (Coccyzus americamus) and the Black-billed Cuckoc (C. erythrophthalmus) (both remarkably small for the size of the birds) are usually made on the flat, almost horizontal, branch of a tree 
or in some dense thorn bush, and, as is usual with most crude nest forms, are flat and shallow, made externally of slender sticlss and roots and lined with finer roots and dry grass, the model of the whole structure somewhat resembling that of a Pigeon. Incidentally we may remark that the eggs of the first-named species are often laid at considerable intervals, so that young birds and fresh eggs may be found in the nest at the same time-a fact that also tends to refute the theory of $\mathrm{Dr}$ Baldamus, already alluded to in the preceding chapter (conf. p. 57). Other nest-building Cuclioos are the Coucals (Centropus) and the birds forming the genus Coua, although their architecture is but of a crude type. The Larkheeled Cuckoo (Centropus toulou) is, however, said to make a rough globular or dome-shaped nest, with an entrance at the side scarcely big enough for the passage of the old birds. Some species in this genus, however, build more elaborate nests, which we shall notice in a future chapter (conf. p. 212). The two species of North American Cuckoo (Geococcyx) also make their own rude nests; whilst lastly may be mentioned the Anis (Crotophaga), also inhabitants of the tropical portions of the New World, and specially remarkable for the fact that several females band together and share one common nest, which is of a crude character.

More familiar builders of the crudest nest-forms are the Pigeons (Columbiformes). The lowest type of 
nest is made by the various species that breed in holes or upon the ground; in fact, we may regard some of these latter species as nestless, as, for instance, the Ground Pigeons (Geophaps) of Australia, which lay and incubate their two buffish-white eggs upon the bare earth. With this exception the nests of the Pigeons (a group of birds numbering nearly five hundred species) are singularly uniform in type, a fact which indicates an exceptional sameness in the conditions of life of these birds. When placed in trees or amongst vegetation of some kind the typical Pigeon nest is merely a crude platform or flat mat of sticks and twigs carelessly interwoven, and less frequently intermixed with stalks and grasses, and often so slightly made that the two white eggs can be seen through the basket-like structure from below. Unquestionably the nests of the Pigeons are by far the crudest form of avine architecture attempted in the branches; yet we must take into consideration the fact that the droppings of the old and young birds accumulate and harden, and thus materially strengthen the whole structure, as the time arrives when it is required to support its maximum of weight. Probably to this fact is due the prevailing low type of architecture in this order of birds. That the crude nest is amply sufficient for the needs of these birds is proved by the fact that Pigeons are not only exceptionally abundant as a group, but very widely dispersed. The very crudeness of the nest renders 


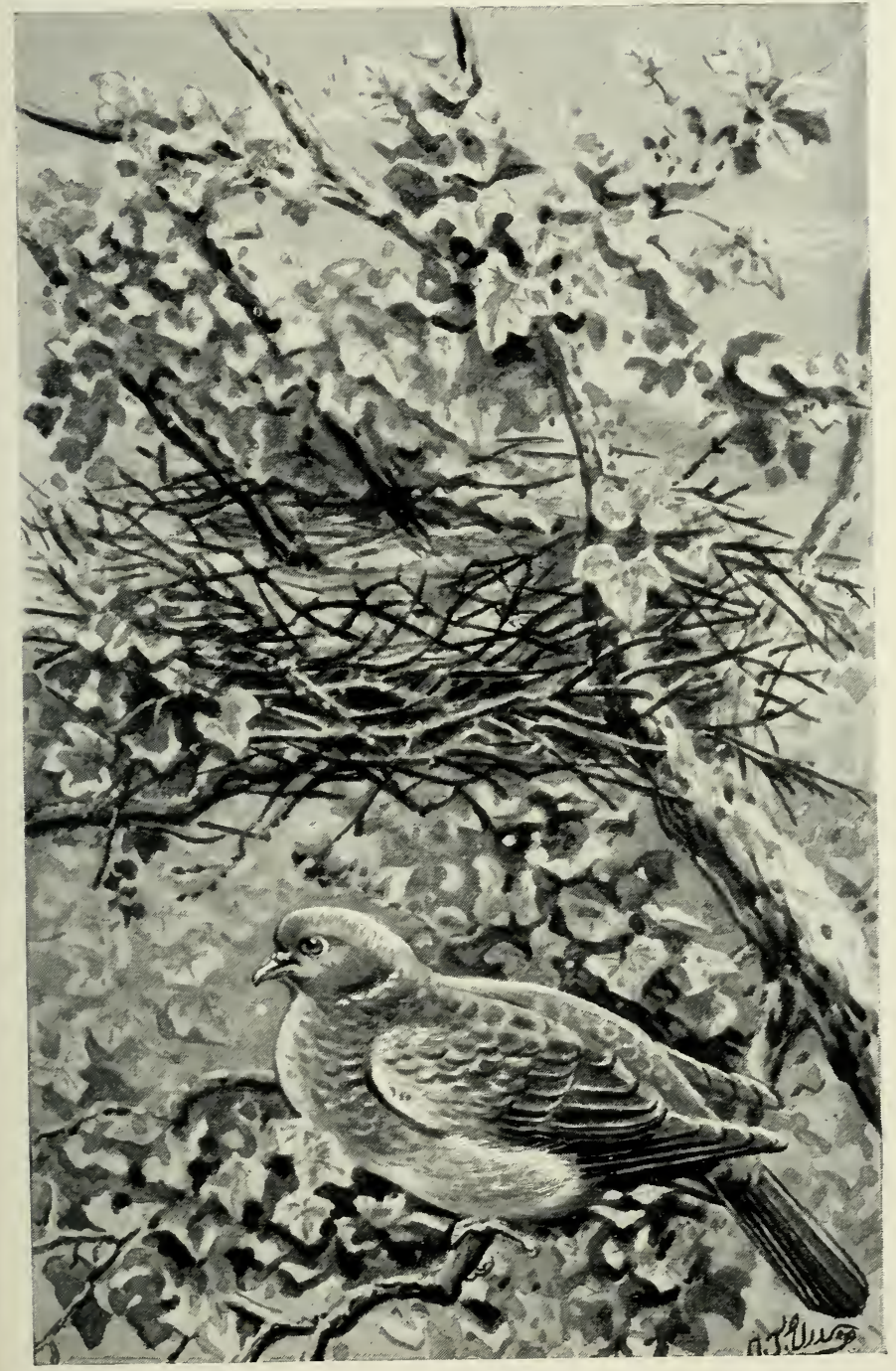



its discovery more difficult, as is conclusively shown by the numbers that escape detection even when built in the most frequented or exposed situations. Some of the Tyrant Birds make very crude nests. Thus, Tyrannus dominicensis is described by Dr Christy as astonishingly small flat structures of just a few twigs placed crossways on each other, and placed at the extremity of a horizontal branch from six to ten feet above the ground.

Having now dealt with the crudest nest-forms that are built away from the ground in trees and other vegetation, we will proceed to examine the leading types of such structures that are placed upon or in the earth. Of these some of the crudest nest-builders are the Sand-Grouse comprising the order Pediophili. In fact we might almost class these birds as nestless species, as the only provision that they make for their eggs consists of a mere hollow scraped in the soil, round the margin of which a few blades of withered grass or bits of dry weed are carelessly arranged; but even this latter finishing touch is frequently omitted. As in the case of the Ostrich and not a few other birds that breed on deserts and sands, the eggs are left during the heat of the day, the sun furnishing sufficient warmth for the purpose of incubation. Incidentally we may mention that Sand-Grouse are specially interesting to the British naturalist, not only because these birds have visited our islands, sometimes in enormous numbers, as 
abnormal migrants, but have even nested, or attempted to nest, in that area.

Another important assemblage of crude nestbuilders is the Game Birds or Galliformes, numbering about four hundred species and races. Some of the more aberrant species, however, differ very remarkably from the ordinary type in the matter of their architecture. These are the Megapodes (conf. p. 126), the Curassows, Guans, and allied forms, and the Hoatzin, the nesting arrangements of which will be dealt with elsewhere (conf. p. 139). The nests of the typical Game Birds are all constructed on much the same crude and simple plan, although some are more elaborate than others. Normally, with the few exceptions just indicated, the nests of these birds are made upon the ground. Of course many instances have been placed on record of such species as Pheasants and Partridges making their nests on haystacks and other equally abnormal places, but such are quite exceptional, and may be disregarded in a scientific review of the architecture of the Galliformes. It would be difficult to find in any other group of species containing such a great diversity of forms a more uniform style of architecture. Indeed the general description of one nest will apply almost in detail to the whole four hundred species. This consists of a hollow scraped out in the ground and lined with dry grass, dead leaves, and other vegetable refuse. As a rule the crude nest is placed under the 
shelter of a bush or amongst tall vegetation and growing crops, and is generally well concealed. One or two slight deviations from the almost universal rule deserve notice. In the case of two out of the three known species of Spur Fowl (Galloperdix), no nest whatever appears to be provided; whilst the Little Bustard Quail (Turnix dussumieri) is said occasionally to form a domed or covered-in nest, as is also the case with the Indian Bustard Quail ( $T$. tanki). That the nests of the Game Birds, crude and simple as they are, are in every way adapted to the requirements of these species seems conclusively proved by the exceptions to the almost universal rule which are furnished by the domestic arrangements of the Megapodes, the Curassows, and the Hoatzin, of which more anon.

The nests of the birds composing the order Charadriiformes are almost equally slight and crude. This order includes the Bustards, Plovers, Sandpipers, Jacanas, and such archaic forms as the Crab Plover, the Sheathbills, and allied birds. Although it numbers nearly three hundred species the uniformity of the nesting arrangements is singularly remarkable. Reviewing briefly the architecture of the principal groups into which the order has been sub-divided by systematists we have the following facts. The Bustards (Otididæ) make a very slight nest, a mere hollow in the ground, scantily lined with scraps of dry herbage. As already pointed out the nearly allied Stone Curlews 
are nestless, as are also the Coursers and Pratincoles and the typical Ringed Plovers. Equally crude nests are made by the Plovers, Sandpipers, and Snipes, forming the family Charadriidæ. Of these, perhaps, the nests of the Oyster-catchers are the simplest, these consisting of mere hollows in the shingly beach, in which the pebbles and broken shells are arranged with some sort of method. Occasionally the Common Oyster Catcher of the British coasts has been known to deposit its eggs in rather curious situations, in the deserted nest of a Herring Gull, in a cavity at the top of a felled pine tree, and in a meadow far from the sea. Another curious fact about the nesting of these birds is their habit of forming several "mock nests" near to the one that is used for the reception of the eggs-a peculiarity also noticed more or less frequently in the domestic arrangements of the Wren. We have the type of a crude nest form running through almost all of the remaining groups, one description of cradle applying equally to the Dotterels, true Plovers, Lapwings, Stilts, Avocets, Turnstones, Phalaropes, Curlews, Godwits, the various Sandpipers, and the Snipes. The nest is normally placed upon the ground, and consists of a hollow of varying size and depth, scantily lined with dead herbage, dry leaves, reindeer moss, pine needles, and so forth. The Stilts make a slightly more elaborate nest, especially when breeding on wet ground, often building a home in shallow water. Some very curious nests of the 
Black-winged Stilt have been recorded from the salt works near Delhi, in Upper India. These nests consisted of little platforms made of pieces of lime, raised about three inches high and from seven to twelve inches across. Upon these platforms a slight bed of dry grass was strewn, on which the eggs were laid. The Woodcock's nest, again, is a trifle more elaborate than usual, as is also that of the Jacanas (Parridæ), possibly in the latter case due to the aquatic haunts of those birds; whilst the nest of the Crab Plover (Dromadidæ) is said to be placed in burrows, in sand-hills. Of the annexing habits of the Green Sandpiper, and occasionally of the Wood Sandpiper, mention has already been made in our previous chapter (conf. p. 50). Some of the nests of the Granes (Gruiformes) are equally crude (conf. p. 153).

Another crude nest form is made by the Divers (Colymbidæ). Some nests of these birds (there are less than half a dozen species) are much better made than others, according to the nature of the ground upon which they may chance to be placed. Thus when these crude nests are made upon dry, bare ground they are mere hollows, sparsely lined with dry grass and other fragments of vegetation; when they are situated amongst grass and other herbage in marshes they are much larger, but the architectural qualities are still crude, the materials-rotten sedges, rushes, reeds, dry grass, and so on-being heaped together 
in the most simple manner. Then we have to consider the equally crude nest-forms of the Penguins (Impennes), a small order of birds numbering upwards of twenty species, confined to the Southern Hemisphere. These remarkable birds breed in societies or "rookeries" on rocky islands in the southern seas." Their crude nests are either made under heaps of rock, in holes or caves, or amongst the hummocks of coarse vegetation, and are composed of grass and leaves. Respecting the species Aptenodytes tæniata breeding on Kerguelen Island, Dr Kidder writes as follows (Bulletin, U.S. National Museum, No. 2), respecting a "rookery" which " is established upon the seaward extremity of a high rocky ridge, running nearly parallel with the trend of the shore, and abutting upon the sea in lofty bluffs. At the foot of this ridge is a little rocky cove, where the Penguins land, and beyond the coast becomes precipitous, the rocks rising perpendicularly some hundred or more feet. Up the very steep inland slope of this hill, thickly overgrown with the 'Kerguelen cabbage' and 'tea,' the Penguins have to climb, after crossing a considerable upland meadow. Numerous very distinct paths have been worn by successive generations of Penguins, until the defiles cut in the sod near the sea are, in some cases, as much as four feet in depth. The track to a Penguin rookery and their landing-place are

1 The range of the order extends from the Galapagos Islands on the Equator southwards into the Antarctic Regions. 
always marked by a-remarkably luxuriant growth of a plant with long feathery fronds, belonging to the order Compositce. The tracks followed the course of a small stream in this instance, and ascended pretty sharp acclivities, steep enough to try one's wind in following them up, until a level plateau was reached on top of the hill. The eggs (which were here never more than one to a nest) were laid either in hollows between the mounds of Azorella, which covered the plateau, or in little bare spots scratched on their tops." The nest of another species, the Rock-hopper Penguin (Eudyptes chrysocome), is described as being made of collected shingle, sometimes plastered in a rough way, and about seven inches in diameter.

Perhaps I might here include another small order of birds amongst the crude nest-builders, the Petrels, Procellariiformes; but all things considered, it seems better to reserve a description of their nesting arrangements for a later chapter, inasmuch as many of the species form more or less elaborate burrows (conf. chap. vi.). One or two, however, must be noticed here. The nest of the Giant Petrel (Ossifraga gigantea), for instance, a bird breeding on Kerguelen Island, is described as a mere hollow some three feet in diameter, either amongst the broken stems of Azorella (where the eggs are to some extent sheltered) or in the sand. Then, again, the Cape Petrel (Daption capense) is a very crude architect. This bird breeds on the same island as 
the former, selecting cavities or grottoes in the rough cliffs for the purpose. In these it forms a simple hollow, and there lays its egg upon no lining whatever. It is interesting to remark, however, that birds sitting in these hollows, with no egg or chick beneath them, have been noticed placing little stones around them with their bills, as if impelled by some almost lost impulse to gather something with which to make a nest. I have also remarked a very similar proceeding on the part of the Fulmar Petrel (conf. p. 43). This latter bird must also be classed as a crude nest-builder, many individuals contenting themselves by hollowing out the soil on the cliffs into a basinlike receptacle, which is generally scantily lined with dry grass. Then the Estrelata parvirostris, breeding on Christmas Island, makes no nest, but deposits its egg in a hole scooped in the bare ground, under a low bush.

Although a few of the Gulls and Terns (Lariformes) make somewhat elaborate nests, these birds, as a group, fairly come within the limits of the present chapter. The crudest nest-builders are unquestionably the Terns. Indeed some of these birds, as we have already seen, make no provision whatever for their eggs, laying them on the bare sand or shingle; others content themselves with the merest apology for a procreant cradle. This usually takes the form of a saucer-like hollow, either amongst herbage or on pebbles and shingle above high-water mark, round 
the margin of which a few bits of seaweed, stalks of marine plants or twigs are artlessly arranged, or in other cases it is scantily lined with dry grass and other vegetable fragments. One of the most elaborate nest-builders amongst the Terns is the Noddy (Anous stolidus), its cradle being described as often a large structure made of dry grass, seaweed, and twigs, but these are so rudely massed together as fully to warrant its inclusion amongst the crude nest forms. The Skuas (Stercorariidæ) have little or no more claim to be regarded as nestbuilders. Their nests are mere hollows trod in the moss or scraped out in barer ground, scantily lined with dry grass or withered vegetable fragments; this description applying equally to the species that breed in the highest latitudes of both hemispheres. The Gulls (Laridæ) are a trifle more elaborate in their architecture, especially the smaller species or such that habitually breed in marshes. The nests of the larger species are usually crude in the extreme, many being nothing but hollows in the sand, amongst marine herbage or on ledges of cliffs, lined sparingly with grass, straws, and scraps of dead vegetation. Sometimes the rim of these hollows may be garnished with a few dead twigs of heath or other similar plants. Some nests (such as those of the Glaucous Gull, Larus glaucus) are composed of heaps of sand, the apex being slightly hollowed and strewn with bits of dry seaweed. The Herring Gull ( $L$. 
argentatus) not unfrequently builds a more substantial nest than usual, made of stalks and twigs, turf, and masses of seaweed, lined with grass and wool, and perhaps a few feathers, but it is made in a slovenly fashion. This bird has also been known to make a large nest on a tree, a change of habit by the way that has taken place within the memory of man. The Kittiwalke (Rissa tridactylus) is one of the most elaborate architects in the order, and its nest may fairly be included in the following chapter dealing with open nests. Some of the Black-headed Gulls make much more substantial nests, yet these may with propriety be included under the present heading. Bonaparte's Gull (Larus philadelphia), however, must certainly be classed with the kittiwake as a fairly able architect. The Black-headed Gull (L.ridibundus) shows a remarkable variety in the structure of its nest, doubtless according to special circ imstances. Some of these nests are little more than hollows in the spongy ground, whilst in other instances the eggs can scarcely be said to rest in a nest at all. Others, especially such as are built in shallow water, are large floating structures composed of reeds, flags, and other aquatic vegetation lined with grass and other fine materials; whilst even more interesting still, nests are occasionally made in trees or on the roof of some building, such as a boathouse. We thus have another most remarkable instance of the adaptability displayed by birds in the matter of 
nest-building, another proof of the way in which birds can construct nests in harmony with special conditions, and unquestionably by the exercise of reasoning powers, and profiting by experience. The fact still further confirms our contention that nests are purely utilitarian structures, and that the cruder forms of cradle are just as well worthy of our admiration as the higher forms of architectural skill. We may rest assured that had a higher type of nest been required, had a more elaborate cradle been necessary, the birds that build these crude structures would have developed much higher types of architecture. So long as the inducement or the necessity for something more elaborate is wanting the cruder form of nest will be made, because it is the one best in harmony with the special needs of its feathered architect or designer. The reader will therefore do well to compare the above remarks with the descriptions given of other Gulls' nests in the following pages in further proof of the assertion (conf. p. 140).

Our last great group of crude nest-builders comprises the ducks and allied birds associated together in the great natural order Anseriformes. In this assemblage, however, we find much variation in the architectural qualities of the procreant cradle. The Screamers, forming the very natural sub-order Palameder, and the Flamingoes included in the equally distinct sub-order Phœnicopteri, may fairly 
claim to be considered as nest-builders of a somewhat higher class (conf. pp. 139, 152); whilst even amongst the birds in the remaining sub-order, the Anseres, the nests are by no means of a uniform degree of crudeness, some being much more elaborate than others. We cannot exactly class the nests of the Swans (Cygninæ), and at least some of those of the Geese (Anserinæ), as crude, and must reserve them for inclusion in another chapter. Even amongst the more crude nest-building Ducks there is considerable diversity, not only in the situation of the nest, but in the elaborateness or otherwise of the structure provided. Notwithstanding their undoubted crudeness, the nests of most Ducks are, when completed, very beautiful structures. This beauty is almost entirely derived from the dense warm lining of down plucked from the female's body, and added as the eggs are laid or as incubation progresses. Crude as the nests of the Ducks are, we have several very distinct types. Broadly speaking, the nests are either concealed in holes or placed among vegetation of some kind. The normal hole-building Ducks include such species as the Golden-eyes, the Buffel-headed Ducks, the Mergansers, and the Smew. None of these hole-breeders can be said to make any nest. The hole in a tree is selected ready-made, and the eggs are deposited upon the decayed or powdered wood at the bottom, but a warm lining of down is eventually added. Then we have the various species of burrow Ducks that incubate 



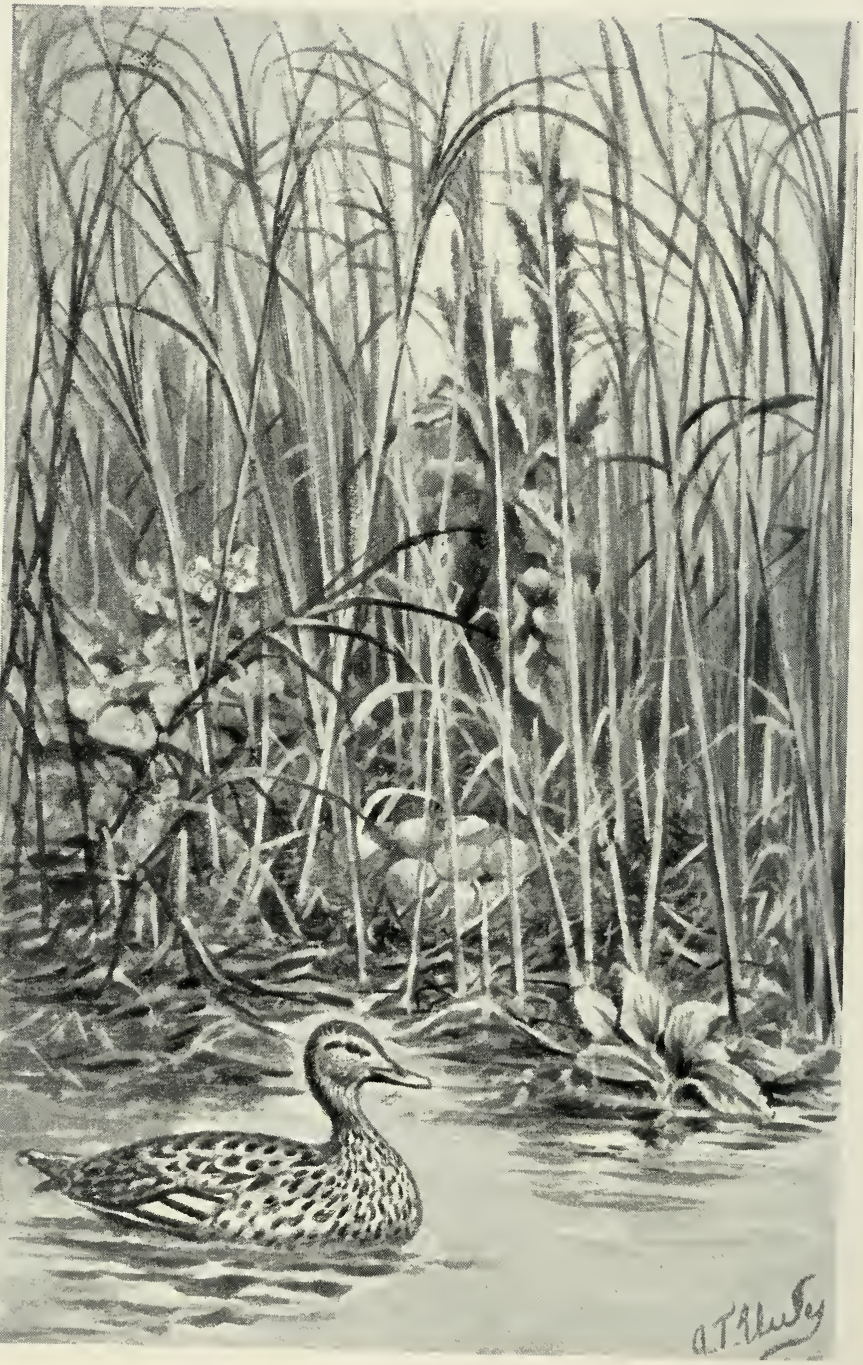

NEST AND EGGS OF THE MALLARD (ANAS BOSCHAS). 
their eggs in disused fox earths, rabbit holes, and so forth, and of which our own Sheldrake is an excellent example. Exceptionally these birds are said to make their own burrows, and in that case they are almost circular. These burrows are sometimes as much as fifteen feet in length. A slight nest is made at the extremity of dry grass, but as likely as not this may have been brought there by the original owner of the burrow, and not by the birds, but as the eggs are deposited a plentiful bed of down accumulates around them. Then there are other species that prefer to nest among holes in rocks, as the Ruddy Sheldrake, but the down added after laying commences is the principal nest; or others yet again like the Eiders that select by choice low rocky islands, making their nests among crannies and clefts, or even in suitable hollows in ruined masonry. These are more bulky than the generality of Ducks' nests, yet rudely made, composed of dry sea-weed, heather, coarse grass, and bits of dead vegetation; the added lining of down, however, softens their crudeness and lends them beauty. The majority of Ducks place their nests in more open situations amongst vegetation of some kind, often aquatic, and especially among heather, bracken, and other long herbage, whilst the shelter of a bush is very frequently sought. These nests usually consist of a hollow of varying depth rudely lined with dry grass, dead leaves, broken sedge and reeds, but in some cases scarcely any nest whatever 
is provided, until the never-failing carpet of down is added. The more or less speckled appearance of this down makes a fully completed Duck's nest look very pretty, and more especially so when, as is often the case, it is well mixed with the bright-hued vegetable fragments that go to form the remainder. Naturalists are by no means agreed upon the precise use of this down in the nesting economy of the Ducks, some maintaining that it is placed there for purposes of warmth, being an admirable non-conductor of heat. Others incline to the opinion that it serves to conceal the eggs from enemies, the sitting Duck being careful to cover these with a downy coverlet when leaving them for a time. I incline to the latter belief, not only because Ducks breeding in the warmest countries of the world, where extra heat is unnecessary, still surround their eggs with down, whilst other species breeding in the same localities, almost side by side, require no such supplementary warmth, or are even nestless, but because I have seen so many instances where the hidden eggs have been most effectually concealed by the harmony of their covering with surrounding objects. It may be worthy of remark that the species nesting in covered sites, in burrows or in holes of trees and so forth, have the down pale and conspicuous-a fact which would only lead to the discovery of the nest were it built in a more exposed or open site. The nests of some of the Geese are quite as crude as those of the Ducks already men- 
tioned, being merely hollows in the ground, into - which a little dry grass or other vegetable fragments are collected. These nests, however, finally receive a warm and copious lining of down.

In bringing this review of crude nest-forms to a conclusion, it may be well to point out the following facts which their scientific study seems to suggest. In the first place the number of species that may fairly be classed as builders of the crudest forms of nest is very little short of two thousand five hundred, or considerably more than one-fifth of the known species of birds. The significance of this fact cannot be over-estimated in demonstrating how certain conditions of life determine this crude type of architecture and inexorably preserve it. Two other facts are brought into very suggestive prominence by this cursory review of the crudest forms of nest. The first is that an exceptionally large percentage of the species are either aquatic or terrestrial in their habits, and naturally select the ground as a site for their procreant cradle. In such a situation an elaborate or bulky nest would in a vast number of instances be exceedingly conspicuous, so that we see a slight and crude nest is the one best adapted to the conditions of existence. The second fact is that the young of an equally large percentage of these crude nest-builders are hatched in a condition that renders them independent of a nest, being in many cases able to run almost as soon as they break from the shell, or are at 
any rate more or less warmly clothed with down, so that an elaborate nest is unnecessary. In other cases the nest arrangements, although crude, are eminently adapted to conditions of existence, as in the case of the Pigeons, where a slight wicker-work cradle is strengthened by the droppings of the birds. 
CHAPTER IV

CONCEALED OR COVERED NESTS 



\section{CONCEALED OR COVERED NESTS}

Nests made in earth tunnels-Sand Martins-Tunnel-boring Wood-Hewers -Nest of Sclerurus umbretta-Of the Kingfishers-Of the Jacamars, Todys, and Bee-eaters-Of certain Parrakeets-Of the Burrowing Owl-Of the Puffins - Of the Petrels-Stormy Petrel-Fork-tailed Petrel-Spectacled Petrel-Of the Whale Birds-Of the Shearwaters-Cave-building Birds-The JackdawThe Choughs-The Rock Dove-The Shag-Cock of the Rock-Oil BirdEdible Swifts-Alpine Swift-Cave-building Swallows-Nests under stones and in holes and fissures of rocks-Various Petrels-Little Auk-Horned PuffinLittle Owl-Certain Parrots-Various Chats-Redstarts and Accentors-Wall Creeper-Rose-coloured Starling-Buntings and Swallows and Pipits-Timberbuilding Birds-Woodpeckers and Wrynecks-Hornbills-Toucans and Trogons-Barbets and Honey Guides-Parrots-Certain Cockatoos-HoopoesRollers - Titmice - Nuthatches-Certain Flycatchers - Sparrows - Nest of Phylloscopus occipitalis-Scop's Owl-Certain Ducks-Nests in holes, in banks, or under tussocks of vegetation-Robins and Buntings - Twite and Ring Ousel-Mound Birds-The Philosophy of Concealed Nests.

In this chapter I propose to make a brief review of those nests that are absolutely concealed from view, either in tunnels or holes, in ground, rocks and timber, under stones, or even by artificial means employed by the feathered architects themselves. We have a great variety of birds coming within such a class of architecture, belonging to widely divergent and remotely related groups, a fact conclusively proving that the method of nest-building, the general plan of architecture, is far more intimately correlated with conditions of life than with taxonomic affinity, special 
appliances (natural tools, such as bill and feet), or even mental development.

We will deal first with those nests that are made in tunnels in the earth. It is somewhat remarkable how comparatively few species resort to this method of providing a procreant cradle; but although few in number, the representatives of this particular kind of nest-building are drawn from widely divergent groups. These tunnels or burrows may either be driven into the face of sand or earth cliffs, or formed in the ground itself. Curiously enough we find amongst these feathered excavators some of the least likely birds-species one would think to examine them very ill equipped for such kind of work. One of the most familiar of these tunnel nests is made by our wellknown Sand Martin, all the more interesting because these birds rank amongst the few known Passeres that excavate out of the five thousand five hundred known forms. As a rule these Martins prefer a cliff of fairly firm clay, loam, or earth, sand pits and the layer of soil at the top of a quarry being favourite sites, but less frequently their excavations are made in soft sandstone, sufficiently hard nevertheless to take all the cutting edge off a hardened steel knife blade! When once the locality has been selected the birds seek out a suitable spot in which to commence their shaft, often malking several attempts before finally deciding. A small circular hole is first formed with the bill (one of the weakest looking, by the way, 
throughout the class Aves), the bird clinging to the bank face meantime and working round and round. Then as the tunnel gets longer the bird is able to stand in the excavation and cast out all the loose soil with its feet. Bill and feet keep steadily at work, chiefly in the early portions of each day, until the gallery extends several feet into the cliff. Sometimes the tunnel has to be deserted should a large stone, a tree root, or other impediment block the way, or in many cases when the cliff is too soft or too hard to admit of successful boring. Although the holes vary considerably in length and general direction, they invariably slope upwards. Some tunnels are almost straight, others turn to the right or left, and are from three to five inches in diameter. As a rule these tunnels are circular, but in some cases they are more or less oval or rectangular. At the end of the gallery the tunnel is enlarged into a sort of chamber about six or eight inches in height, and here a loose nest is formed of dry grass and straws, lined sparingly with feathers. Sand Martins breed in colonies of varying size, and in some places the cliffs are literally honeycombed with their burrows, the birds returning year by year to the same spot to rear their young. The Rock Sparrow (Petronia stulta) also bores into banks and makes its nest in a burrow three or four feet in depth, a cutting or railway embankment being a favourite situation.

Our next burrowing Passere is a somewhat aberrant 
member of the family Dendrocolaptidæ, the Lochmias nematura of ornithologists, a species inhabiting South America. I believe Dr Goeldi was the first naturalist correctly and fully to describe the domestic arrangements of this interesting bird. From his contribution to the Ibis I derive the following facts. This beautiful bird, known to the people of Minas Geraes by the uncomplimentary nickname "Presidente da porcaria," in consequence of its partiality for dirty places, builds its nest at the end of a nearly horizontal burrow, the end of which gallery being enlarged into a spacious cavity to contain it. The next, which Dr Goeldi was able to remove entire after much careful excavation, is described by him as wonderfully large, reminding him of that of the European Dipper. "Like that it is a vaulted globe with a lateral entrance. The exterior is made of small roots and branches; the interior lining consists of regularly-crossed dry bamboo leaves. The walls of the central cavity especially are very well made, and consist of crossed bamboo leaves woven in a really artistic manner. The sagittal diameter of the nest is $13.5 \mathrm{~cm}$., the transverse $12.5 \mathrm{~cm}$. The entrance aperture has a diameter of $3.5 \mathrm{~cm}$. The thiclnness of the walls is everywhere less than $3 \mathrm{~cm}$." Dr Goeldi further states that there is a striking resemblance between the size and shape of this nest with that of the Oven-bird. The materials and situation of the latter, however, are very different, notwithstanding the fact that the 
two birds are somewhat closely allied (conf. p. 244 for a description of this nest).

Another species in the same family (Sclerurus umbretta) nests in a very similar manner, but the nest is a flat and open one, intricately interwoven and composed entirely of dry leaf ribs. It burrows into banks and the nest chamber is a circular one, both tunnel and chamber being smooth and clean. Lastly, we may mention that some of the species in the Passerine family Pteroptochidæ excavate tunnels several feet in length in banks, at the end of these galleries constructing their nests in a slightly enlarged chamber.

Other remarkable tunnelled nests are made by species belonging to a remotely allied group, of which our own familiar Kingfisher (Alcedo ispida) is typical. Some of the species belonging to the family Alcedinidx, however, prefer to nest in holes of trees, or in hollows scooped out of termites' nests placed in eucalyptus trees. These are the Laughing Kingfishers (Dacelo), whilst another Australian species (Tanysiptera sylvia) bores a tunnel into an ant-hill for nesting purposes. Although Kingfishers not unfrequently take possession of a deserted rat hole, or some other similar convenient burrow, they are quite capable of boring one for themselves, as they very often do. These tunnels are usually excavated in some suitable spot on the steep banks of a stream, but sometimes they may be made in the sides of gravel pits, in the sides of ant-bears' 
earths, and other even less likely situations at some distance from water. Kingfishers, although they possess remarkably weak feet, are well equipped with strong, powerful bills, and with these, pick-axe like, the work of excavation is performed. The burrow is constructed upon very similar principles to that of the Sand Martin's, sloping slightly upwards from the entrance and penetrating for several feet into the solid earth. Our British species often takes as long as a fortnight or three weeks to complete its burrow. At the end a sort of chamber is formed, and in this a nest is made of fish-bones, the remains of the birds' food. It is flat and saucer-shaped, and more likely then not rests upon and is surrounded by excreta and fish remains, which produce a most evil smell. The Jacamars (Galbulidæ), the Todys (Todidx) and the Bee-eaters (Meropidæ) are other groups of birds that nest in a very similar manner to the Kingfishers. ${ }^{1}$ The Common Bee-eater (Merops apiaster), an abnormal migrant to the British Islands, and one that breeds very commonly in various parts of Southern Europe, may be taken as a typical species. Like the Sand Martin, this Bee-eater is gregarious, and numbers of tunnels are made by different pairs in the same locality. Its favourite haunts are earth cliffs on the banks of rivers. Unlike various other burrowing

1 Of the nidification of the much duller coloured Puff Birds (Bucconidæ) but little is known. That they are hole-builders, however, seems to be fairly conclusive. 
birds, the Bee-eater seems to prefer to excavate a new residence every season. The long tunnel, which sometimes extends as many as nine feet into a solid earth bank, is chiefly made by the bird's long pointed bill, which, according to Irby, is sometimes worn down to half its usual length by the work! The feet and claws also assist in the excavation. The tunnel is generally nearly straight and horizontal, but sometimes very tortuous, and communicating with other burrows by narrow galleries. Both birds assist in the task, each working in turn. On an average, the passage is three or four feet in length, but sometimes much more. At the end it widens out into a sort of chamber, and here the eggs are laid with no further provision, if we except the wing cases of insects, which form the refuse of the birds' food, which generally surround them as incubation proceeds. In some places where banks are not available, the Bee-eater sinks a nearly perpendicular or oblique shaft into the level ground. The Roller (Coracias garrulus) is said sometimes to burrow into a bank for nesting purposes, but it generally prefers holes in wood, and therefore is more aptly included with the birds mentioned on a future page (conf. p. 120). Some of the Parrakeets (Comurus) might also be mentioned here as instances of burrowing species did space permit.

Another remarkable bird coming into the present division of nest builders is the Burrowing Owl (Speotyto 
cunicularia) of America. This is the little bird that is popularly supposed to live in harmony and share its burrow with the prairie dog and the rattlesnake, but such sentimental stories have long been disproved by such accurate observers as the late $\mathrm{Dr}$ Coues and Captain Bendire, the latter remarking that no such happy families exist in reality, the Owl being pugnacious and more than a match for dog and snake, the presence of which it apparently resents in its own particular dwelling. In some localities this Owl prefers to burrow into a hillside; in others the choice seems to be for level ground. Sometimes a burrow of a ground squirrel or a badger is annexed; if that of the former, the tunnel is considerably enlarged. This Owl is to some extent gregarious, its "towns" consisting of from three to a dozen or more pairs. Bendire states that in burrowing (which appears to be done principally if not entirely by the feet) the loosened sand or earth is thrown out backwards with vigorous kicks, the bird backing gradually towards the entrance and moving the dirt outward as it advances. The burrows vary considerably in length and depth, but are rarely less than five feet in length, and frequently double as much. If made on level ground the shaft is first sunk diagonally for two or three feet, sometimes almost perpendicularly for that distance, when it turns abruptly, the chamber containing the nest being invariably situated above the lowest part of the burrow. When a hillside is bored the burrow runs straight in 
for a few feet and then makes a sharp turn to the chamber, or it will follow a horse-shoe shaped curve. The tunnels are about five inches in diameter, and the nest chamber from about a foot to a foot and a half in width. The nest is generally made of dry horse- or cow-dung, this material carpeting the chamber to a depth of several inches, but sometimes a more elaborate structure of dry grass, stalks of plants, and feathers is formed.

Other remarkable bird burrowers are furnished by the Puffins (Alcidæ). The habit of burrowing, however, is by no means universal amongst these birds, some species rearing their young in hollows and crevices of rocks and cliffs. A very typical burrowing example of these birds is the Common Puffin (Fratercula arctica) found breeding in abundance in certain parts of the British Islands. Like most burrowing birds the Puffin occasionally annexes the hole of some other creature, that of a rabbit especially, but in the great majority of instances it is its own architect. This bird burrows into the soft earth on sea-cliffs, as well as into the level ground, whilst in other cases it finds a convenient shelter in old and ruined masonry. The formidable beak-shaped something like a coulter of a ploughand the excessively sharp claws are both used in the excavation of the burrow. Like the Burrowing Owl, the Puffin casts out the loose earth and stones behind it with its legs and feet, and I have often stood below 
the cliffs and watched the almost continual shower of débris as the active little birds have worked away hundreds of feet above me. As a rule the Puffin excavates a much larger burrow than it actually needs, especially in districts where the soil is soft and crumbling. The burrow, which often resembles that of a rabbit, is excavated by both birds working in turn, and in some cases one common entrance will branch out into several tunnels occupied by as many pairs. It is rarely straight, often winding about in a most extraordinary manner, sometimes shaped like a horse-shoe, and may extend several yards under ground. As a rule the tunnel is about three or four feet in length. At the end, in a slight hollow, a scanty nest of dry grass and occasionally a few feathers is formed, upon which the solitary egg is deposited. Puffins are eminently gregarious during the breeding season, and as the birds return annually to certain spots to nest, the ground often for many acres is undermined in every direction, as well as covered with deep hollows where the excavations have fallen in. Some of these colonies of Puffins, notably those at St Kilda and the Farne Islands, are intensely interesting places to visit, as the number of birds is past all belief. One of these colonies at St Kilda, situated in a sandy bank on the shores of Village Bay, close to the store, is almost exactly like a colony of Sand Martins, the great height of the cliff -and the consequent distance at which the holes 
are viewed - assisting to make the comparison complete.

The last group of typical burrowing birds that I shall notice here is the Petrels, forming the great natural order Procellariiformes. We have already had occasion to glance at the domestic arrangements of some of these birds building crude nests in the open. The majority of species, perhaps, breed in places where the eggs are concealed from view, and not a few of the birds tunnel into the ground to secure that purpose. Beginning with the more familiar species we may instance the nest burrow of the Stormy Petrel (Procellaria pelagica). This tiny bird-the smallest known web-footed speciesalways endeavours to secure a burrow ready made, the discarded hole of some other creature, or failing that will seek a nesting-place under rocks or in heaps of stones or masonry; but in some localities it is compelled by circumstances to excavate a tunnel for itself. This is rarely more than a foot or two in depth, at the end of which it forms a bed of dry grass for its solitary egg. Another, and much rarer species, the Fork-tailed Petrel (P. leachi), breeds locally on the western coasts of our islands. This species is a much more elaborate excavator, its burrows sometimes extending as many as six feet, but more usually four or five feet. This burrow is seldom straight, but winds about in a very erratic manner, and often has several outlets. It is usually made in 
the soft soil on or near the summit of a cliff. In some cases one of these "earths" will shelter several pairs of birds. The slight nest is made of dry grass, moss, roots, and a few bits of lichen torn from the surrounding rocks, whilst in exceptional cases the single egg is laid upon the bare ground. Both these Petrels are gregarious, and some of the colonies contain a great many pairs of birds. Some of the less familiar species are equally interesting in their domestic arrangements. One of the most remarkable of these bird-burrowers is the Spectacled Petrel (Majaqueus aquinoctialis), a species that breeds on Kerguelen Island. Some very interesting observations made by $\mathrm{Mr} \mathrm{R}$. Hall, and contributed to the Ibis (1900, pp. 21, 22), may be aptly quoted here: "Of eleven nests found, only one was in dry ground; the others were in hillsides, down which snow water ran at all seasons of the year. The earth was simply saturated with water, and in it were tunnels, always beginning under a small cascade, and running back for a distance varying from five to eight feet, and in one instance I dug eleven feet to reach the egg. The holes are in groups of from three to six, judging from four colonies examined by myself. At the end of a crooked tunnel is a semi-spherical cavity, with a flat floor covered with water, and in the middle of this space is a raised circular bed of rootlets, saucer-like, inverted, with an indent just above the water-level." Surely this is one of the most remarkable nests 
ever described, the birds, in some instances, having literally to wade through water to reach the entrance of the burrow concealed under the bank. Some of the Whale-birds and Prions are also accomplished burrowers. Dr Kidder records the following respecting the underground nest of one of the former, the Halobana carulea of ornithologists: "The burrows are excavated beneath the mounds of an umbelliferous plant, which abounds on the Kerguelen hillside (Azorella selago), growing in dense masses of often several feet in diameter. The holes usually run straight inward for a foot or more, then turn sharply to the right or left, parallel with the hillside, thence downward, often doubling once or twice upon themselves and communicating with other entrances. At the bottom is an enlarged cavity, lined with fine rootfibres, twigs, ferns or leaves of the 'Kerguelen tea' (Acana affinis), and quite dry. Here the single egg is to be found, always quite covered with dry powdered earth or the leaves above mentioned. The diameter of the burrows at their entrance is about that of a man's wrist." Then, again, the Shearwaters (Puffinus) are most expert burrowers, and form a slight nest at the end of a tunnel. One of the most familiar species is the Manx Shearwater (Puffinus anglorum), which gathers in certain spots on the British Islands to rear its young. All these birds are more or less gregarious, and the ground of their chosen haunts is honeycombed in all directions. 
From nests made in burrows we may conveniently pass to a consideration of those which are concealed in caves. The number of species that breed in caves is not very great comparatively speaking, and of those not a few make use of other situations as well. Of the species that occasionally make use of caves for nesting purposes one of the most familiar is the Jackdaw (Corvus monedula). The nest of this bird is often a huge pile of sticks wedged into some crevice of the rocks in a cave. At the apex of this pillar or heap of sticlss a nest of dry grass, moss, dead leaves, and straws, lined with fur, wool, and feathers, is formed. Another, but in our country unfortunately now much less common, cave dweller is the Chough (Pyrrhocorax graculus). This species again is by no means confined to caves for nesting purposes, for it selects holes in cliffs or ruins as well. When the nest is made in a cave some fissure in the sides or roof is selected. This nest is made externally of sticks, branches of heather, and stalks of plants, and the cup containing the eggs is formed of dry grass, roots, wool, fur and occasionally hair. The structure varies a good deal in bulk, according to the size of the site selected, the birds evidently liking to cram as much material into the fissure as it will conveniently hold. The Rock Dove (Columba livia) is a much more persistent cave haunter, always selecting such a spot for nesting duties if such be available. Colonies of this Dove, varying in size according to the amount of 
accommodation, are scattered over most parts of the British coast where suitable breeding places occur. The nest, typical of the Pigeons already described in a previous chapter (conf. p. 69), is placed on convenient ledges, or in chinks and fissures in the sides or roof of the selected cave. The Shag (Phalacrocorax graculus) is another species that prefers a cave for nesting in if one is to be had. Its nest is a bulky structure, placed on some convenient shelf or in a fissure made externally of sticks, dry stalks of plants, and seaweed, and lined with dry grass, straws, and turf, the whole being more or less matted together with droppings and decaying fish refuse. This nest, I should say, is used year after year, and numbers of pairs breed in the same cave if sufficient sites are available. The Cape Petrel, the nest of which we have already mentioned (conf. p. 77), may also be instanced as a breeder in caves or grottoes.

Coming now to the most typical cave dwellers, we may give as our first instance that curious species, the Cock of the Rock (Rupicola). Several species of these birds are known, inhabitants of the tropical portions of South America. The nest is made of mud, possibly mixed with a sticky saliva, the inner structure composed of twigs, lined with moss, and is attached to the sides of some darl cave. Then we have that extraordinary species, the Oil Bird (Steatornis caripensis), perhaps better known by its Spanish name "Guacharo," an inhabitant of various parts of South 
America. The Guacharo is a cave dweller in every sense of the word, not only rearing its young in caverns but spending the entire day in these gloomy retreats, coming forth at night in quest of food. The nest of this bird is said to be made of clay, and bowllike in shape. Vast numbers of these birds live in company, and their caves are harried by the Indians for the sake of the young Oil Birds, which are exceptionally fat, and yield a certain oil much prized for culinary and illuminating purposes. The last avine cave dwellers that we may notice here are the species forming the genus Collocalia. These are the Swifts, the nests of which are made into the famous birds'nest soup, a delicacy so highly prized in China and other parts of the East. Perhaps the best known species is the Collocalia esculenta, an inhabitant of the Moluccas, but three others are found in the Andaman Islands. A very interesting account of these latter appeared some years ago in a Calcutta paper, and was republished in the Ibis for 1892 (pp. 578, 579), and which may be quoted here. "The Swifts arrive at the Andamans towards the end of November. Before their advent a party of convicts and Andamanese is sent round to all the caves in which the birds build, to clear away the old nests in which the previous season's young have been hatched out, to bring in all the refuse, which is sold for Rs. 5 per seer, and generally to clean the caves. The fine break between the monsoons, in October, is 


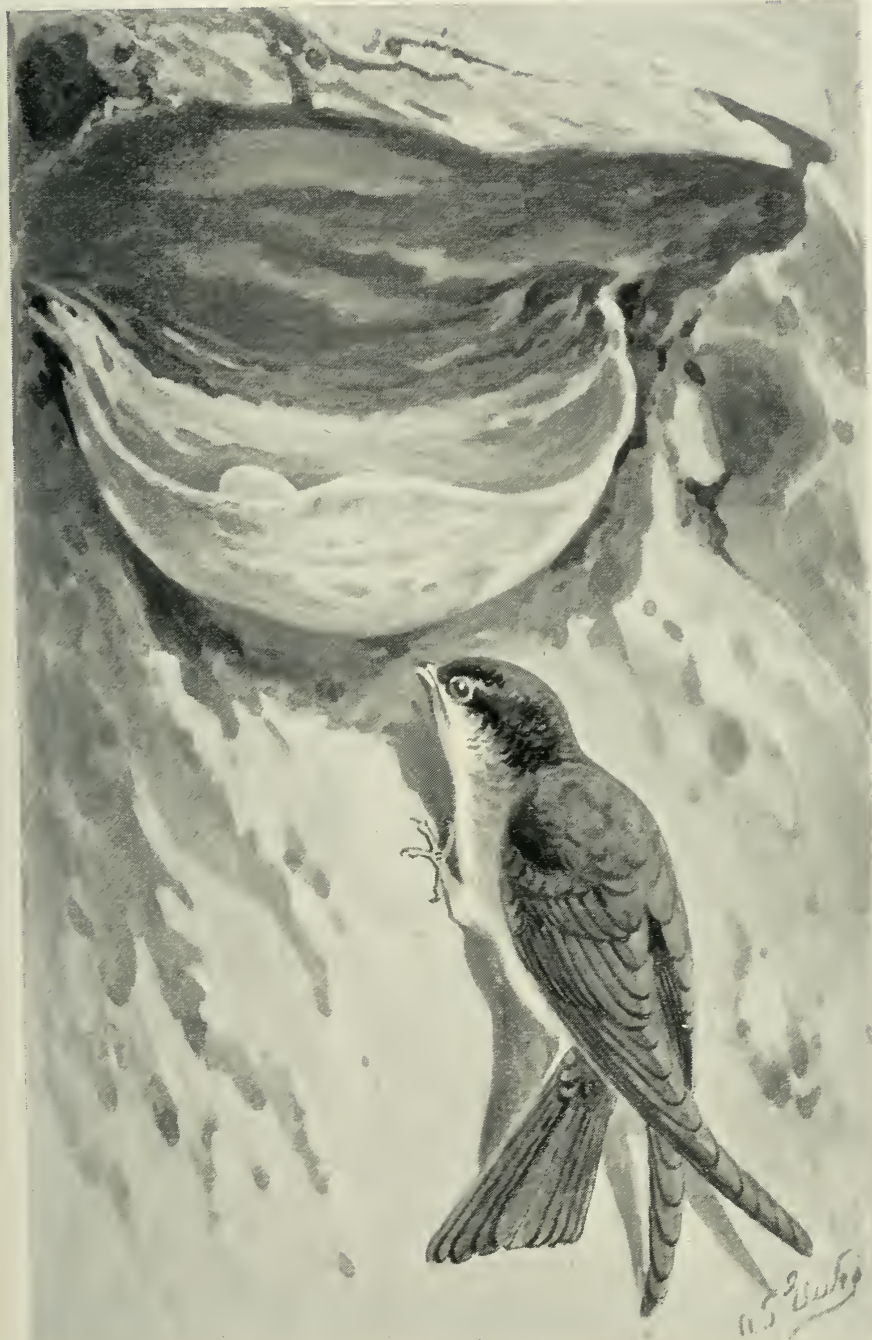

NEST OF THE EDIBLE SWIFT (CULLOCALIA). 

generally taken advantage of for this work, but instances have occurred where the collectors have been overtaken by a storm, their boats smashed up and lost, and they themselves placed in rather an awkward position. The birds take their time about commencing to build, and if there has been a wet December the first crop of nests is generally a poor one, being soiled by the damp and drippings from the roofs of the caves. However, about the last week in January, the collectors go round the islands to the different caves, a journey which takes about three weeks in an open boat, and bring in all the nests that have been built. The best quality, resembling pure isinglass, and worth their weight in silver, are found in caves in limestone and volcanic rock, the nests built in sandstone and serpentine being inferior. The birds now build much faster, and at the end of February a second collection is made, which is usually the best of the season. The third collection is made in April, when the nests, though of good quality, are thin and dry. The birds are then left to build and hatch out their young. They leave the islands soon after the south-west monsoon sets in. The nests are very carefully removed from the rock by an iron trident, and are kept in clean linen bags, as it is important that they should not be crushed, soiled, or wetted by the seawater. When brought into Port Blair they are cleaned from all feathers and impurities, and then 
packed in circular bundles weighing about four pounds each, and sealed according to their quality. There are three classes of nests-1st class, which are pure white, resembling isinglass, and which realise from Rs. 130 to Rs. 145 per viss ; 2nd class, which are clean, but yellow in colour, and realise about Rs. 100 to Rs. 110 per viss; 3rd class, which are discoloured, and have feathers and other foreign matter in them, and realise about Rs. 90 per viss. The refuse and clippings over from cleaning the nests realise about Rs. 4.8 per seer. The nests are formed from a gelatinous secretion from the salivary glands of the birds, but there is one kind of Swift which makes its nest of grass, straws, moss, and feathers glued together, and fastened on to the rock by this secretion. The caves in which the nests are found are scattered about the islands, some, such as those at Stewart's Sound, far inland; others in rocks concealed in mangrove swamps; and the Malays, who were the original traders here in these articles, must have been very persevering to have found them-I suppose they watched the flight of the Swifts. Many of the caves are quite dark, and in these torches are necessary, and occasionally ladders; others are only to be approached through the surf." Some of the other Swifts are occasionally met with breeding in caves, as, for instance, the Alpine Swift (Cypselus melba); also certain species of Swallow, as, for instance, Hirundo hyperythra, and less frequently 
the British Swallow (H. rustica). There can be little doubt that before buildings were available these birds bred much more commonly in caves and crevices of cliffs than they do at the present time.

From nests made in caves we will pass to a consideration of those that are habitually concealed under stones or in crevices, holes and fissures of rocks. The birds that resort to these situations are not only numerous, but representatives of remotely allied groups. Some of the Petrels, for instance, habitually resort to stones and broken cliffs for breeding purposes, whilst some others that generally nest in burrows in the ground occasionally do so. Confining our remarks to the most typical rock and stone builders, we may illustrate these in the first instance by the home of Wilson's Petrel (Oceanites oceanicus). Of the nest of this Petrel on Kerguelen Island, $\mathrm{Mr}$ R. Hall writes (Ibis, 1900, p. 20) as follows: "Go straight to a wild-looking piece of the coast if you want nests. Look under large or small slabs of stone, or within the crevices of the cliff-sides. Most of the nests are saucer-like, and neatly put together with loose twigs. Your shovel will act as a lever to lift the slabs and expose them, when the sitting bird moves away to the farthest corner to escape the light, never offering to bite, although the act would be harmless." Mr Hall goes on to say that the nests were built principally of Azarella stalks, that they were flat in shape, and placed in shallow indentations beneath 
a stone, with no definite tunnel running to them, although in some cases the bird would scratch an entrance. A typical nest measured seven inches by five inches, and the depth of the bowl was five inches. Then we may mention Bulwer's Petrel (Bulweria columbina), which places its egg under rock fragments or large stones at the foot of cliffs, whilst the Stormy Petrel is especially addicted to nesting in heaps of loose stones. Mention might here also be made of the Little Auk (Mergulus alle), which deposits its solitary egg under large stones and rock fragments, but does not, however, make a nest. Taking another example from the same family (Alcidx) of birds, we may instance the Horned Puffin (Fratercula corniculata), a species which breeds in some numbers on Bering Island and the Commander Islands, and which lays its egg between stones or in holes in rocks. Then some of the Owls must be included in the present class of rock-breeders. Perhaps one of the most familiar is the Little Owl (Athene noctua) with its southern representative Athene glaux. These birds often lay their eggs on a scanty nest (usually of food refuse after the manner of their kind) in a rock crevice or beneath a large boulder; whilst in Algeria, in localities where cliffs are absent, the Southern Little Owl seeks a suitable substitute in the sides of the wells. Mention should also here be made of such species as the Jackdaw and the Starling, which not unfrequently resort to such localities in quest of a nesting site. 
Some of the Parrots also nest in rock crevices, whilst some of the Geese make their nests in hollows in sandy cliffs, as, for instance, the Chloephaga melanoptera of Chili (conf. Ibis, 1897, p. 190).

Amongst Passerine birds we have many instances of nest-builders amongst rocks and stones. Such sites are in some cases peculiar to entire groups; in others they form exceptions to a very different method of nidification. Amongst the most thorough rock-builders we may first mention the Chats (Turdidx), of which our own Wheatear (Saxicola cenanthe) is a very familiar example. Between thirty and forty species of these birds are known to science. Their nests are remarkably uniform, not only in the manner of construction, but in their situation. The Chats are pre-eminently rock birds; they are birds of the bare, stony hillsides and boulder-strewn plains and desert sands, showing no partiality for arboreal haunts. Many of the species build their nests under masses of broken rock, or in heaps of stones, others select holes in the ground, often the deserted burrows of some small animal, or in holes in ant-hills, as in the case of Saxicola pileata. Their nests are cupshaped, somewhat loosely put together, and made externally of dry grass, moss and roots, and lined with finer roots and grass, sometimes hair and feathers, but in some species both the latter soft materials are omitted, as, for instance, in the Desert Wheatear $(S$. deserti). Some of these nests are placed 
several feet from the open air. The Common Wheatear very frequently selects a crevice in a stack of peat for a nesting site-a purely artificial position, and one that indicates a change in selection within comparatively recent times. Another typical group of rockbuilders are contained in the genus Monticola. These are the Rock Thrushes, birds somewhat closely allied to the Chats and the Redstarts. They are dwellers among the rocks, and place their nests in holes of them. These nests are made on precisely the same model as those of the Chats, being loosely made of dry grasses, roots and moss, and lined with finer fibres, hair, and feathers. A hole in a rock, or a hollow beneath a boulder, or in a heap of stones, is frequently chosen, whilst the materials of the nest vary a good deal according to local conditions, the softer linings being often omitted in districts where such are difficult to obtain. Many of the closely allied Redstarts (Ruticilla) make very similar provision for their eggs, placing their cup-shaped nests in holes and crevices of rocks, and forming them of like materials. These birds occasionally find a substitute for a rock in some hole in a tree-a trait common to various other species normally breeding in the former sites. Again, some of the Accentors (Accentor) make their cup-shaped nests in holes of rocks, whilst that exquisitely beautiful bird, the Wall Creeper (Tichodroma muraria), constructs its nests in rock crevices, an open structure fabricated of moss and grasses and hairs, 
and lined with wool and feathers. The equally beautiful Rose-coloured Pastor (Pastor roseus), like so many of the allied birds in the family Sturnidæ, conceals its nest in clefts of rocks, or under heaps of stones and loose rock fragments on mountain sides. Rose-coloured Pastors breed in societies in various parts of south-eastern Europe, but rarely if ever return two seasons in succession to the same spot. They place their cup-shaped nests in the crevices, or under rocks and stones, making them externally of dry grass, twigs, straws, stalks and moss, and lining them with finer fibres, leaves, and in many cases feathers. A great many of the species that nest in rocks and under stones occasionally find a suitable site in holes of trees, whilst an even greater number build their homes in holes of buildings, or amongst masonry or earthworks of some kind. This change of site, comparatively speaking, must have occurred within recent times, and must be taken as another example of that wonderful adaptability displayed by birds in the matter of their domestic arrangements-another proof that reason is the dominant impulse, and that blind instinct, so popularly invoked as the guiding medium, is a totally erroneous assumption with nothing tangible to support it. There are many other birds that have become in a sense parasitic upon the dwellings or other handiwork of man, although perhaps in every instance the habit has not yet become complete, 
certain individuals of each of these species still retaining the normal methods, and serving as an indication of the source whence the divergence has sprung. Thus the Martins and Swifts and Jackdaws and Sparrows that now crowd into man's dwellings and masonry still retain in many instances the habit of breeding in cliffs, in caves and hollow trees, as no doubt all the ancestral individuals did at some more or less remote epoch. Possibly the habit may date its change from the earliest era in which man commenced to make an artificial shelter; and to this day there are certain species as familiar with savage man, nesting in or about his huts and rude dwelling-places, as others are with his more civilised brother. The House Bunting (Emberiza saharce) of Algeria is so familiar with the Arabs that Canon Tristram tells us there are few houses in the M'zab without a few pairs in their courtyard, and I have also repeatedly remarked its trustful familiarity about the mud-built houses of the Arabs in the Tell and the Desert. Then, again, a South African Swallow (Hirundo smithi) makes itself equally at home with the Kaffirs, building its nest on the roof-trees of their huts, and flying in and out through the doorways, utterly oblivious to the crowds of children playing near them.

Amongst the Pipits (Motacillidx) there are some occasional rock-builders, and others more or less habitual ones. The Meadow Pipit (Anthus pratensis) sometimes builds its artless little cup-shaped nest 
under a flat stone. This nest is made externally of moss and dry grass, and lined with finer fibres and hairs. The Rock Pipit (A. obscurus), a dweller on the sea coast, especially of the British Islands, finds a very favourite nest site under a large flat stone, or in a crevice of the rocks and cliffs close to the water. This cup-shaped nest also varies considerably in its materials, sometimes being entirely made of fine dry grass; at other times this material is mixed with moss, bits of dry seaweed, and stalks of plants. Many nests are only lined with finer grass; others are neatly finished with hair, and very exceptionally a feather or two are introduced. Some of the Wagtails (belonging to the same family as the pipits) are also very partial to nesting under stones and in crevices of rocks, making cup-shaped nests-more substantial, as a rule, than those of the Pipits - of dry grass, straws, stalks, twigs, roots, fibres, dry leaves, moss, and other vegetable fragments, lined with finer fibres, hair, wool, and feathers. It is noteworthy that some species of Wagtails more habitually nest amongst vegetation on banks, but their homes are generally well concealed; whilst it is also worthy of remark that the rocknesting species have availed themselves in numbers of instances of sites furnished by walls and other masonry as well as the other handiwork of man That beautiful Arctic bird, the Snow Bunting (Plectrophenax nivalis), must be my last example of rock and stone builders. The nest of this species is carefully 
hidden under heaps of loose stones and rocks, or in crevices of the latter. For such a situation it is exceptionally bulky, being cup-shaped, and made externally of dry grass, moss, and roots, and warmly lined with finer fibres, hair, wool, and feathers. No doubt in prehistoric ages this was the Snow Bunting's only nesting-place, but in later eras it has availed itself of piles of driftwood on the shores of the Polar seas and rivers, and taken to hiding its pretty nest in them.

We have now to deal with an equally important assemblage of birds that conceal their nests in holes in timber, or deposit their eggs in such spots without making any other special provision for them. Some of these timber-builders resort to such places as alternative sites, nesting more or less frequently in other concealed or covered situations, as in rocks, in caves, or even in burrows. Others belong to families or genera in which the timber-resorting habit is more or less exceptional. It is also worthy of remark that some of the gaudiest of avine forms resort to such situations; whilst if the colour of the eggs (or rather want of it) can be taken as any indication, the habit of nesting in timber must be one of great antiquity. As in the other divisions of the present class of concealed or covered nestbuilders, we find examples of the habit scattered through many and distantly related families and orders; but although the habit is such a general 


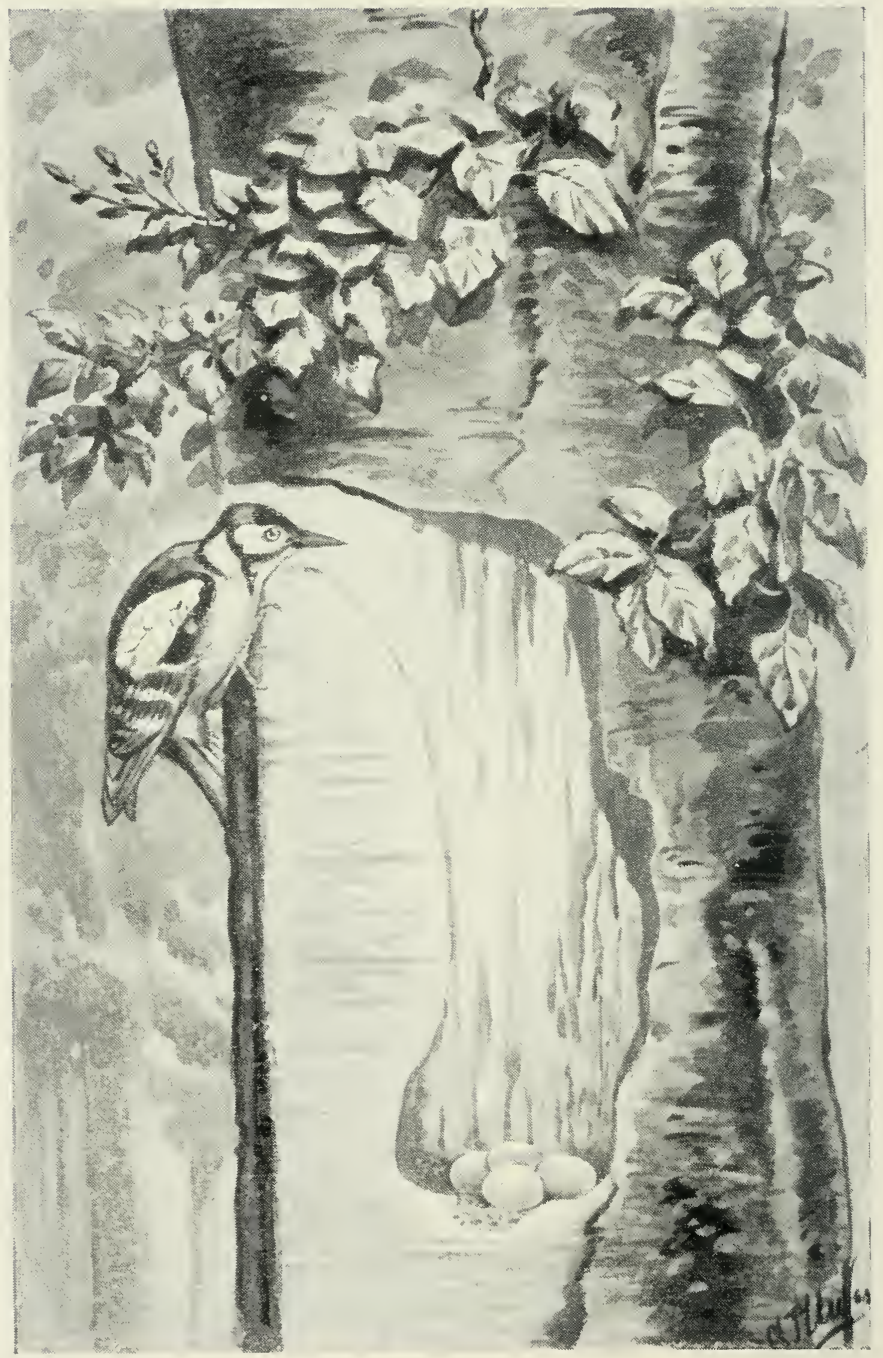

SECTION OF BEECH-TREE SHOWING TYPICAL NEST OF A WOODPECKER. 
one, we shall find that it prevails much more uniformly in some groups of birds than in others.

It will perhaps be most convenient to consider first those groups in which the habit of breeding or nesting in timber is most universal. One of the most characteristic of these is the family of IVoodpeckers (Picidx). Woodpeckers are almost cosmopolitan in their distribution (with the exception of Madagascar and Egypt and the Australian region), being inhabitants of all wooded areas from the Arctic regions to the Equatorial forests. Broadly speaking, their habits are very similar throughout this vast area, and the method of preparing the procreant cradle of one or two species will amply suffice for the entire group. Probably it is the rule for these birds to bore or excavate their own nesting holes (which are frequently used for years in succession), but in not a few instances ready-made ones are selected, which are in some cases more or less altered to suit the requirements of the Woodpeckers. Almost every kind of timber is selected, and as a rule that which is more or less decayed, even though covered with a shell of sound wood, seems to be preferred. To English readers the nest-holes of the Woodpeckers inhabiting the British Islands are most familiar. Perhaps the best known species is the Green Woodpecker (Gecinus viridis). The nest-hole of this bird, made, by the way, in almost every kind of tree, is circular, and usually follows a horizontal direction 
for a short distance, then the perpendicular shaft is bored for a foot or more, at the bottom of which a slightly enlarged chamber forms the receptacle for the eggs. So beautifully bored are these Woodpecker nests that it is difficult to believe they are the work of a bird and not the result of a carpenter's gouge or similar sharp-edged tool. Both birds assist in this wood-boring operation, male and female working in turn until the hole is completed. It is popularly believed that the chips and refuse are carried away by the busy birds in order to prevent discovery of their retreat, but such is not the case; and one of the most unerring signs of tenancy is the heap of such borings which gradually accumulate on the ground below. We should also state that the entrance hole is only just large enough to admit the owners, the aperture increasing in size as the bottom is reached. The extraordinary power of the Woodpecker's bill, which is compressed and chisel-like, enables the bird to excavate its dwelling with comparative ease. No further nest is made, the eggs being laid on the powdered wood and chips at the bottom of the hole, the birds evidently considering that sufficient preparation has taken place in the process of boring into the timber. Many of the larger species bore into sound wood with ease, but our British species, I believe, seldom or never attack any but tainted timber-places where water has already prepared a way through lknot-holes, or old scars 
where branches have been broken off. The Wrynecks (Iynginæ) form a small group associated with the Woodpeckers in the family Picidæ, nest in a very similar manner, but are not known to excavate their own holes, selecting these ready made, or at most altering them slightly to suit their requirements. Their eggs are laid upon the powdered wood at the bottom of the hole. As an instance of perverted habit, I may mention that the Green Woodpecker has been known to bore its hole into the wooden spire of a church in Norway.

One of the difficulties with which we are confronted in a work of the present character is that of classification, a good deal depending upon the point of view from which we deal with many types of nest. This is especially the case with many hole breeding species in the present class, not a few of which might with almost equal propriety have been included with the crudest nest-builders or even with nestless birds. I have, however, decided to include them here although alluding to some of them elsewhere, because they are not only closely allied, but by seeking a ready made hole they provide themselves with a cradle at least as elaborate as other birds that excavate a similar hole as in the case of the Woodpeckers.

The first of these to be dealt with here is the family of Hornbills (Bucerotidæ), numbering upwards of sixty species, distributed over the Ethiopian and Oriental regions and entering the Australian region as far as 
the Solomon Islands. The most remarkable feature in these exceedingly curious birds is the bill, which is furnished with a more or less developed casque. Little less remarkable is the manner of their reproduction. These birds breed in holes in trees, ${ }^{1}$ selecting one ready made for their purpose, and depositing a single white egg on the powdered wood at the bottom. So far all is perfectly normal, but now the most extraordinary part of the business begins. As soon as the hen bird commences to incubate, the cock makes her a prisoner by plastering up the entrance with mud, leaving, however, a small hole through which he faithfully supplies her with food. Our next group of hole nesters consists of the Toucans (Rhamphastidæ), numbering about sixty species, and confined to South America and Central America as far north as Mexico. The most striking feature in these birds is the remarkably large and often beautifully coloured bill, out of all proportion to the size of the body. Toucans are forest birds, and, like the Hornbills, select a suitable hole in some tree in which to deposit their white eggs, for which no other provision is made. Another group of exquisitely beautiful birds nesting in a similar manner is the Trogons (Trogonidæ). These birds are dwellers in the equatorial forests right round the world, and all of them,

1 The Ground Hornbill (Bucorvus abyssinicus) is said to build a large nest of sticks in a tree standing alone (conf. Ibis, I897, p. 422). 
so far as is known, seek shelter in some suitable hole in a tree, where they incubate their two eggs. Then we have the Barbets and the Honey Guides, together forming the family Capitonidx, and numbering more than one hundred species, distributed over the tropics, and breeding in holes in trees which the latter select, so far as I can ascertain, ready for the purpose, but the former undoubtedly in many cases bore for themselves. Our last most important assemblage in this class is the extensive order of Parrots (Psittaciformes). Nearly all these birds breed in holes in trees, which they choose ready made. Some of these holes extend for long distances into the timber. Mr D. Le Soueff records that he found the eggs of the Crimson-winged Lory (Ptistes coccineopterus), in Northern Australia, at the bottom of a spout of a eucalyptus tree ten feet from the entrance. Others (including some of the South American Parraquets) resort to burrows in white ants' nests. Parrots make no nest as a rule, but some of the Australian Cockatoos make more elaborate provision. Thus Microglossus aterrimus chooses a hollow in some tree and lines the bottom for some depth with pieces of broken twigs from scrub trees, the apparent reason being to preserve the single white egg from the moisture that is apt to accumulate during tbe rainy season-the period of its reproduction. The Hoopoes (Upupidæ) form another small group of hole nesting species, but they are not absolutely confined to holes in trees, occasionally using a hole in a wall 
or other masonry. Hoopoes do not excavate the nest hole, but they select one, frequently in a willow tree, and in it often form a slight nest of straws, roots and bits of dry cow-dung, but at other times lay their eggs on the powdered wood alone. The nests of these birds are perhaps the foulest and most evil-smelling avine residences throughout the entire class. It is worthy of remark that the male feeds the female throughout the period of incubation, she rarely leaving her charge, in this respect resembling the Hornbills, a group to which the Hoopoes are thought by some naturalists to be closely allied. Those beautiful birds the Rollers (Coracidx) are typically breeders in holes in trees, often annexing one made by a Woodpecker, where the eggs are deposited upon the powdered wood at the bottom. When a hole in a wall or bank, or a crevice in a rock is selected, the bird apparently constructs a slight nest of dry grass, roots, twigs, and a few feathers-possibly the relics of the nest of some previous tenant of the place. An Ethiopian species, Coracias caudatus, generally chooses a hole in a baobab tree for a nesting place. Some of the Swallows also resort to holes in trees (often deserted ones of Woodpeckers) for nesting purposes, such as Tachycincta albiventris, and certain species in the genus Progne.

We now pass to the consideration of those species that conceal their nests, not universally, but more or less frequently in holes in timber. Some of the most 
persistent of these timber haunting species are the Titmice (Paridæ). These little birds rarely appear to make a hole for themselves, except in very rotten wood, although there is no doubt that they will alter one to some extent, as I have repeatedly watched them carrying material out of holes and picking away bits of plaster and the like from walls. Neither is their choice of site confined to trees, for they are perhaps even more partial to stumps in hedgerorvs, gateposts and so forth. Some of the species with a remarkable sense of adaptability conceal their nests in most unlikely places, such as flower-pots, pumps, cupboards or boxes placed in trees for their special accommodation; whilst their preference for walls and similar artificial places shows how readily birds can avail themselves of any new advantage in the matter of a nesting site. For hole-builders the nests of the Titmice are elaborate and well-made structures, cupshaped and composed of a great variety of materials that are easily felted together, such as moss, wool, hair, feathers, dry grass, leaves and so forth. As illustrating the extreme complexity of the study of birds' nests, we have in the present group of birds species (Acredula) that malie elaborate globular nests in branches, whilst at least one other Titmouse constructs two very distinct types of nest. This latter bird, the Great Titmouse (Parns major), besides making the usual cup-shaped nest in a hole, sometimes forms a beautiful globular nest of moss lined 
with feathers, etc., which it places in the deserted home of a Crow, Magpie, a Rook, or even in the old drey of a squirrel. Again, some, but not all, of the Nuthatches (Sittinæ) more or less habitually resort to holes in timber for nesting purposes, not, however, boring these for themselves, but in most cases plastering up the entrance with mud, leaving a circular entrance just large enough to admit the parent birds. At the bottom of the selected hole a slight bed of dry leaves and flakes of barls is arranged, and upon this the eggs are deposited. The amount of plaster work at the entrance varies considerably according to the size of the hole. As many as eleven pounds of clay have been found attached to one nesting site of the Common Nuthatch (Sitta casia), in the side of a haystack, this latter nest being still, I believe, in the Natural History Museum at South Kensington. Then some of the Flycatchers resort to holes in trees for nesting purposes. One of the most familiar species to British ornithologists is the Pied Flycatcher (Muscicapa atricapilla), the nest of which is very frequently built in a hole of a birch tree, often in the deserted hole of a Woodpecker. The habit, however, is not universal even in this single species, for the bird on occasion finds a similar site in a hole in a wall or a crevice of a rock. The nest is cup-shaped, and made of dry grass, dead leaves, moss, wool, hair and feathers, all more or less felted together. Other allied birds nesting in a similar way are con- 
tained in the genera Siphia and Cyornis. Again, some of the Redstarts depart from what is, perhaps, their more normal choice of a site in a wall or rock crevice, and place their homes in holes of trees, never, however, excavating these for themselves. Starlings again very commonly resort to holes in timber for nesting purposes, but these birds are very adaptive, and seem ever ready to avail themselves of any covered nook in which their slovenly cup-shaped nest can be concealed. Likewise the Sparrows (Passer) are just as eager to take possession of any suitable hole in timber for a nest site, and this peculiarity is by no means confined to the common British House Sparrow (Passer domesticus), for the Tree Sparrow ( $P$. montanus, is just as adaptive, breeding indiscriminately in holes in timber, in walls and cliffs, in deserted nests of Crows and Magpies, as well as under eaves and amongst thatch; whilst in China another Mountain Sparrow ( $P$. nutilans) evinces the same partiality for holes in trees. Still more remarkable, Mr J. Davidson records (Ibis, 1898, p. 18) that the nest of Phylloscopus occipitalis is often placed in holes of trees, as well as in holes in rocks, banks and even in the ground or under stones-cup-shaped structures made of green moss. Precisely the same remarks apply to the Scops Owl (Scops scops), holes in timber being preferred, but if not readily obtainable the bird contents itself with holes in walls. Passing allusion may also be made to the various 
species of Ducks (Anatidæ) that resort more or less regularly to holes in timber for breeding purposes. Some of the most characteristic of these are the Mandarin and Wood Ducks (Aix) of China and North America respectively; the Golden-eyes (Clangula), Buffel-headed Duck (Charitonetta), Hooded Mergansers (Lophodytes), Goosanders (Merganser), and the Smews (Mergus), all inhabitants of the Palæarctic and Nearctic regions. None of these birds makes the nest-hole for itself, and the eggs are deposited upon the débris at the bottom, until they eventually become surrounded by the characteristic coverlet of down plucked from the parent's body during the course of incubation.

Then, again, we have to consider another very extensive and heterogeneous group, in which the birds conceal their nests more or less effectually in holes, in or under banks or beneath tufts of vegetation. Some of these nests, strictly speaking, come within that division containing "Domed Nests," and must, therefore, be reserved for a future chapter; but, on the other hand, a very considerable number of them are open cup-shaped structures, yet so cunningly and completely concealed that the eggs and brooding bird are hidden from all ordinary observation. By far the greatest number of nests concealed in this manner are built by various Passerine birds; and as the number of species nesting in this manner is so large, it would be practically im- 
possible, with the limited space at our disposal, even to give a mere list of them. All that we can do is to illustrate the habit by quoting a few of the more familiar examples. This habit is a very widely prevailing one amongst Passerine species nesting upon the ground, and is evidently practised primarily from motives of concealment, or to ensure protection for the procreant cradle and its contents, including the incubating bird. We need not travel beyond the limits of our own islands to obtain many striking examples of such nests. Perhaps the most familiar of all is that of the Robin (Erithacus rubecula). The nest of this Robin more likely than not is built far under some overhanging bank, whilst in other cases the bird will gratify its desire for concealment by seeking a site amongst dense ivy or exposed roots of trees, or more exceptionally take possession of an old can, or even a shed. The nest is a bulky structure made of moss, dry grass, leaves and fibres of various kinds, the cup being placed as far back under the cover as possible, and formed of fine roots and hairs. The nest of the Nightingale (E. luscinia) is usually placed in very similar spots on banks and amongst ivy, roots, and drifts of dead leaves, and resembles that of the Robin very closely in form and materials. Many of the Buntings (Emberiza) build their nests in much the same situations, whilst the Twite and the Ring Ouzel not unfrequently seek similar spots. These are types of which many examples are furnished by various 
exotic species in almost every other part of the world, but which it is not necessary to specify here. They all illustrate the same interesting fact that such situations are sought in a most intelligent manner for the purpose of concealing an otherwise conspicuous nest.

The Mound Birds (Megapodiidæ) furnish our last examples of covered or concealed nests. In this family are included, not only the typical Mound Birds, but the Brush Turkeys and the Maleos. These birds are distributed over most parts of Australia and northwards among the various islands from New Guinea to the Philippines, westwards possibly to the Nicobars, although the species of the latter may not be strictly indigenous. Unquestionably the method of nesting adopted by the species in the present family is not only unique, but the most extraordinary of all known means of avine reproduction. Briefly, the eggs are deposited in the sand, or in mounds constructed by the parent bird, and left without any more attention on their part, the young being hatched by artificial heat, and being fully feathered when they break from the shell are able to fly almost as soon as they reach the outer world. No less than twenty-six species of these birds have been described in the British Museum Catalogue of Birds and elsewhere. These wonderful mound nests differ somewhat in dimensions and materials, as well as in situation, according to the species that form them. Some are 
made close to the sea shore on sandy beaches; others at varying distances inland in the forests. One or two of these mounds may, with advantage, be described in detail. That made by the Nicobar Mound Bird (Megapodius nicobariensis) is described by Davison as being made of dry leaves, sticks, etc., mixed with earth, and from three to eight feet high and from twelve to sixty feet in circumference, according to its age. The eggs were buried from three to four feet deep. He described the surface soil only of these mounds as being dry; about a foot deep the sand is slightly damp and cold; but deeper the sand gets damper and the warmth increases. Another species, Megapodius cumingi, forms a mound just within the jungle above high-water mark of very similar materials and some twenty feet in diameter, the eggs being deposited at a depth of from one foot to three feet, the ground round them being very hard. Very similar remarks apply to the Megapodius macgillivrayi, which forms the same kind of mound, about five feet high and fifteen feet in diameter. Several of the species ( $M$. eremita, Eulipoa wallacii) excavate a burrow in the sand, laying a single egg in each hole, the latter then being sealed up with sand and the egg left to hatch in due course. Another typical Megapode (Megapodius duperreyi) forms a mound five feet high and twenty feet in circumference of sand and shells mixed with a little soil on the shore a few feet above high-water mark, depositing the eggs in burrows six 
feet deep, one egg being placed in each hole and the earth carefully smoothed over the entrance. Another mound of this species is described as being made entirely of rich vegetable mould, fifteen feet high and sixty feet in circumference; it contained a single egg buried five feet below the surface. Lastly, the Lipoa ocellata is somewhat different in its methods, appearing to lay a clutch of eggs in the centre of the mound, each stuck about three inches apart at the same depth and in the form of a circle. The more aberrant Brush Turkeys are, however, very similar in their domestic arrangements. One of these, the Talegallus fuscirostris of ornithologists, constructs in the forest a mound of earth, sticks and leaves in the form of a truncated cone eleven feet high and twenty-five feet in circumference, the eggs being laid in perpendicular burrows about four feet in depth. Another species, Catheturus lathami, builds a mound often six feet high and from twelve to fourteen yards wide at the base, at other times more conical. Of these mounds Dr Ramsay writes: "The central position consists of decayed leaves mixed with fine débris, the next of coarser and less rotten materials; and the outside is a mass of recently-gathered leaves, sticks and twigs not showing signs of decay. In opening the nest these are easily removed, and must be carefully pushed backwards over the sides, beginning at the top. Having cleared these and obtained plenty of room, remove the semi-decayed strata, and below it, 
where the fermentation has begun, in a mass of light, fine leaf-mould, will be found the eggs placed with the thin ends downwards, often in a circle, with three or four in the centre about six inches apart. At one side, where the eggs have been first laid, they will probably be found more or less incubated, but in the centre, where the eggs are placed last, quite fresh; and if only one pair of birds have laid in the mound, about twelve to eighteen eggs will be the complement, and will be found arranged as described above. On the other hand, if several females resort to the same nest the regularity will be greatly interfered with, and two or three eggs in different stages of development will be found close to one another, some quite fresh, others within a few days of being hatched. There are usually ten eggs in the first layer, five or six in the second, three or four only in the centre." Lastly, the Maleo (Megacephalon maleo), an inhabitant of the forests on the Sanghir Islands and Celebes, comes down in the breeding season to the sandy beaches, often from forest haunts ten or fifteen miles away, to deposit an egg periodically in a burrow in the loose sand. Sometimes but one or two eggs are found in a burrow, sometimes seven or eight, each egg placed at a distance of six or eight inches apart, and each laid by a separate bird.

With regard to the origin of this most extraordinary method of reproduction, Dr Wallace has suggested that it may be due primarily to certain peculiarities 
in the organisation of these curious birds, which necessitates a considerable period between the production of each successive egg, an interval of three months being required to produce eight eggs. That the birds do produce their eggs at long intervals (possibly a fortnight between each) seems to be unquestionable, but this may be caused by the peculiarities of their nesting methods and not vice versa. Reasoning by analogy Dr Wallace's explanation, ingenious as it certainly is, does not seem to us a satisfactory one. The Mound Birds are considered by anatomists to be morphologically the lowest in the order Galliformes; and possibly their abnormal methods of reproduction may represent an equally archaic means of incubation, inherited from some early avine ancestor, living in those remote eras when the divergence between Aves and Reptilia was not so wide as it is at the present time.

In bringing the present chapter to a close a few general remarks seem necessary upon what we may term the philosophical aspect of the whole subject of concealed or covered nests. In the first place, we may begin by repeating the axiom that a bird's nesting arrangements are in complete harmony, not only with the peculiarities of its organisation but with the special conditions of its existence. We may, therefore, fully rest assured that these nests dealt with in the present chapter are concealed or covered from some utilitarian motive. When we find certain means 
adopted for concealment, common to more or less extensive families or even orders of birds, it is not difficult to suggest a general reason for them; but in other groups, where these special means are less frequent or even exceptional, we are often at a loss to suggest any probable explanation. Diverse, however, as are the methods of concealment adopted by the species described in the present chapter, the same great end is gained. Оn the one hand we must take into consideration the fact that a very large proportion of the birds that rear their young in these concealed or covered nesting places are very conspicuous in colour, and also that their eggs are white, or at least very pale in general coloration. Both showy parent and conspicuous egg require concealment, and this is obtained in that variety of ways the present chapter has sought to describe. For instance, the Kingfishers, the Jacamars, and Bee-eaters are exceptionally gaudy birds, and all lay white eggs; hence we may very naturally attribute their burrowing habits to a necessity for concealment during the comparatively helpless period of incubation. Then we have the equally showy Woodpeckers, Hornbills, Toucans, Trogons, Parrots, Rollers, and so on, which seek a similar immunity from danger in holes of timber. Then, again, we have various other groups of species that nest in concealed or covered situations from other motives. The Petrels, for instance, are a group in which crepuscular or nocturnal habits almost 
universally prevail. This peculiarity necessitates these birds seeking dark retreats during daylight. Hence they may possibly have excavated burrows or sought hiding places in caves and crevices or under rocks and stones, not for a nest in the first place (as seems proved by the spotted eggs), but for a refuge from the light. We can then readily understand how the eggs became to be laid in such spots, and the incessant period of incubation (day and night without ceasing) passed in the only comfortable manner. Then as regards many other species which nest in covered sites we may fairly assume that the habit has been acquired to evade special enemies rather than to conceal a showy plumage, as, for instance, in the Chats. This is more particularly the case in groups where the nest is not universally concealed, as in the Flycatchers, the elusion of some danger, or the concealment of some exceptional bright or conspicuous plumage in families or genera where dull colours generally prevail, being the ruling motive. Whether the eggs in such cases are spotted or white and colourless is a good and reliable indication of these isolated instances of a changed method of reproduction to escape certain dangers or better to conform to some altered condition of existence.

Bearing these facts in mind I do not think that we are justified in considering holes (with the possible exception of the Ratitx and the Mound Birds) as an archaic method of nesting, but rather as the best 
method of reproduction that a probably long and continuous natural selection has evolved. Judged by analogy there is not a single species of holebreeding bird (we more particularly allude to those species that make no preparation by way of nest) that we could feel justified in describing as not fully equipped for producing a more complicated type of architecture if such were necessary. Not only so, but the very fact that we often find a more or less elaborate nest constructed in these holes and crevices seems conclusively to prove that birds have adopted such methods for some special reason, and which is still further confirmed by the fact that in many of such cases we find nearly allied birds making similar or equally elaborate nests in open situations. In many of these instances of covered or concealed nests the nest-building habit might almost be regarded as in a transitional state at the present time, and in such cases the coloured eggs are an additional confirmation of the fact. Who, for instance, could doubt that the Puffin or the Chough once occupied open sites for nest-building when examining the faintly-marked eggs of these birds; or, on the other hand, fail to see in the white and shining eggs of the Woodpecker and the Kingfisher a certain sign of the long-continued endurance of the present methods of reproduction? We are confronted with precisely similar phenomena when we come to deal with domed nests, but we must reserve their consideration for a later chapter. Inci- 
dentally we may remark that the eggs of not a few of these species building concealed or covered nests show a strongly-defined tendency to paleness or loss of coloration when compared with the eggs of other species in the same family or genus that are incubated in more open structures. The eggs of the Robin, as compared with those of the Nightingale, or those of the Pied Flycatcher with those of the Spotted Flycatcher, may be taken as illustrative instances. 
CHAPTER V

\section{OPEN NESTS}





\section{CHAPTER V}

\section{OPEN NESTS}

Open Nests a widely prevailing type-Nests of certain Geese-Nest of the Screamer-Nests of Curassows, Guans, and the Hoatzin-Of Bonaparte's Gull -Classification of "Open" nests-Nests of the Albatrosses-Of the Herons and Bitterns-Of the Spoonbills and Ibises-Of the Storks-Nests of the Pelecaniformes-Of the Gannets-Of the Cormorants-Of the Darters-Of the Pelicans -Of the Frigate Birds-Of the Flamingoes-Of the Cranes-Of the Rails and Finfoots-Nests of various Falconiformes-Of the Vultures-Of certain Eagles -Of the Kites-Of the Hawks and Harriers-Of the Ospreys-Nests of the Humming Birds-Of certain Swifts-Of the Colies-Nests of the Passeriformes - Of Crows and Allied Birds-Of the Birds of Paradise-Of the Drongos-Of the Orioles-Open Nest of a Hangnest-Of the Tanagers-Of the Finches and Allied Birds-Of the Larks-Of the Wagtails and Pipits-Of the American Wood Warblers-Of the Honey Eaters-Of the White-eyes-Of certain Flower Peckers-Of the Goldcrests-Of the Bearded Titmouse-Of the Shrikes-Of the Waxwings-Of the Vireos-Of the Thrushes-Of the Whinchat-Of the Warblers-Of the Mocking Birds-Of the Timeliidæ-Of the Tailor Birds-Of the Laughing Thrushes-Of the Bulbuls-Of the Cuckoo Shrikes-Of certain Flycatchers-Of certain Swallows-Of the Tyrant Birds-Of the Chatterers - Of the Ant Thrushes-Of the Pteroptochidæ-General Remarks on the Open or Cup-shaped Type of Nest-Mimicry in Nest-building.

There can be little doubt that an open nest is the normal type of avine architecture, not only because it is by far the most widely prevailing, but also the most convenient for the ordinary methods of reproduction. It may be found more or less frequently in almost every great group into which birds have been divided by systematists. In our review of open nests, however, we shall find that the type is subject 
to an immense amount of modification, and presents an almost endless diversity, not only in the materials of which it is composed, but in the situation in which it is placed. We shall find that the type, although always "open," presents every possible amount of variation in form from that of a shallow saucer to a deep cup, and from the size of a walnut to a gigantic structure containing a cartload or more of material, the latter varying from the softest downs and mosses to sticks and branches several inches in circumference. Its position is none the less variable, for we shall find it in almost every conceivable situation, in trees and bushes, amongst grasses, aquatic vegetation, and herbage of all kinds, as well as on rocks and the ground, or even in water, upon the surface of which it in some cases safely floats.

In the first place, it may be as well to deal with a few of those simpler forms of open nests made by species belonging to groups already noticed, such as the Anseriformes, Galliformes, and Lariformes, in which the predominant type of procreant cradle is a crude one. The Grey-lag Goose (Anser cinereus), for instance, generally constructs a huge nest-three feet in diameter at the base, and upwards of a foot in height-of branches and twigs of heather, dead rushes and reeds, dry grass, bracken leaves, and turf, and lined with moss, to which is added, as incubation advances, a thick bed of down and feathers. This open nest is built upon the ground amongst tall 
heather or rank vegetation in swamps. Other species of Geese make equally elaborate nests. Then the nests of the Swans are elaborate and bulky-great conical heaps of dead reeds, rushes, dry grass, straw, twigs and turf, lined with finer materials and a few down flakes and feathers. A nest of Bewick's Swan, discovered by Mr Battye in Kolguev, was a huge conical heap of moss with a shallow cavity at the top for the eggs. Incidentally, we may mention that Swans possess the habit common to various other birds of adding to their nests from time to time during the whole period of tenancy, probably for the purpose of protecting it from any sudden rise in the water level. Then the Screamer (Palamedea cornuta) of South America, an aberrant Anserine form, constructs an open nest of rushes, the foundation of which is in the water. Some of the most elaborate nests of the Galliformes are constructed by certain species of Curassows, Guans, and the Hoatzin. These are placed in more or less lofty trees in the forests, and are composed of sticks and twigs with a rough lining of dry grass and leaves. Other species nest in parts of the tree trunks where leaves have accumulated in the forks of several branches, making no further provision for their eggs. Respecting the nest of the only known species of Hoatzin (Opisthocomus hoazin), Mr J. J. Quelch writes: "The nests, which are made solely of a slightly concave mass of dried twigs and sticks 
taken from the plants on which they are built, and loosely laid on top and across each other, are placed in conspicuous positions high up over the water or soft mud, on the top of or amongst the bushy growth, where they are fully exposed to the direct sunshine. ... From the binding nature of the spiny twigs the nests last for a considerable time, and these are certainly made use of again, possibly after more or less repair. The same nest has been found in use after an interval of seven months." The two or three eggs are very similar in appearance to those of the Corn Crake-double spotted-a fact which indicates a more distant relationship with the true Galliformes than many systematists seem to suspect. Lastly, we may deal here with the nest of Bonaparte's Gull (Larus philadelphia). This North American gull almost invariably appears to nest in trees and tall bushes. It makes a substantial nest in the branches composed externally of sticks, and lined with dry grass, moss, lichen, and bits of dry reed. Several nests are often made in a single tree.

In the present chapter, instead of classifying nests according to the peculiarities of their situation, it will be better to confine ourselves, as far as possible, to a taxonomic arrangement, not only because there is a great similarity in the general plan of these open nests (although the materials are diverse enough), but almost every description of site may be met with in each group (in not a few cases even in the same 
species). As we have already seen, the type of an open nest very generally prevails amongst the crude nest-forms, so that it will not be necessary to notice these again, but confine our observations to such nests as are of more or less elaborate architecture.

Beginning with the lower groups in the avine system, we must revert once again to that order which includes the Petrels and termed Procellariiformes. In this order the nests of the Albatrosses must be included in the present chapter. We have already had occasion to describe various types of nest in this assemblage of birds, none of them being very elaborate; those of the Albatrosses, however, are much better made. Five species of these birds apparently resort to lonely Kerguelen Island for nesting purposes, returning to the old colonies year by year, and in some cases at least using the same homes each recurring season. The nests of several of these species have been described by Mr R. Hall, and from his notes we derive the following particulars. The favourite breeding grounds of the Great Albatross (Diomedea chionoptera) appeared to be undulating ground near a low beach, the cliffs not being so much in request. In no less than three large colonies, as well as in the case of isolated pairs, the nests were usually built within fifty feet above sea-level. Some of the nests were quite out of sight of the sea, half a mile inland, and on ground where ridges and small fresh water lakes intervened. The nests were made 
of peaty grass intermixed with fibrous earth, the bowl or cup at the top being lined or "matted" with natural short grass. Some of the nests were conical and had well-trimmed sides of earth. Three or four of the nests were made within a couple of yards of each other, but more often they were many yards apart, and continued in a line along the higher grounds of the beach. $\mathrm{Mr}$ Hall gives as the average dimensions of these nests - thirty-seven inches in breadth, eighteen inches diameter of bowl, and five inches as depth of latter, and two inches the thickness of the lining. The Sooty Albatross breeds on the hills. Three of its nests were examined by this gentleman on Murray Island in Royal Sound. Two of these were built within three feet of each other, whilst the other was several hundreds of yards away. All were made under ledges of rocks, some three hundred feet high and facing the sea. These nests were neat saucerlike structures composed of caked fine fibrous loam, and measured seventeen inches in breadth, the cavity twelve inches in diameter and three inches deep, the depth of the whole structure being about four inches. Dr Kidder describing the nest of this Albatross in the same locality states that one was made upon a shelf formed by tufts of cabbage and azorella at the entrance of a small cavity in the face of a lofty cliff near the top of a hill. The nest was a conical mound seven or eight inches high, hollowed into a cup at the top and lined rudely with grass. Some of the nests 
are built as many as four miles inland. I may here remark that I shall have occasion to notice several more of these mud made nests belonging to very distantly related orders, as the review of open nests progresses.

The nests of that order of birds which includes the Herons, the Storks, Ibises, and so forth (Pelargiformes), come next under consideration. These are generally large structures, built in a variety of situations ranging from the ground to the branches of trees and the ledges of precipices. These birds naturally divide themselves into a number of groups, the nests in which are more or less different and characteristic. We will now proceed to describe a representative selection from these. It should be mentioned, however, that many species in this order build several types of nest according to the site in which it is placed, the birds accommodating themselves to circumstances in the usual manner, and evincing an amount of intelligence in the construction of their utilitarian cradles. Thus the Purple Heron (Ardea purpurea), when it breeds in trees, makes a large open nest of sticks, but when in reed beds the nest is built upon a trodden-down mass of aquatic vegetation, and is chiefly composed of broken bits of reed and similar plant fragments gathered from the marshes around. The typical nest made by a Heron in a tree usually consists of a bulky flat mass of interlaced branches and twigs, the slight hollow in the centre occasionally 
being lined with turf and moss. Our own Common Heron (Ardea cinerea) constructs such a nest, and the same type is used when it is situated on a ledge of a cliff. Gregarious habits largely prevail amongst this order of birds during the breeding season, and numbers of nests are built close together, not only in trees, but on the ground in marshes. They are also social birds, and very often several species may be found breeding in the same chosen spot. We find the same double type of nest amongst the Egrets, the one being a platform-like mass of sticks and twigs, sometimes with the leaves still attached, placed in a tree or large bush; the other equally bulky, but composed of dead reeds and fragments of other aquatic vegetation. The same remarks equally apply to the Cattle Herons, the Night Herons, the Squacco Herons, and so forth. Seebohm records that a peculiarity in the nests of the last-named species and those of the Little Egret (Ardea garzetta) and the Night Heron (Nycticorax griseus) that he met with during a visit to the great colonies of Herons in the valley of the Danube was that all the twigs radiated from the centre, but that those of the Common Heron were built in the normal way, the sticks being arranged round the centre in the form of arcs. The Bitterns are more uniform in their type of architecture, although even here there are occasional instances of the dual form of nest. These birds are much less social and gregarious than the typical Herons, gene- 
rally breeding in isolated pairs, although there is some evidence to suggest reproduction in colonies by the American Bittern (Botaurus lentiginosus). The typical nest is made upon the spongy ground in swamps, and is a flat basket-like structure of dead flags, rush leaves and reeds, the finer materials being reserved for the shallow central depression which contains the eggs. The amount of material used depends a good deal upon the exact location of the nest, those in the wettest spots being almost invariably the bulkiest. The Little Bittern (Botaurus minutus) sometimes builds a nest firmly moored to reeds growing in the water, and may then almost be described as a floating structure. Bitterns are said occasionally to make a flat nest of sticks, twigs, coarse grass and leaves in the branches of trees, but this must be very exceptional. The Spoonbills (Plataleidæ) and the Ibises (Ibididæ) are very similar in their nest-building methods, and, as usual, we find a double type, one placed on the ground in swamps, the other on more or less lofty trees or large bushes. These birds, like the Herons, are more or less gregarious. Spoonbills nest in swamps, on the shallow margins of lakes, and in dense water-logged forests of alder and willow and in other trees by the side of water, returning each season to certain spots for the purpose of reproduction. When made in branches the nest consists of a large pile of sticks more or less carelessly interlaced, the cavity containing the eggs being 
generally lined with dry grass. When built in swamps it is less carefully constructed yet substantial, and largely composed of dead reeds, rush leaves and a few sticks, and lined with dry grass. The tree nests are generally the largest, being several feet in diameter and a foot or more in thickness, the cup, however, being more or less flat and shallow. Almost precisely the same remarks apply to the cradles of the Ibises, but these birds are more addicted to building in trees, their nests being chiefly composed of sticks and bits of reed and turf. They are not quite so gregarious and social, although often found breeding in company with allied birds. Some species, such as the Hagedash Ibis (Geronticus hagedash), although gregarious at other times, are said to separate into pairs during the breeding season. The Storks (Ciconiidæ) make nests of a very similar type, but never on the ground, placing them on trees, cliffs, and buildings, the latter sites having been selected more recently, as we have found to be the case with so many other birds. Some of the Storks are very familiar birds, breeding on homesteads, and exceptionally tame and confiding, because they are never molested; indeed, in some countries, they are objects of veneration, and held sacred by the inhabitants. They are more or less gregarious, and return with unerring certainty to their old haunts season after season. The White Stork (Ciconia alba), for instance, builds its nest indiscriminately upon the 
roof of a house, a mosque or even on the capitol of a ruined pillar, as well as on the ledge of a precipice or in the branches of a tree. As the nest is returned to each year, it gradually increases in size, some of the structures consisting of huge piles of sticks six feet high, and four or five feet across. The sticlss are more or less intermingled with lumps of earth and vegetable matter, whilst the hollow at the top is lined with an immense assortment of soft materials, such as dry grass, feathers, straws, masses of hair and wool, moss and such curious odds and ends as rags and paper. On the other hand, the Black Stork (C. nigra) is much more seclusive in its habits, delighting to nest in large forests or woods close to marshes. It returns each season to the old locality and consequently the nest becomes a very large one during the course of years. The nest is usually made in a tree, but occasionally a convenient site in a cliff is selected for it. This nest is a huge flat structure of sticks, as much as six feet across, the shallow cavity containing the eggs being lined with green moss, the latter always being renewed each season. Here I may remark that one of the most curious known nests is made by the Hammerhead (Scopus umbretta), an aberrant member of the present group, but, as it does not come within the division of "open nests," I must reserve a description for a future chapter (conf. p. 210).

We now pass on to the consideration of the nests 
of another somewhat extensive and heterogeneous group of birds, the Pelecaniformes, in which are included the Gannets, Cormorants, Pelicans, Tropic Birds, Darters and Frigate Birds. Some of these species (the Tropic Birds), as we have already seen, are absolutely nestless, yet many of the others construct more or less elaborate open nests-which still further emphasises the fact that affinity is not necessarily any indication of uniformity in the type of nest, the latter being influenced, we might almost say, entirely by the conditions of life of each individual species. Although many of the nests in this order of birds cannot be described as elegant-in fact, most of them are more or less offensive, owing to the ways of life of their builders-they are, on the whole, fairly well made. Yet even these remarks cannot be taken in too literal a sense, for we shall find considerable difference in the degree of finish even in the nests of species belonging to the same genus, and occupying almost precisely the same localities. This is one of the most interesting facts that confront the caliologist during the course of his investigations.

First, then, we have to consider the nests of the Gannets (Sulidx). These birds are gregarious, and resort in vast numbers each recurring season to some rock-bound isle to rear their young. Seven species are known; the majority of these are found in the tropics, two inhabit the Southern Hemisphere, whilst another is confined to the North Atlantic basin. 
This latter species is the Gannet (Sula bassana), which breeds in such abundance at St Kilda, the Bass Rock, Sulisker in the Hebrides, and a few other places. The nest of this bird may best be described as a flattened cone with a cavity at the top for the single egg. This may be built almost anywhere amongst the cliffs, on ledges, in crevices, and amongst the broken rocks at the summit. Numbers of nests are built close together, in some colonies almost every available spot being occupied. The bulk of the nest materials consists of sea weed, turf, straws, tufts of moss, and stalks of marine plants, the whole being matted and caked together almost into a mortar-like mass, and thickly coated with slime, droppings, and remains of fish. The cavity is shallow, and the whole structure may be a foot or more in height, but some nests are much trodden out of shape by their apparently indifferent owners-a proceeding which often necessitates repairs and additions during the progress of incubation. The noisy stirring panorama of a Gannet's breeding-place during the height of the season forms one of the most remarkable scenes in bird-life. Another species of Gannet (Sula piscator) which breeds on the Fanning group of islands in the North Pacific presents several features of exceptional interest, inasmuch as the birds' habits vary considerably according to locality. On Palmyra Island, according to the observations of Dr Streets, the birds build their nests on low trees, constructing 
them of coarse twigs. On Christmas Island the Gannets have a very curious habit of breaking off all the twigs within reach of their bill and dropping them under the nests as they sit incubating. These mounds were from one to two feet high, and in some cases solidly cemented together by excrement. We should mention that the nests in the latter locality are made in shrubberies of low stunted bushes. As another type of nest in this group we have that of the Sula cyanops, which is also made on Christmas Island. This nest is nothing but a slight concavity scratched out in the fine coral sand, and might very aptly be included in the series of crudest nest-forms.

From the nests of the Gannets we pass to a consideration of those of the Cormorants (Phalacrocoracidæ). These differ largely, even belonging to the same species, not only in materials but in position. The Cormorant (Phalacrocorax carbo) of the British Islands, for instance, makes several types of nest according to locality. This bird breeds not only upon marine cliffs, small sea-girt islands and reefs, but also on the ground and on trees and rocks inland, miles away from salt water. When near the sea, either on the ground or cliffs, it is usually a pile of seaweed and stalks of marine plants, the cavity lined with fresh green thrift, sea parsley and campion, the whole structure being from one to several feet high. When built inland on cliffs it is generally as large and formed on the 
same model of sticks and twigs, lined with green herbage; or if the breeding-place is near reed-beds, broken reeds are often intermixed with the sticks. Lastly, when built in trees the nest is chiefly composed of a huge mass of sticks, the cavity being lined with green herbage. The whole structure is more or less coated with droppings and remains of fish. The nests of the Shags have already been alluded to, as they generally occupy a covered site. Cormorants, we should say, are more or less gregarious during the breeding season, some of their colonies containing many hundreds of nests, and these places are used season after season. The nests of the nearly allied Snake Birds, or Darters (Plotidæ), are very similar, generally being placed on trees and formed of sticks, the cavity being lined with roots and moss. These curious birds, of which but three or four species are known, are tropical or sub-tropical in distribution, and are found round the world in these latitudes. They have the same gregarious and social habits as their allies. The nests of the Pelicans (Pelecanidæ) do not differ in type from those of the other birds in this order, and are either made upon the ground amongst reeds in marshes, or placed upon trees. Nor do we find anything exceptional in the nesting arrangements of the Frigate Birds (Fregatidæ). But two species are known confined to the tropics and the Southern Hemisphere. These birds make rather slight nests 
of sticks, etc., in the mangrove trees and bushes, building in societies, as is generally the case.

As we have already dealt exhaustively with the nests of the species included in the order Anseriformes, we may now pass them by, with one important exception, however. The Flamingoes (Phœnicopteridæ) are included in that order, and their nests being open structures may be conveniently described now. The nests of these curious birds again illustrate the fact so often brought before us in our study of avine architecture, that many types of nests prevail amongst closely allied groups, each type presenting some special feature of adaptiveness to equally special conditions of life. No more beautiful instance perhaps could be furnished. Flamingoes breed on vast mud flats, on low islands, and the flat shores of lagoons and lakes where the water is not only shallow, but often subject to periodical change of level. No better nests than those made by these birds could be imagined in such a locality. They are simply conical pillars of mud with a shallow cavity at the top for the eggs. When built on dry mud the nests may be little more than rings, or rather "soup plates" of mud, a few inches above the level of the ground; but in other cases they are constructed in shallow water a foot or more in depth, and then they rise from the bottom and tower six or eight inches, or even more, above the surface. These birds also breed in colonies of 


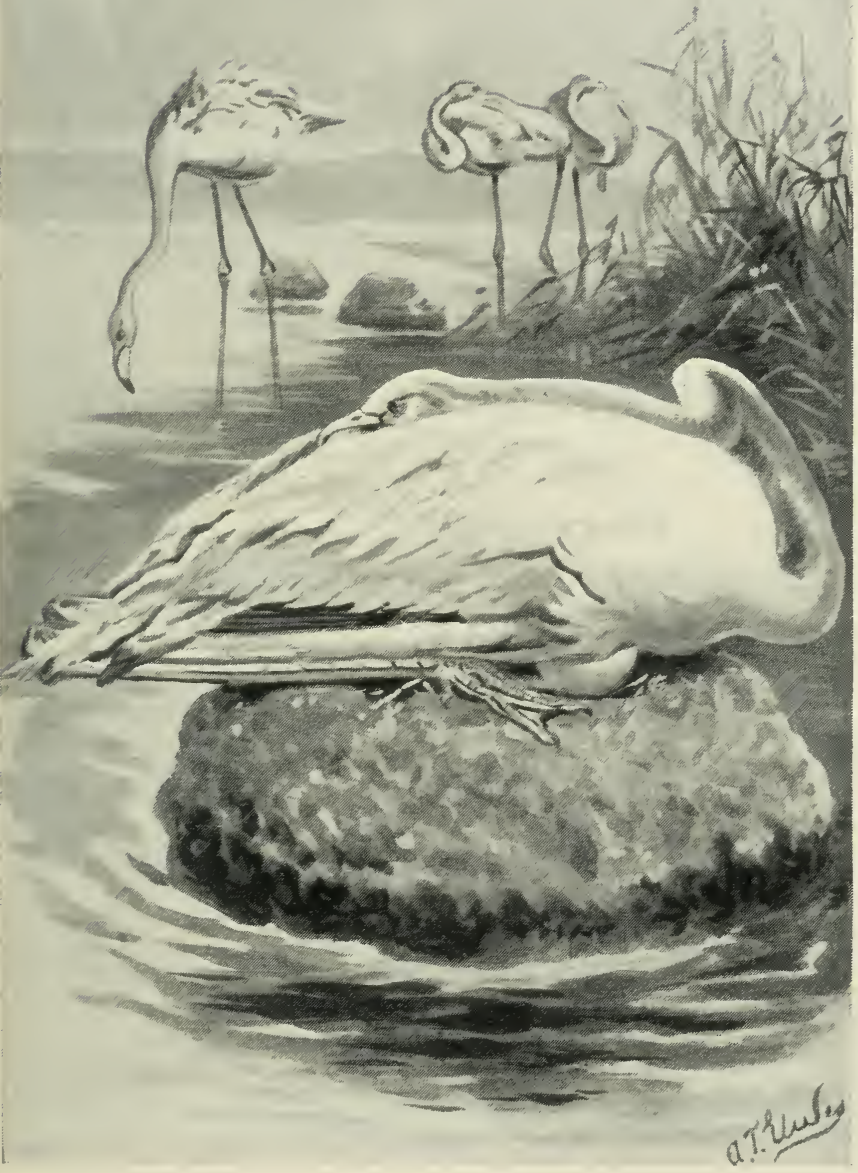

FLAMINGO AND NEST. 

varying size, and their nests are scattered thickly over the chosen spot, sometimes a deep hollow filled with muddy water marking the common spot where the materials for the nests have been gathered.

Next in order of sequence we have to consider the open nests of the Cranes and various allied birds associated under the term Gruiformes. Here again we find not a little divergence in the character of the nest to accommodate it to the peculiarities of the site. Some of the nests, as we have already indicated, must be classified as crude; others, however, are massive and elaborate, both types occurring in some cases in the same species, according to the place on which they rest. We may take as our typical Crane's nest that of the Common Crane (Grus cinerea). Cranes breed in scattered pairs in vast swamps and salt marshes, and the size of the nest depends upon the nature of the ground, the wetter the district the larger the structure. The larger nests tower high above the shallow water or swampy ground, and are made of sedges, rushes, branches and twigs, and lined with grass. The smaller ones, generally resting on grass-clothed mud, are low flat structures of beaten down herbage-mats several inches in thickness and about eighteen inches across. The smallest nests of all are those situated on the dry hummocks, and are little more than trampled hollows lined with pieces of dead vegetation. Then the nest of the Demoiselle Crane $(G$. virgo) is described as being a very slight 
structure-placed amongst grain or grass or on the rocky banks of rivers-a mere hollow trodden in the ground and scantily lined with bits of vegetation; but there may be a more elaborate type constructed if the nature of the ground demands such. Cranes, in some cases at least, return to the old nest each season, adding to and renovating it as required. The more aberrant Limpkins (Aramidæ) and Trumpeters (Psophiidæ) build open nests upon the ground.

The nests of the somewhat nearly allied Rails and Finfoots (Ralliformes) come next for consideration. Some of these birds are said to breed in burrows, and hence fall naturally in a previous chapter; others make spherical nests and must be reserved for a future one; but the majority of species incubate their eggs in open structures and therefore come into the present division. There is a remarkable similarity between the nests of the various groups-such as Rails, Crakes, Moorhens, Gallinules, Coots, and so forth-into which the order may be naturally sub-divided, due unquestionably to the sameness of the conditions of reproduction and the haunts affected. There are, however, many indications of great intelligence in the architectural efforts of these birds-their skill in sub-aquatic building, in the construction of floating nests, and their wonderful adaptiveness in seeking to evade the perils surrounding such a method of reproduction being of great interest, not only to the professed caliologist but to 
the ordinary observer of bird life. These birds, all the world over, are dwellers in wet localities, marshes. swamps, and dense thickets of reeds and other vegetation on the banks of rivers, broads and ponds. Their open nests are generally well concealed amongst such vegetation, and owing to the wet or damp nature of the ground are bulky structures. They are formed of rushes, flags, reeds, and dry grasses, the finer materials being used to line the flat shallow cavity containing the eggs. The foundation of many of these nests is under shallow water, the birds piling up materials from the bottom and forming the nest proper when the structure has been raised above the level of the surrounding water. Other nests are literally floating in water too deep for such a preliminary preparation, large rafts of dead and rotten aquatic vegetation upon which a dryer stratum of materials supports the egg cavity at the top. These nests are often ingeniously moored to the stems of reeds and flags and other plants, the materials being deftly wound round them. The bulk of some of these aquatic nests is enormous. Nests of the Giant Coot (Fulica gigantea), found in Chili, are described by Mr Ambrose Lane as composed of materials enough to fill a horse-cart, the part above water being about one yard in diameter. Another species ( $F$. leucoptera) breeding in the same country also builds a floating nest. We shall also find that these raft-like homes are made by distantly related birds of another order but with similar conditions of 
life-another proof that similarity of nest-type is very often due to analogy and not to affinity. The nest of the well-known Corn Crake (Crex pratensis) demands a few special words of description. The haunts of this species differ considerably from those usually frequented by birds in the present order, and the nest just as unerringly reflects the fact. Corn Crakes generally resort to dry ground for breeding purposes, making their nests in meadow grass or amongst fields of growing grain. Aquatic vegetation is therefore discarded in their architecture, and the bird forms a well-made nest of dry grass, bits of moss and a few dead leaves, about as big as an ordinary soup plate. The cavity is remarkably neatly lined with the finest grass, much of it half green. Then as an instance of adaptability we may mention the home of the Moorhen (Gallimula chloropus). The nest of this bird may either be a floating raft at some distance from the bank on deep water amongst reeds and flags, or on dry ground under brambles and coarse vegetation; or it may even be built many feet above the ground in the branches of trees or placed on a flat branch close to the water, in either case being safe from any sudden rising of the pool. Rails are frequently known to add materials to their nests after the eggs have been laid-a habit common to not a few aquatic species, this means being adopted to prevent waste from the action of the water and to increase the stability of the structure. Of the nidification of the Finfoots (Heliornithidæ) 
nothing appears to be known, but there are facts which seem to suggest a great divergence from the normal Rail methods of reproduction. We may also state that generally the Rails are more or less solitary during the breeding season, but social tendencies are not infrequent amongst such forms as the Moorhens and Coots.

Passing over the Game Birds, Sand-Grouse, Pigeons, Bustards, Plovers, Sandpipers, etc., Gulls and Auks, the nesting arrangements of which having already been dealt with, we have now to consider the nests of such raptorial birds (Falconiformes) as come within the limits of the present chapter. Here we are confronted with a great amount of variation in the degree of architectural skill. Some species, as we have already seen, are practically of non-nest-building habits, but annex the deserted homes of other birds (conf. p. 47); others are included in the chapter dealing with the crudest nest-forms. On the other hand, many of the species in this order construct more or less elaborate open nests, and these we will proceed briefly to describe. Beginning first with the Vultures, we shall find a most remarkable variation in the nesting methods. Some of these birds make no nest whatever, or only the slightest provision for their eggs; or they may annex the deserted home of another bird as the Egyptian Vulture frequently does. Others, however, build large and elaborate structures. The Griffon Vulture (Gyps fulvus), for instance, breeds 
on precipices, and constructs a huge nest (the largest structures being the accumulation of many years) of sticks, branches, twigs, lined with dry grass, leaves, and dead palmettoes. Some of these nests are very well finished, the bowl being fifteen inches or more across and four or five inches deep. Then the nest of the Old World Black Vulture (Vultur monachus) is made on the spreading summit of some lofty giant pine tree, and consists of an enormous platform of sticks often eight feet in diameter, the depression in the centre being lined with tufts of fine grasses plucked from the ground below. Such a nest, after it has once been reached, would admit of a man standing in safety upon it. Another similarly enormous nest is made by the Bearded Vulture or Lämmergeyer (Gypaetus barbatus), a species breeding in various mountain ranges in the south of Europe and Asia. This nest is built upon inaccessible ledges of cliffs, and is formed of sticks and branches, and lined with grass, wool, hair, and similar materials. Then, again, the Eagles are elaborate nest-builders, constructing their eyries on cliffs and trees, or even on the ground, and tenanting them for years in succession. They are made on much the same general plan as the preceding, being huge piles of sticks, somewhat flat, and several feet in diameter. One of their peculiarities is the presence of green leaves in the lining, which in addition consists of coarse grass, wool, turf, and so forth. Possibly the typical Eagles 
(Aquila) are most addicted to building in trees; the Sea Eagles (Haliaëtus) being more partial to cliffs, although some of these birds may be said habitually to nest in trees also, as, for instance, Pallas's Sea Eagle (H. leucoryphus), which in India, at all events, generally constructs its huge nest of sticks lined with leaves in the forking branches of a pipal tree, near to some jheel. Then, again, the American Bald Eagle (H. leucocephalus) constructs a huge nest of sticks, some six feet in diameter, lined with grass, on some lofty tree, but occasionally this species nests on the ground of a small island, and in such cases it is very slight, a few sticks covered with food refuse. The American Harpy Eagles (Thrasaëtus) also nest indiscriminately upon trees or cliffs, and make equally elaborate structures. The Buzzards (Buteoninæ) are builders of similar big nests composed primarily of sticks occasionally mixed with turf, and variously lined with finer twigs, strips of bark, dry grass, roots, weeds, and moss. Here, again, a green lining either of leaves or twigs, with green buds on them, is in many cases provided. These nests are made in trees of varying heights, or upon ledges of cliffs. The Kites (Milvinæ) differ very little in their nesting arrangements, choosing precisely similar sites, but the lining is very characteristic, usually consisting of dry dung, rags, paper, or wool, some of these materials often being festooned about the exterior also. The Brahminy Kite (Haliastur indus), however, builds a 
somewhat small flat nest of sticks, which is lined with mud. The Hawks (Accipitrinæ) are equally elaborate nest-builders, but the materials are much the same, as is also the style of nest-a more or less bulky yet flat heap of sticks and twigs, many of the latter with green buds adhering, and lined in some species with roots, moss, and strips or flakes of bark, but the habit of inserting green leaves does not appear to prevail. The Harriers also included in the same sub-family appear almost invariably to breed upon the ground amongst herbage. These nests are often very similar to those of the Rails breeding in similar localities, thus showing how the habit of adaptability has developed on precisely the same lines in the two groups of very remotely allied birds. The nests of the various species of Harriers vary somewhat in bulk, the largest nests generally belonging to the species that breed in the most aquatic haunts. Thus the nest of the Marsh Harrier (Circus aruginosus) is bulky and made of reeds, sticks, and twigs, and lined with dry herbage, ${ }^{1}$ the bird occasionally adding to the structure as incubation proceeds, doubtless to protect it from any sudden incursion of water. The nest of the Hen Harrier ( $C$. cyaneus), on the other hand, is much less elaborate in many cases when made on dry heaths and mountain sides, consisting of a hollow surrounded by a few twigs and lined with dry herbage; yet when breeding

I Incidentally, we may mention that this species sometimes annexes the nest of a Coot. 
in wetter spots the nest is said sometimes to be a foot or more in height. Montagus Harrier (C. cineraceus), a bird living on heaths and moors, makes a scanty nest like the first named type of that of the Hen Harrier. Lastly, the somewhat aberrant Ospreys (Pandioninæ) build enormous eyries, placing them in trees (as is especially the case in North America), or on cliffs or ruined buildings. Many of the nests are the accumulation of years, and consist of huge stacks or piles of sticks as much as four feet high and as many broad, intermixed with turf and lined with fine twigs and grass, much of the latter in a green state. The cavity containing the eggs is shallow and about twelve inches in diameter. This latter bird builds in societies in North America, but unfortunately it is far too rare in our islands now for such an indulgence in social instincts. Ase said before, perhaps the most remarkable feature in the nesting arrangements of Raptorial birds is the frequency of the green lining. This lining, judging from the fresh state in which it is usually found, seems to be renewed as required. Its use appears to be totally unknown to naturalists. The same habit has also been alluded to when we were dealing with the nests of the Cormorants.

As we have already seen, most of the birds com. posing the order Coraciiformes are either nestless, build crude nests, or conceal them in a variety of ways. There are, however, certain important exceptions to this rule in one of the families (the Humming- 
birds), an open type of elaborate nest being built; in another (the Swifts) such a form of nest occasionally occurs. The Humming-birds (Trochilidæ) are specially famous for their wonderful architectural skill, their nests, although always open or cupshaped, presenting an amount of beauty, ingenuity, and diversity attained in few other groups with the same degree of uniformity. Unfortunately the limits of my space prevent me dealing with these wonderful nests to the extent I should wish, but I think sufficient may be said to indicate the measure of their beauty. The Humming-birds are a New World group, and occur in greatest abundance in the equatorial regions, where they constitute, as Ridgway tersely remarks, the most charming element in the wonderfully varied bird-life of that vast area. As the Humming-birds themselves number amongst them some of the smallest avine forms, so also do the nests many of them fabricate rank as the tiniest examples of bird architecture. Some of these minute homes are exquisitely neat, so deftly and perfectly finished that we might suppose none but fairy fingers had woven them, or that human intelligence had been the prime mover in their design and workmanship, and not the little mind that is encased in such a small feathered casket. The principal materials used by Humming-birds in nest-building are vegetable downs of various kinds, spiders' webs, fine fibres, lichens, wool, hair, and moss, and more rarely 
feathers. Although the general shape and size of these nests present considerable variation, they may all be said to be fashioned on one plan. Whatever their form and bulk may be they all culminate in a cup-shaped receptacle, in which the two tiny white eggs are deposited. The sites chosen for them vary considerably in the different species, but there are none in which the nest can fairly be classed as pensile. The favourite or most general situation is for the nest to be attached to the upper surface of a horizontal or obliquely growing twig. Other nests are fastened to the extremities of long flat leaves; others suspended like hammocks from twigs; others yet again are cemented or glued to cliffs and thick branches by spiders' webs; whilst some are fixed in clusters of drooping leaves. A few of these beautiful nests may now be described in greater detail.

One of the simplest forms of Humming-birds' nests is that made by the Frilled Coquette (Lophornis magnificus), a simple little cup formed of down and fibres, the materials of the under surface and one side being worked round the slanting branch or twig that supports it, whilst a garniture of lichens on the outer walls serves to assimilate the whole structure with its surroundings. Another equally simple nest is made by the Ruby-throat (Trochilus colubris). This is a tiny cup about the size of one-half of an ordinary walnut-shell, also fabricated of vegetable down, wonderfully neatly lined with the same, and studded 
externally with a mosaic of lichen, which causes the nest to appear nothing but a knob or excrescence upon the similarly lichen-garnished limb or trunk of a tree. A third and similarly constructed nest belongs to Costa's Humming-bird (Calypte costce). This is also attached or saddled to the upper surface of a branch, and is composed externally of lichens and flakes of bark bound together by spiders' webs and lined with feathers. A fourth of the same general type is made by the Calliope Humming-bird (Stellula calliope), and usually fastened to the upper side of some dead twig. As an instance of the intelligence and adaptability of Humming-birds we may mention that a nest of this species, discovered by Dr Merrill in Oregon, was built upon a dead, flattened cone of Pinus contorta. It was fashioned externally of thin strips of grey bark, cemented together with spiders' webs; lined with the same kind of bark, with a few added tufts of cottony blossom, and so closely matched in colour the cone that supported it, that it was discovered with difficulty. A somewhat different type of nest is slung in the fork of some twig. A capital example of this type is presented by the nest of the Circe Humming-bird (Iache latirostris); another built in precisely similar situations is that of Xantus's Humming-bird (Basilinna xantusi). This latter is securely interwoven between two forks or prongs of a twig resting between them. It is composed chiefly of raw cotton, thickly coated outside with spiders' 


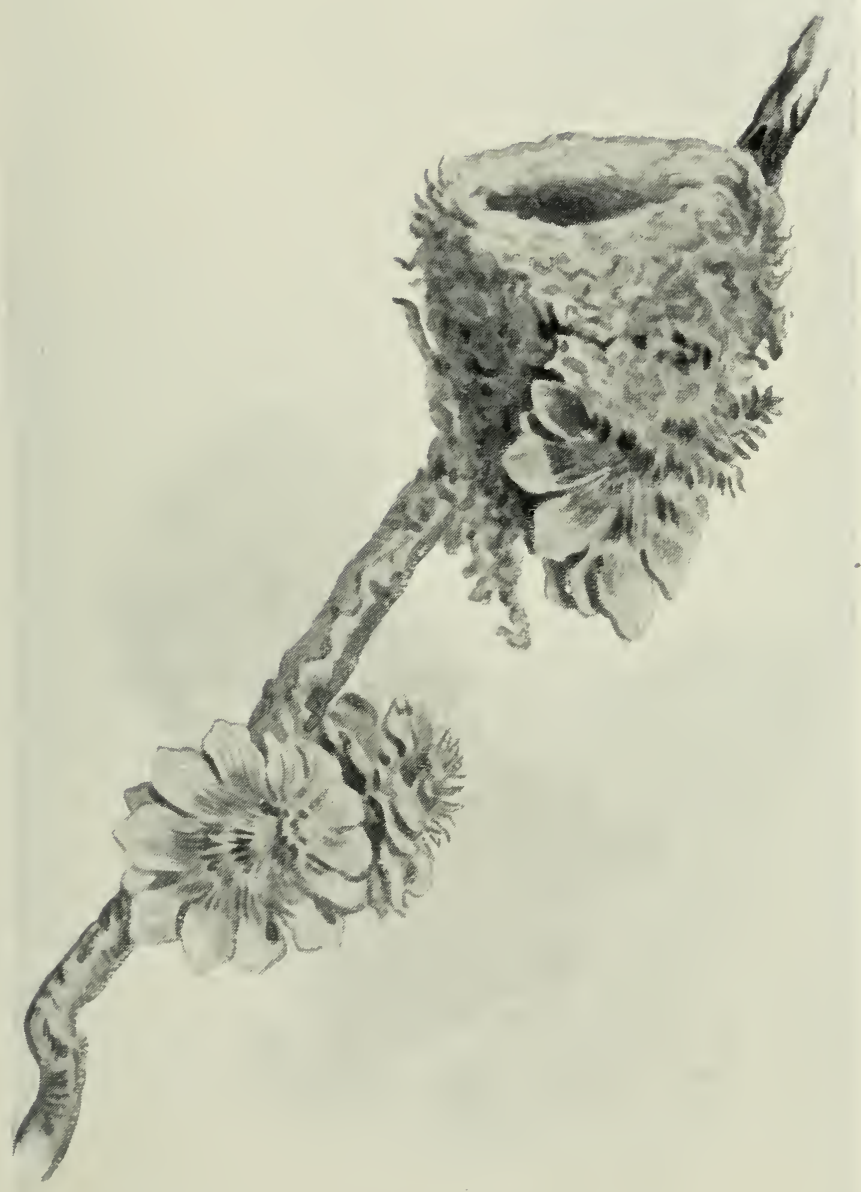

NEST OF CALLIOPE HUMMING BIRD (STELlULA CALliOPE).

(After Plate in Report National Museum, 18go.) 

webs or leaf stems and seed capsules, and in some cases is lined with a few soft white feathers. Other types of nests are suspended from the tip of some hanging twig of a vine or creeping plant. One of these is formed by De Laland's Plover-crest (Cephallepis delalandi), which is more or less cone-shaped, and the materials interwoven with a cluster of leaves. Another is the work of the Brazilian Wood Nymph (Thalurania glaucopis). Vegetable fibres and lichens, cemented with spiders' webs, form the outside, the inside being lined with down and similar soft material. The nest of the Red-throated Sapphire Hylocharis sapphirina) is suspended in a very similar manner from a slender drooping twig. Then we have that exceedingly beautiful type of nest suspended from the extremities of some palm or other ribbonlike leaf. This type largely prevails amongst the Hermit Humming-birds (Phaëthornis), the nests being funnel-shaped, tapering off to a point and conforming to the shape of the lance-like extremities of the leaf to which they are attached. In some cases the nest itself forms an artificial terminal point to the leaf, notably so in that of the Pygmy Hermit (P. pygmaus). The usual materials are the delicate fibres of certain plants, the cottony down of certain seed vessels, bound together and to the leaf by masses of spiders' webs. Other nests in this group are formed of slender tendrils and roots, but the attachment is again secured by the aid of sills-like and tenacious spiders' webs. 
Another leaf-suspended nest is that of the Saw-billed Humming-bird (Grypus navius). In this case the materials are chiefly fibres woven in a net-like manner, the inner foundation, however, being more compact, and made of tiny leaves and moss fibres. Another and exceptionally interesting type of nest is well represented by that of the Fiery Topaz (Topaza pyra). It is funnel or horn shaped, and saddled on the upper side of a bunch of twigs, most of which are interwoven with the lower part of the nest. The materials are almost like leather in appearance, and bear a very close resemblance in colour to the twigs that support them. These are a certain kind of fungus (Boletus). Lastly, we may allude to the nests made by some of the Hill Stars (Oreotrochilus). These are hammock-shaped structures made of lichens or moss, vegetable downs, and feathers, and attached to the face of some rock, on one side only, by spiders' webs. In some cases the upper part of the nest is protected by an overhanging ledge of rock. The Sappho Comet (Cometes spargamurus) weaves a nest of fibres and moss, lined with hair, and sometimes attaches it to the sides of a wall, or to some pendant twig, where it is sheltered by a ledge of rock above it. Some other of the Hill Stars make exceptionally big nests, as large as a man's head, with a tiny cup at the top for the eggs. Another species, the Mellisuga minima, one of the smallest known, not much bigger than a bumble-bee, 
constructs a tiny cup-like nest of wool and fine hair, disguising the outside with little bits of green moss and lichens, attached with cobwebs, placing it between the fronds of some small fern on the banks of a stream. This bird breeds at San Domingo. Humming-birds have frequently been watched during the actual process of building their delicate little nests. Gosse records how he watched a female Long-tailed Humming-bird (Trochilus polytmus) in the act of building its nest, formed of moss, cotton down, lichens and spiders' webs, and suspended from a slender twig. He watched her fly to the face of a rock clothed with fine soft moss, and whilst hovering before it pluck piece after piece until a large bunch had accumulated in her bill. With this she flew to the nest, seated herself on it and began to work in the new material, pressing and arranging and interweaving them with her bill, while she fashioned the cup of the nest by pressure of her breast, moving round as she sat. $\mathrm{Mr}$ Otto Emerson similarly remarked the nest-building of Allen's Humming-bird (Selasphorus alleni) whilst constructing its cradle on a climbing rose tree beneath a porch. He tells us how the female commenced the nest on the end of the stalk by bringing a quantity of willow cotton and spiders' webs; how she placed herself on the chosen spot, "then with her bill, running it here and there around the edge of the bottom, picking out a bit here and there, to place some other in its place, then working her wings in 
a fluttering manner to shape the nest around her body." After the first egg was laid, she continued to add to the nest by putting a bit of web or cotton round it, being apparently hindered in her operations by a high wind, which caused her to continue sitting to prevent the eggs from being thrown out. Hummingbirds appear to be much attached to their breeding places, in some cases being known to return to them yearly and make new nests on the remains of the old ones.

The open nests of the Swifts must now claim a passing notice. Although but a small group (numbering less than eighty species), the Swifts present considerable diversity in their nesting arrangements. Most of these birds build covered or concealed nests in buildings, caves, and so forth; others construct a domed or roof type of nest (conf. p. 211); whilst some form open cup-shaped structures, and these must be described here. Of these the species associated in the genus Dendrochelidon nest on stumps. Others forming the genus Macropteryx, popularly termed "Tree Swifts," make a very curious nest, remarkable specially for its small size, and attached to the side of a thin bough of a tree. Hume describes one of these nests as follows: "The stem to which the nest was attached is about 0.8 inch in diameter; against the side of this the nest is glued, so that the upper margin of the nest is on a level with the upper surface of the branch. The nest itself is half of a rather deep 
saucer 1.75 inches in diameter and about 0.6 in depth internally. The nest is entirely composed of thin flakes of bark, cemented together by the birds' saliva, and is about an eighth of an inch in thickness. The female, in incubating the solitary egg, is said to sit transversely across the thin branch. The nest of the Colies (Coliidæ) require passing notice.

We have already dealt with the nests of the Parrots, the Plantain-eaters and Cuclioos. Some, however, belonging to the latter birds, as well as a few of the Parrots, are sufficiently elaborate to be included in the following chapter devoted to the consideration of domed and roofed nests (conf. p. 212). We now reach that vast assemblage of birds scientifically termed Passeriformes. This, by far the largest order of existing birds, numbering upwards of five thousand five hundred species, contains not only the most highly specialised, but the most widely distributed avine forms. They are found in more or less abundance over all the earth, and are consequently exposed to an infinite variety of conditions, which fact is reflected in their architecture. As we stated when briefly reviewing the reproduction methods of this group in our recently-issued introductory volume to ornithology, ${ }^{1}$ so may we here repeat. The variety in the nests of the Passeres can only be described as amazing, and must be taken as an indication of the high degree of specialisation to which the order has The Story of the Birds, p. 250. 
attained, of their wonderful intelligence and power of adapting themselves to a multitude of conditions and circumstances. The nests in each family are by no means confined to certain types, and the variation in their structure is by no means correlated with affinity. Indeed, it is by no means unusual to find several very distinct types of nest in a single family or even in the same genus, whilst in other cases a certain type of nest will run through more or less distantly related groups. Amongst all these bewildering examples of Passerine architecture we have here to confine ourselves to the open or cup-shaped types, and even the limits of our space will only admit of a brief consideration of the many more pronounced forms. Some few of the nests of the Passeres have already been dealt with in preceding pages, where the peculiar type of nest rendered this necessary, as, for instance, when the nest was placed in burrows, or concealed in some special manner; whilst on the other hand, a very considerable number come within the limits of the two following chapters.

In this review of the open cup-shaped nests of the Passeres, it will still be most convenient to follow the same taxonomic method as we adopted for those of the other orders in the present chapter, dealing in sequence with the typical examples in each family. Commencing, therefore, with the most highly specialised groups, we have first to consider the open nests 
of the Crows and allied birds (Corvidæ). As we have already had occasion to point out, some of the nests of these birds do not come within the present division or "open" type, being concealed in holes or caves. Then, again, that of the Magpies being elaborately "roofed," must be reserved for the following chapter. As a very typical open nest in this family, we may instance that of the Raven (Corvus corax). This bird breeds indiscriminately on trees as well as on rocks, although in our islands incessant persecution has exterminated almost every tree-building Raven, and the very existence of the species as British depends upon its cliff-frequenting habits during the season of reproduction. The nest is placed therefore either in the branches of some large tree, or upon a ledge or in a fissure of the least accessible portion of some cliff, marine or otherwise. Its size depends a good deal upon the length of its tenancy, for the Raven, if left unmolested, returns to the same nest each season, adding to and repairing it just before use. The nest is made externally of sticks, branches of heather and pieces of turf, the soft lining to the somewhat shallow egg cavity being composed of wool, roots, moss, fur and hair. Some of the allied birds are in the habit of cementing many of the sticks together with mud or clay, as, for instance, the Rook (C. fuigelegus), this material sometimes forming an inner lining, upon which the softer substances are afterwards arranged. The Magpies are another instance (conf. p. 215). If 
we include the Australian Magpie Lark (Grallina australis) in the present family, although its affinities are by no means clear, some authorities establishing a separate family (Prionopidæ) for its reception, we have another bird-worker in mud of a still more interesting character. The nest of this curious bird resembles a massive cup-shaped earthenware vessel, being built of mud or clay mixed with grass, bits of stick and stems of plants, and even feathers, these substances being used to strengthen and bind the plastic mud together, much as human builders employ hair to consolidate their plaster. No special effort is made to conceal this nest, which is generally placed very securely on the upper side of some horizontal branch, often one overhanging water. We shall again have to refer to bird architects in mud, not only in the present but in the succeeding chapters. These workers in mud belong to various and distantly related families, and show us, as we have so often remarked before, how the nest-building habit has been developed on almost precisely similar lines, not only by remotely allied species, but in widely separated parts of the world. Some of the Pies (Dendrocitta) make shallow cup-shaped nests of a rather flimsy description, in many cases at no very great height from the ground in bushes. They are made of fine twigs, stems of creepers and weeds, generally with no lining, but occasionally with a scanty one of hair, the fibrous roots of ferns and bamboos, and the 
soft stems of green weeds. The nests of the Jays introduce us to another and somewhat different type of corvine architecture. The true Crows breed principally on the higher forest trees and on rocks, but the Jays form their nests in brushwood, hedgerows, and lower vegetation generally, never resorting to cliffs. They are pre-eminently woodland birds. The nest of the Common Jay (Garrulus glandarius), a species common in many parts of the British Islands, may be taken as fairly typical. A site for this is usually selected in some tall bush or sapling, especially in a holly, yew, or other evergreen, or amongst a clustering mass of woodbine, and other trailing plants. The outer structure is composed of small sticks, the slenderer twigs being used as the nest approaches completion, these being sometimes bound together here and there with mud, whilst the final lining is formed of roots. Although bulky, the nest of the Jay is neatly made, and the cup is deep and well finished. Lastly, we may briefly notice the nests of the Nutcrackers (Nucifraga). These birds are also forest dwellers. The Common Nutcracker (N. caryocatactes) breeds in pine and fir forests, commencing usually before the snow has melted off the ground. It places its nest at a height of from fifteen to thirty feet from the ground, in a fir, spruce, or pine tree, on one of the nearly horizontal branches close to the trunk. It is an open, somewhat flat, structure, composed externally of twigs from the surrounding trees, 
sometimes cemented with mud or clay, and lined with moss, roots, strips of bark, and grass, the latter either in a dry or half-green state. Although the extreme diameter of the nest may be a foot or more, and its total height about half as much, the cup containing the egg is no more than four inches in diameter and two inches in depth. Both Jays and Nutcrackers are solitary during the nesting season, but some of the Crows are very gregarious at that time.

Following the Crows, and somewhat closely allied to them, we have those wonderful avine forms the Birds of Paradise (Paradiseidæ). Unfortunately the nests of very few species are known to science, and possibly when more are discovered there will be a much greater amount of variation in the type of nest than is now suspected. Speaking generally, the nests of the Birds of Paradise are placed in bushes and trees. They are of the open cup-shaped type, formed of sticks and twigs, and lined with dead leaves, moss, fibres and grass. Detailed descriptions of one or two of the more aberrant forms may, however, be given. In $1898 \mathrm{Mr}$ D. Le Souëf described the nest of Gould's Manucode (Manucodia gouldi) from a specimen taken near Cape York in Queensland. He informs us that it is a shallow open structure, made of curly vine tendrils, the inside being lined with similar but finer material; whilst on the branch on which the nest was built, and in conjunction with it, an orchid was growing, a portion of which plant had been worked 
into the outside of the nest. The external diameter of this nest was six inches, internal four inches; external depth three and a half inches, internal one and three quarters inches. It was built on a horizontal fork of a tall scrub tree, amongst forest country, and about twenty yards from dense bush, at a height of nearly fifty feet from the ground. The nests of the equally aberrant Rifle-birds (Craspedophora), inhabiting much the same regions, are also of another type. That of Prince Albert's Riflebird (C. alberti), also from the vicinity of Cape York, has been described by the same naturalist. One of the most remarkable features about this nest is the exceptionally loose way in which the materials are put together. One of the nests was made in a small palm about seven feet from the ground; others were in pandanus trees, or in small trees that had had their tops broken off and a few shoots growing out; others were placed against the stems of small trees where two or three vine branches met; whilst in a solitary instance a nest was found on the top of a stump only eighteen inches from the ground. The nest is little more than a loose heap of material made of green twigs with the leaves still attached, large dead leaves, and the tendrils of vines. The external depth of the nest is about five inches, internal two and three-quarter inches, outside diameter nine inches, internal about half that amount. The singular, we might say almost unique, 
Bower-birds (Ptilonorhynchinæ) are associated by most systematists with the Birds of Paradise. As is generally known, these birds construct more or less elaborate and decorated "bowers" in which to conduct their courtship; but these structures are in no sense " nests," and only indirectly associated with the function of reproduction. The Bower-birds appear to have exhausted most of their architectural skill in the construction of their bowers, for their nests are comparatively crudely fashioned. The love arbours of these birds, so far as is known, are always made upon the ground, but in the matter of nesting they appear to be strictly arboreal species. Three nests of the Great Bower-bird (Chlamydodera muchalis), described by the same authority. above quoted, from North-Western Australia, were built on an "ironwood" tree in the open forest, about fifteen feet from the ground. They were placed near the extremity of a branch, one of them being built in a cluster of mistletoe. They are of the usual open type, slight, and made entirely of twigs, the entire depth of the structures being five inches, the cup two inches, the outside diameter eight inches, and the inside four inches.

Our next family of open nest builders is composed of the Drongos (Dicruridæ). These birds generally place their nests in forking branches, either upright or horizontal, near the summit or outermost parts of trees, attaching them strongly to the supporting twigs either by interlacing the materials with them, 



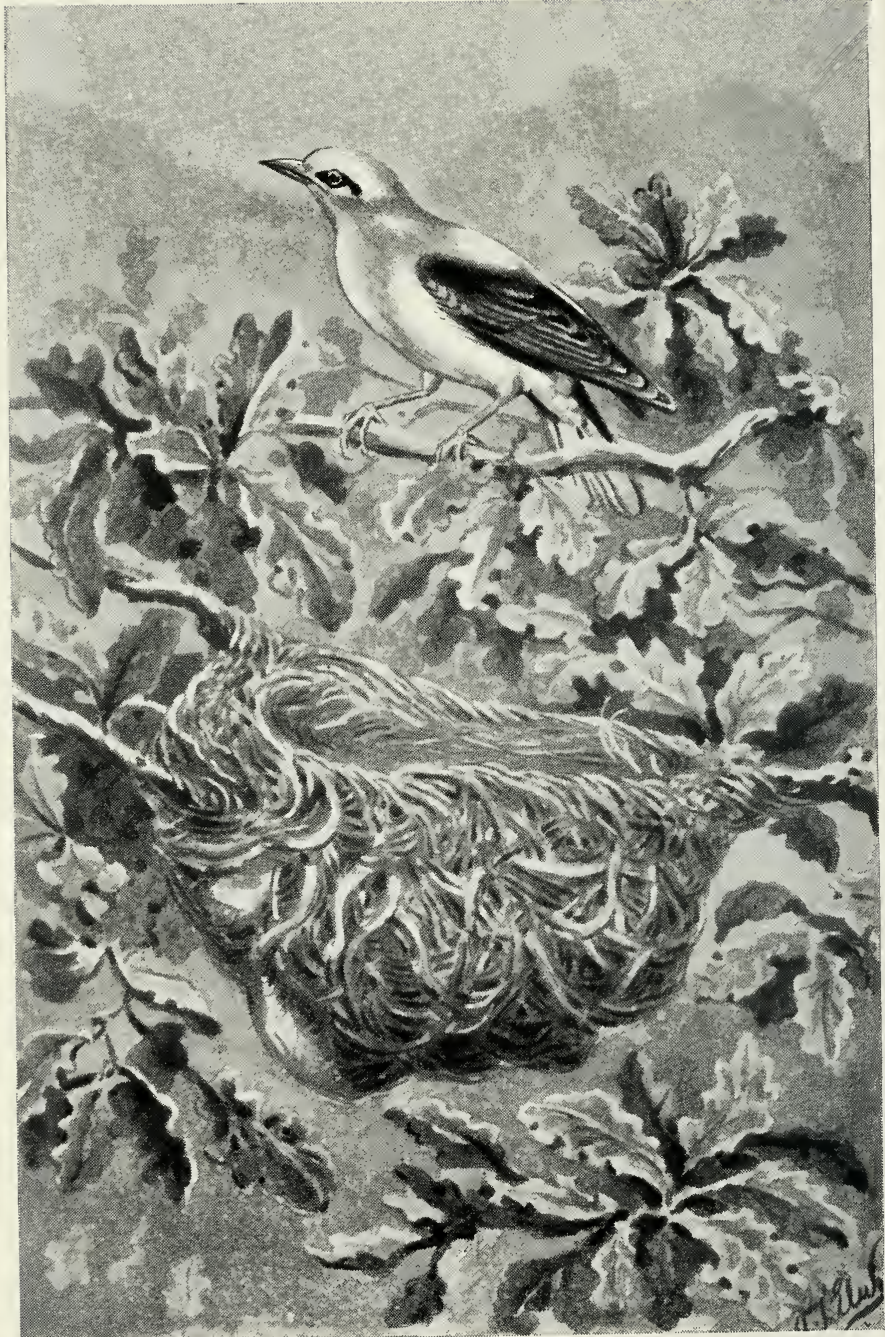


or by the aid of tenacious cobwebs roped round nest and branch. They are rather small cup-shaped structures, four or five inches in external diameter, and composed of slender twigs and coarse grass cemented with spiders' webs and garnished outside with scraps of lichen, moss, bark, and cocoons. Passing on to the Orioles (Oriolidæ) we are introduced to another and somewhat different type of open nest. This is of the usual open form, but is slung hammock or cradle like from some forking branch. The Orioles are skilful weavers and thoroughly felt the materials together, enclosing the supporting twigs near the rim of the nest on either side. The most familiar species to us is the Golden Oriole (Oriolus galbula), which builds a nest that cannot be confused with the abode of any other European bird. This nest is slung from a fork of some horizontal branch (an oak, perhaps, by preference), and is made externally of the leaves of sedge and narrow strips of bark, these being twisted round the twigs in many places, and often intermixed with dry leaves and even bits of paper. The lining chiefly consists of the stalks and flowers of grasses. Of course these materials vary a good deal according to the species that uses them, but the general plan of the nest is very similar throughout the group. We may pass over the birds popularly known as Hang-nests (Icteridæ), for their cradles must be reserved for a future chapter, 
although we ought to mention at least one or two instances of a variation from the usual type of pendulous nest. One of these is made by an aberrant member of the family popularly known in Lower Amazonia as the "Aritana'" (Gymnomystax melanicterus). It is deeply cup-shaped, more resembling that of a Thrush, and is composed of grass leaves (both split and entire), slender roots, and fragments of small climbing plants. For these particulars we are indebted to the researches of Dr Goeldi, first recorded in the Ibis (1897, p. 367). Other members of this family build open nests, such, for instance, as some of the Grackles.

The nests of the Weaver-birds (Ploceidæ) are almost invariably domed or pendulous, so that we are not concerned with them at present, and our next assemblage of open nest-builders will consist of the Tanagers (Tanagridæ). The architecture of these birds is not particularly striking, the nests being as a rule somewhat flat and shallow, and often placed or "saddled" on horizontal boughs, although a domed type occasionally occurs (conf. p. 242). The Tanagers are exclusively confined to America, by far the greater number of species inhabiting the Neotropical region. Their usual nest materials are twigs, roots, fibres, leaves, and moss, but the lining is not particularly soft or plentiful. Passing over the nests of the Sugar-birds (Cærebidæ), which are domed, we arrive at a very extensive family of 
open nest-builders, the Finches and allied species (Fringillidæ). The prevailing type of nest in this family is an open one, but there is a wonderful amount of variety not only in the materials but in the manner in which they are worked. Some of the most beautiful examples of avine architecture are included in the present family of birds; whilst on the other hand not a few must be ranked amongst the most slovenly, untidy, or even crude. It would be absolutely impossible to treat fully and exhaustively with the architecture of these birds in the space at our disposal here; all that we can do is to give a general idea of it so far as it is at present known (details being exceptionally meagre in some cases), and illustrate our generalisations by some of the most prominent and interesting types. The nests of the Finches are, as just stated, open and cup-shaped, but they vary a good deal in depth and amount of materials. The latter principally consist of twigs, straws, dry grass, moss, wool, vegetable downs, hair and feathers; whilst lichens, cobwebs, cocoons, and flakes of bark are often employed as an external garniture for harmonising the structure with its surroundings and thus ensuring concealment. We may dismiss such nests as those of the Sparrows and some of the Buntings, as they are either domed or placed in concealed or covered sites. The usual situations for the nests of the Finches are amongst comparatively low vegetation, 
bushes, small trees, hedges and shrubs; the Buntings are mostly ground builders. Perhaps the most elaborate builders are found amongst the typical Finches, of which our own Chaffinch is a familiar example-the Linnets, Redpoles, and Goldfinches; next in order of finish we may include the Crossbills, and Bullfinches, and Grosbeaks; whilst the least elaborate number amongst them such forms as the Hawfinches and Rose-finches, and more especially the Buntings. The shallowest nests are made by such species as the Hawfinches and Bullfinches, the deepest ones by the Chaffinches, Goldfinches and Redpoles. One of the most beautiful nests in the entire family is made by the Common Chaffinch (Fringilla calebs). This nest is most frequently made in a fork or crotch of some lichen-covered branch, although other situations are often selected. In shape it is a rounded cup, and is variously made of moss, dry grass, fine roots, cobwebs, lichens and wool outside, lined with feathers, hair, vegetable down and wool. The Chaffinch always appears to aim at assimilating her nest with the colour and appearance of surrounding objects, hence the materials employed in one situation would be totally out of place in another. The external part of the structure is therefore subject to the greatest variation. Some nests are made externally almost entirely of green moss; others have this green moss outer wall thickly studded with variously tinted lichen, bits of decayed wood, cocoons, or even 


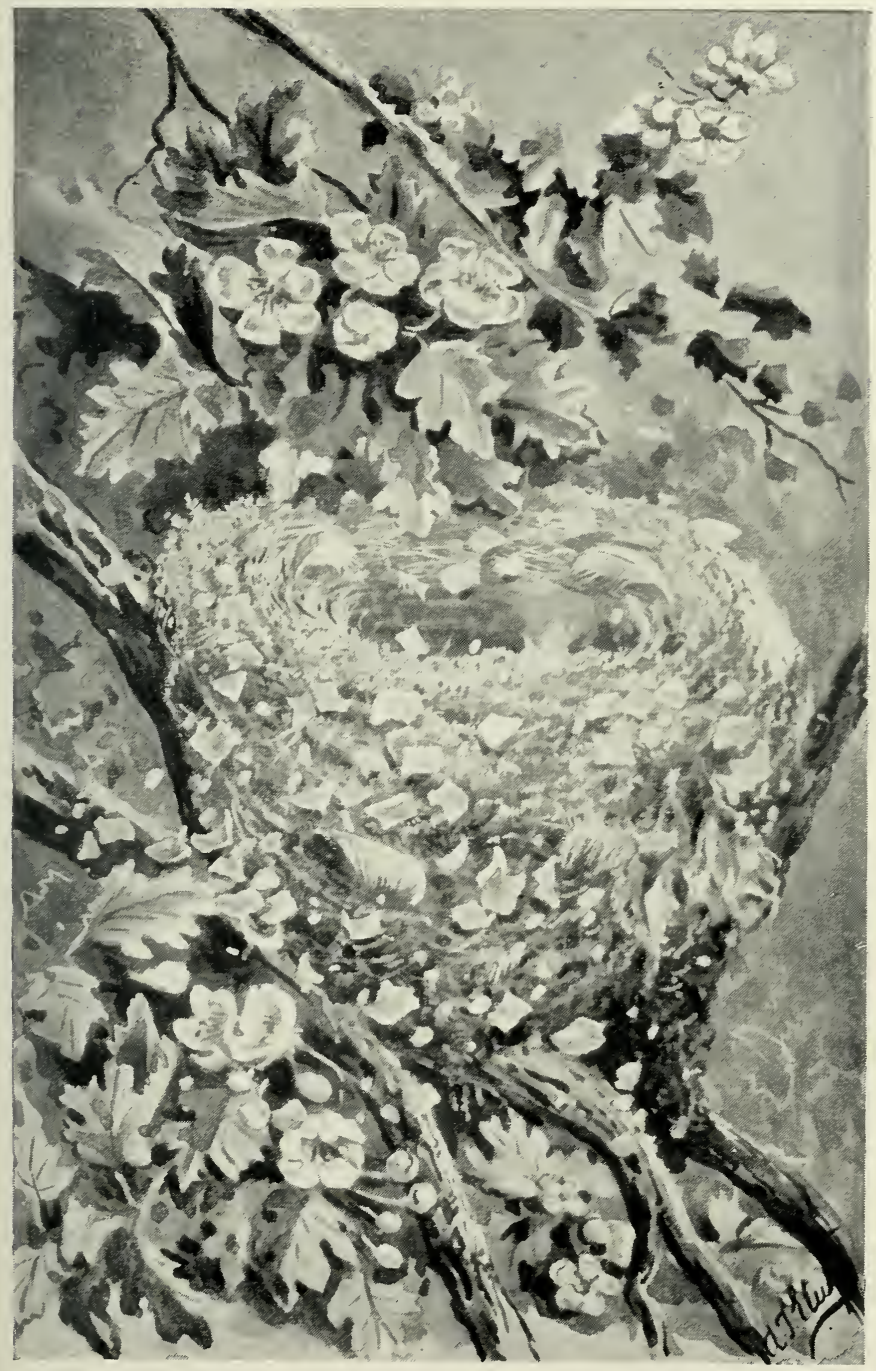

NEST OF THE CHAFFINCH (FRINGILLA CELEBS). 

scraps of paper, all fastened to the moss with spiders' webs. This garniture is often more abundant on one side of the nest than the other, and the whole structure is moulded and felted to the exact shape of the crotch or fork that supports it. The inside cup is remarkably well finished, smooth, and neat, with scarcely a hair protruding above the rest. There are many other birds that seek to conceal their nests by practising the art of mimicry, but none excels the Chaffinch. We might also mention that the female alone is the builder, and that a well-finished nest will often take nearly a fortnight to complete-a wonderful example, truly, of intelligent perseverance. An almost equally exquisite nest is made by the Goldfinch (Fringilla carduelis). This is frequently placed in the fork of a tree, or at the extremity of some drooping branch. It is almost as neat as that of the preceding species, the materials being equally well felted and made of very similar materials, but the garniture of lichens is not so prominent and it is considerably smaller. The Linnets are equally elaborate builders, delighting to place their nest in a gorse bush; but in their case small twigs and stalks are often worked into the margin and foundation, as they also are into the very similar abode of the Twite (Linota flavirostris). The Crossbills (Loxia) also make use of a still greater number of twigs loosely twined together, and forming with grass and roots the outside of the nest, which 
is warmly lined with wool, furs, hairs, and feathers. These birds generally place their nests in firs or some other evergreen tree. Other Finches that employ a good many twigs in the outer portion of their nests are the Bullfinches, Hawfinches, and Grosbealss. The nest of the Common Bullfinch has already been described (conf. p. 62). The Hawfinches (Coccothraustes) construct somewhat flat nests, bulky, and fashioned outside of twigs, dead stallss, and roots, and lined with finer roots, grass, and hair. The Grosbeaks (Pinicola) place their similarly flat nests on some horizontal branch usually near the trunk, of a conifer by preference, and made on a very similar plan-a mat of twigs for foundation, finished off with roots and stems and lined with finer roots, dry grass, and shreds of hair-like lichens. The Rose-finches (Carpodacus) are less elaborate builders, but their nests are somewhat deeper. Twigs are generally absent, the outer nest being composed of coarse grass stalks, the lining of finer grasses and horsehair. The cup, however, is very neatly finished and beautifully rounded. The usual site is a fork in some bush or low tree. The simplest type of Finch nest is made by some of the Buntings, although these nests are not unfrequently bullyy, and in certain species more elaborate. They are variously placed upon the ground, amongst brushwood, in bushes or low trees, and are always cup-shaped, although, as we have already stated, 
sometimes built in covered sites. The usual materials are roots, dry grass, stallis, and moss for the outer part of the structure, finer roots, more slender grasses and hair for the lining.

Our next family consists of the Larlss (Alaudidx). There is nothing specially remarkable to record concerning the nests of the majority of species in this group. The prevailing type of nest is a slight, open, cup-shaped one, but exceptionally we have a domed style of architecture (as in the genus Mirafra), noticed in the following chapter (conf. p. 220). The Larks generally nest upon the ground, placing their cradles amongst herbage, and constructing them of dry grass, roots, stalks and bits of moss, lined with finer grass and roots, and in some cases hair or vegetable down. Very similar remarks apply to the architecture of the Wagtails and Pipits (Motacillidæ), some of the former birds making slightly more elaborate nests; whilst in both sections the nest is exceptionally hidden or concealed under stones in rock crevices domed as in some nests of the Indian Pipit (Anthus rufulus), as we have already described. The Pied Wagtails are uniformly the most elaborate builders, constructing their cup type of nest of dry grass, fine twigs, bent roots and moss, lined with wool, hair, and feathers. The Yellow Wagtails make as a rule slighter nests, and the lining differs a good deal, not only in quantity, but in description of material, even in the same species. The exclusively American family of Wood Warblers 
(Mnioteltidæ) generally make open cup-shaped nests, which they place in trees and bushes, more exceptionally on the ground, and in some cases arched over, as in the Golden-crowned Thrush (Siurus auricapillus), or even completely domed, as in Dendrœca capitalis, the "Yellow Bird" of Barbados. The materials employed are twigs, roots, dry grass, leaves, lichens, and moss, the linings (more or less elaborate) consisting of hair and feathers. Passing over the more or less concealed nests of the Creepers (Certhiidæ) we come to those of the Honey-eaters (Meliphagidæ), where the open cup-shaped type again prevails, although in one or two instances a globular type is said to be made. These birds are confined to the Australian region. Their nests somewhat resemble those of the Orioles in the way they are suspended by the upper rim to forks of branches. Coarse grass, fibres, strips of bark, moss, and spiders' webs are the principal external materials, cotton and other vegetable downs and feathers compose the lining. The nests of some of these Honey-eaters have been very minutely described by Mr D. Le Souëf. That of the Banded Honey-eater (Myzomela pectoralis) was, as usual, suspended between a fork near the extremity of a branch of an ironwood tree, and made externally of a few vine tendrils and strips of bark, bound together by spider's webs, which also serve to attach the nest to the supporting branches. The inside is sparingly lined with fine grass. Owing to the thin lining in the 
nest of this species the eggs can easily be seen through the bottom from below. The nest of the Graceful Honey-eater (Ptilotis gracilis) is generally placed amongst the leaves at the end of a branch of some densely foliaged tree. The tiny cup-shaped nest has the foundation chiefly composed of flat pieces of paper-bark and moss, the upper portion being finished off with green moss and shreds of bark, the whole being covered and bound together with spiders' webs, whilst the inside of the cup is warmly and thickly lined with down from the native cotton plant. The nest of another species in the same genus, the Yellow-spotted Honey-eater ( $P$. notata) is very similar, but is a little more loosely put together, and the exterior is principally composed of shreds of a coarse grass, intermixed with bits of bark, and lightly covered with web; the lining, however, is the same, the glossy white down from cotton pods. The generally domed or porched nests of the Sun-birds (Nectariniidæ), ${ }^{1}$ and those of the Flower-peckers (Dicæidæ), must be reserved for the following chapters, but mention may here be made of the dainty cup-shaped nests of the White-eyes (Zosteropidæ), which are slung hammock-wise to forking twigs at the extremities of branches or placed in upright crotches, and made of similar materials to

${ }^{1}$ The nest of the Indian Æthopyga longirostris, for instance, is cup-shaped and attached to the under side of some leaf by a series of stitches or punctures, the material of the rim being used for threads. 
those employed by the Honey-eaters. The nest of Dicæum minimum (a widely distributed bird in Ceylon) is described by Mr F. Lewis as being cup-shaped and built in the angle of two forking twigs. The nests of the typical Titmice (Paridæ) have mostly been dealt with already (conf. p. 121), but those of some of the more specialised forms (Acredula, Egithalus) must be reserved for later chapters (conf. pp. 225, 255). The nests of the delicate little Goldcrests (Regulinæ) must, however, be described here. These nests also belong to the Oriole and White-eye class, being slung like hammocks or purses between forking twigs at the extremities of branches, usually of some nondeciduous tree. That of our own Goldcrest (Regulus cristatus) is chiefly composed of moss and lichens; these and the surrounding foliage being deftly interwoven with the aid of spiders' webs and hairs, and lined with hair and feathers. The nest of another and perhaps still more aberrant member of the Paridæ must also be noticed. This is the home of the single known species of Bearded Titmouse (Panurus biarmicus). The Bearded Tit is an inhabitant of reed beds, and builds its nest amongst the vegetation of its marshy home, selecting as a site some tuft of sedge or aquatic herbage where the overhanging stems offer it concealment. This nest is made of dry marsh grass, bits of reed, dead leaves and other scraps of vegetation, lined with finer grass and the flowers of reeds and rushes. Although loosely woven, it is neatly finished. 
Our next group of open nest-builders contains the Shrikes (Laniidr). The nests of these birds are placed in trees and bushes, and are of the normal cup-shaped type, loosely but skilfully constructed of twigs, roots, grass stems, and the flower stalks of various plants, often with the flowers attached, and lined with soft materials, such as moss, wool, hair, and feathers. From the Shrikes we pass on to the Waxwings (Ampelidæ), in which the same open type of nest prevails. The most familiar species to British ornithologists is the Bohemian Waxwing (Ampelis garrulus), although it does not breed within our limits, only visiting them as an abnormal migrant at irregular intervals. This species breeds in open, scattered colonies in the northern fir and spruce forests, being very erratic in its choice of a nesting place, seldom resorting to the same locality for two seasons in succession. The bullyy and rather deep nest, built from eight to twelve feet from the ground on some convenient branch, is composed externally of twigs and reindeer moss, and lined with dry grass, hair-like tree lichens, strips of inner birch bark, and feathers. The nest cavity is about two inches in depth and four inches in diameter. Our next family of open cup-shaped nest-builders contains the Vireos or Greenlets (Vireonidæ), another strictly American group. Here, again, we have the hammock-like type of nest, very similar to that made by the Orioles and White-eyes, being placed in the forking twigs at the 
extremities of branches. These nests are remarkably well-woven, the rim on either side enclosing the supporting twigs, and are formed of a variety of fibrous and soft material, the interior especially being very neatly finished. Some of the species stucco the sides of their exquisite little homes with lichens, as, for instance, the Yellow-throated Greenlet (Vireo flavifrons).

We now arrive at the very extensive family in which is contained the Thrushes and Warblers (Turdidæ). The nests of many of the species included in this group have already been described, such as those of the Rock Thrushes, the Redstarts, and the Chats; some others, especially in the Warbler section, must be reserved for the following chapter. The remaining number of "open" nests is, however, not only very considerable, but includes numerous well-defined types. The nests of the Thrushes (Turdinæ), with the above mentioned exceptions, are certainly the most uniform in type-a well-made, fairly bulky structure, which may be placed either on the ground or in bushes, trees, and other vegetation, at a moderate height above it. A description of one or two of the most divergent nests must suffice for the present purpose. As a nest thoroughly representative of the Thrushes, we may take that of the Blackbird (Merula vulgaris). This nest, placed in a variety of situations, but usually in the centre of a bush or on a bank, passes through three distinct 
stages (as in fact do those of the majority of Thrushes and Ouzels) before it is completed, as we pointed out twenty years ago. ${ }^{1}$ The first stage consists of a structure formed of coarse grass, amongst which a few twigs are sometimes woven round the rim or sides, a little moss, and dead leaves. The second stage sees this loose cup firmly cemented together inside with a thick plaster of mud or clay. The third or final stage brings the nest to completion by a thick lining of finer grasses arranged very neatly and smoothly. A divergence from this type is presented in the nest of the Song Thrush (Turdus musicus), which, however, may fairly be said to pass through the triple stages. The first two are very similar to those which the nests of the majority of Thrushes undergo, but after the mud lining is inserted a second lining is formed, this time composed of wet rotten wood, which is very skilfully manipulated, so that when dry it is almost as smooth as an earthenware vessel. Then some of the species in the present sub-family build more or less concealed nests on the ground-a type of architecture which we have already illustrated by the nests of the Robin, the Nightingale, and so forth. There are, however, certain other genera in which the birds more or less habitually nest upon the open ground amongst herbage. The Whinchat (Pratincola rubetra) is one of the most familiar examples. This bird very often

${ }^{1}$ A History of British Birds, i. p. $24 \mathrm{I}$. 
builds its nest in a slight hollow in the ground amongst the long meadow grass, making it externally of dry grass and moss, and lining it with fine roots and hairs.

The "open" nests of the Warblers (Sylviinæ) present a far greater amount of variety, and range from the slight net-like cradles of such species as the Whitethroat and Blackicap to the compact and bulky structures fabricated by such forms as the Marsh Warblers, and so on. To a very great extent these types of nest are peculiar to the various genera. Confining ourselves for the present to the open cupshaped type of nest, we may briefly sketch this divergence and illustrate it by a few examples taken from the more familiar species. Beginning with the least elaborate, we have the nests of the birds comprising the genus Sylvia. Of these the Blackcap ( $S$. (tricapilla) makes a flimsy, loosely-woven nest composed chiefly of dry grass stalks, with a scrap or two of moss, a few leaf-stallss and roots, sparingly lined with horsehair. It is so frail and net-like in composition that the eggs can often be seen through the material. Some of the other species in this genus, however, make more elaborate homes, as, for instance, the Orphean Warbler (S. orphea), which adds a lining of vegetable down to its cradle. Then we have the nests of the birds associated in the genus Locustella. Of these the Grasshopper Warbler (L. navia) makes a somewhat compact and deep nest of dry grass, 
moss, and dead leaves, lined with finer grass stalks, and placed on or near the ground amongst brambles or rank vegetation. Another species, Savi's Warbler (L. luscinioides), constructs a cup-shaped nest made of flat ribbon-like leaves of sedges, the narrowest ones being reserved for the lining, and placing it among the aquatic vegetation of its haunts. The Reed Warblers (Acrocephalus) introduce us to another type of architecture, many of these species suspending their open nests from the stems of reeds, often such that are growing in water. The bird selects three or four stems suitably situated for the purpose, and round them weaves a deep well-made nest formed of dry grass, roots, and the flat leaves of reeds, lined with finer root-fibres, hair, and occasionally a few feathers, a little moss or bits of wool and vegetable down. One of these birds is a fairly common if local visitor to England and Wales, the Reed Warbler ( $A$. arundinaceus). ${ }^{1}$ Then we may instance the Icterine or Tree Warblers (Hypolais). These birds build very beautiful little nests, placing them in forling branches of low trees. That of the Icterine Warbler (H.icterina), for instance, is almost as elaborately made as that of the Chaffinch, but somewhat smaller and a trifle deeper. Externally, it is made of dry grass and moss, interwoven with strips of bark and felted together with

${ }^{1}$ The Grass Warblers Prinia (an aberrant group) build cup-shaped nests slung between the stems of reeds near water, made of grasses, flowering aquatic weeds, and lined with finer grasses. 
spiders' webs, wool, and vegetable down, the walls more or less garnished with lichens; internally it is finished off with fine roots, grass stems, and horsehair. Lastly, we have the Rufous Warblers (Aëdon). These birds construct rather bulky nests made of dead twigs, roots, straws, coarse grass, and bits of lichen, and line them well with wool, vegetable down, feathers, or hair. It is a somewhat remarkable fact that the lining almost invariably includes a piece of the dry skin of a serpent, which the Arabs assert acts as a charm in protecting the eggs from snakes!

The nests of the Dippers (Cinclidæ) are invariably domed; as are also the majority of those of the Wrens (Troglodytidx), and these must therefore be reserved for a future chapter. Some few of the latter birds, however, construct open nests. Then we come to the American family Mimidæ, of which the well-known Cat-bird (Mimus carolinensis) is a representative species, or the still more celebrated Mocking-bird (M. polyglottus). The methods of nidification in this family very closely resemble those of the typical Thrushes, to which birds the Mimidx must be closely related. The Cat-bird builds a large, clumsy nest at no great height from the ground (three to ten feet, perhaps, on an average) on the branch of a cedar, or some other tree. It is made of dry grass, the stems of plants and twigs, and lined with fine roots. One of its most striking peculiarities is the way in which it is often decorated outside with bits of rag and paper and 
macerated leaves. The Mocking-bird places its nest in very similar situations in bushes or small trees, and constructs it of almost precisely the same materialsgrass, twigs, dead leaves and a lining of roots. This species also decorates its nest with wool and similar things. The architecture of the next family of birds (Timeliidæ) is of a most varied character, partly because it is one of the most heterogeneous groups in the entire avine class-a receptacle, " or refuge for the destitute," as Seebohm used to say, into which almost every Passere of doubtful affinities has been cast by bewildered. systematists. This family still requires revision, when more natural limits may be set to its boundaries. Almost every type of nest may, in the existing order of things be found within it; but as the species are principally tropical, domed or otherwise concealed structures are dominant. In the present chapter, all that we need concern ourselves with is the open type. One of the most remarkable of these is adopted by many of the famous Tailor-birds (Orthotomus), a group which is rightly or wrongly associated with the Timelines by one of the most recent cataloguers of the group. The taxonomic position of the Tailor-birds, however, we have fortunately nothing to do with here; all that need concern us are their wonderful nests. A description of that made by the well-known Indian Tailorbird (Orthotomus longicaudas), will amply suffice for the present purpose. The extraordinary intelligence 
of the bird appeals to us more strongly than anything in the nest itself. In the first place, the Tailor-bird selects some broad leaf, or frequently two leaves, usually at the end of some slender branch, and with its long, slender, awl-like bill it pierces a series of holes irregularly along the margins. Then, with a thread which it either weaves for itself out of cotton or similar fibres, or obtains in other cases ready made, it commences to sew or draw the leaves together, being careful, after passing it through the leaf, to make a knot at the end of it. Through and through the holes the feathered tailor draws its thread, until the leaf or leaves are formed into a hollow, coneshaped receptacle or pocket, in which the actual nest is placed. This latter is cup-shaped, and principally composed of cotton, wool, or similarly soft materials. Tailor-birds, I should mention, are not the only species that ply needle and thread in their nestmaking for almost, if not quite, equal "tailors," or perhaps we might more properly say, "sempstresses," are found in the Sylviinæ genus Cisticola (conf. p. 229) and amongst some of the Sun-birds, as for instance, species in the genus Æthopyga (conf. p. 185).

Among the other characteristic builders of the open type of nest in the present family may be mentioned the Laughing Thrushes of the Oriental region contained in several genera, such as Garrulax and Trochalopterum. That of Trochalopterum virgatum, for instance, is placed in very similar situations to those 
selected by our own Blackbird, such as near the ground amongst weeds and brushwood, or some distance above it in the fork of a bush or low tree. It is cup-shaped, deep and well made of a great variety of materials, such as grasses, dead leaves, roots, moss, the tendrils from certain creeping plants, fibres, and sometimes bamboo leaves and fern fronds, roots and fern stems forming the lining. In some nests bamboo leaves are omitted, but tendrils appear to be a special feature of all. The inside cup measures, on an average, about four inches in diameter by three inches in depth. The nest of Garrulax gularis, another of these Indian Laughing Thrushes, is made of almost exactly the same materials, tendrils again being a speciality, and in some cases forming the bulk of the materials, even the lining being partly formed of the finest ones. The favourite sites are within a few feet from the ground, amongst thickets of bramble and fern, some distance within the dense jungle or forest. Then we may mention the nest of Stactocichla merulina. This bird breeds in mountain forests of evergreen trees and in bamboo jungles, placing its nest in some thick shrub or clump of bamboo. The nest is somewhat bulky, although the cup is rather shallow. Two classes of materials are employed, according to the site chosen. Thus, when in bushes the outside is formed of roots, grass, bamboo and other leaves, intermixed with moss and bracken, the interior being lined with delicate roots of ferns and moss, the finest 
stems and tendrils of creepers or twigs. When placed among bamboo the leaves of that plant form the chief external material, bound together by stems of plants and roots. This is lined first with coarse roots of ferns and fibrous roots of bamboo, well interlaced, whilst the final lining consists of fern and moss roots of the finest character. Some of the nests in the present family, although cup-shaped, approach the domed type, one side being much prolonged and slightly overhanging the egg cavity, as for instance, that of Corythocichla striata. In other Indian genera of Stachyrhis and Stachyrhidopsis we have species that build no fewer than three types of nest, ranging from an open cup to a completely domed structure, although we should say that the first type is placed under shelter of some kind, such as a mass of plants and roots, and more naturally comes into the division treated in the previous chapter. I mention the instance to impress still further upon the student the wonderful adaptability displayed by birds in almost every great natural group.

The Bulbuls (Pycnonotidæ) comprise the next family, of which the nests require notice here. These are open structures, made of a great variety of materials and placed in bushes, low trees, and more exceptionally amongst creepers. The nest of the Striated Green Bulbul (Alcurus striatus) is composed externally of twigs and fern roots compactly interlaced, lined in the first place with more twigs and roots and stems of 
weeds, these materials being wound loosely round and round and not interlaced, and finally finished off with a bed of very fine grass laid in a similar way. In some nests fronds of fern moss are used. They are shallow, the egg cavity measuring little more than an inch in depth. The nest of the Finch-billed Bulbul (Spizixus canifrons) is a specially remarkable one, for the bird is said to use scarcely any other material in its construction but the tendrils of various climbing plants. According to $\mathrm{Mr}$ Stewart Baker, to whom I am much indebted for many particulars concerning the nests of these and other Indian species, as recorded by him in the Ibis, almost any kind of tendril sufficiently pliable is used for the outer part of the nest, but for the inner part the bird prefers the fine but strong tendrils of the small yellow ground-convolvulus. As a rule no real lining is inserted, but in some nests a scrap or two of bracken, or even more rarely a few bents or grass stems. The nest is usually built in stunted bushes and saplings, wedged in between several upright twigs, less frequently in a stout fork. Blyth's Bulbul (Xanthixus flavescens) makes a rather neat and compact but shallow nest of twigs, stems of weeds, roots of ferns, dark-coloured tendrils and less frequently dead leaves and fern stems, lined with grasses, especially the flowering ends from which the seeds have been stripped. This nest is built in dense bushes, in a cluster of twigs or thick forks, from three to five feet from the 
ground. The Bulbuls in the genus Iole are remarkable for the fact that they build their nests in horizontal forlks, after the manner of the Orioles. The Olive Bulbul (Iole virescens) slings its somewhat bulky compact yet shallow nest from a fork of twigs, inclosing the latter in the material, and at a distance of nearly five feet from the ground. The principal external material consists of long strips of inner bark, with a few scraps of outer bark, and a large number of very fine and elastic twigs. The outside of the nest is also studded with small dead leaves, fastened to the other materials with spiders' webs, the latter not only serving to bind all together, but to attach the nest to its supporting twigs. The lining consists of black fern-roots, long fibres of a reddish colour, and the tendrils of some creeping plant. In some nests the latter material predominates in the lining; in others the black fern-roots occupy the greater part. It is interesting to remark the change in materials with the change of method of attaching the nest, the Bulbuls adopting cobwebs for the purpose just as so many other remotely allied birds have been found to do.

Our next assemblage of open nest-builders consists of the Cuckoo Shrikes (Campephagidæ). These birds construct cup-shaped nests (many of them very padlike and shallow) in bushes and trees, often placing them at the extremity of a branch forty feet from the ground. As fairly representative the nests of the fol- 
lowing species may be mentioned-Graucalus macii, Campophaga sylkesi, and Pericrocotus cinereus. Considerable diversity characterises the architecture of the Fly-catchers (Muscicapidx), an exclusively Old World group where they are most abundantly distributed in the tropics. As we have already seen, some of these birds nest in holes, some others construct domed nests, therefore do not require consideration here. Of the three hundred or more species, however, a considerable number make open nests, a description of a few of which we will now proceed to give. Two of the most familiar of these belong to European species, one of which is a common summer visitor to the British Islands. This is the Spotted Flycatcher (Muscicapa grisola). The cup-shaped nest of this bird is placed in a great variety of situations, one of the most familiar being in a shallow knot-hole close to a tree trunk. The small and loosely fabricated nest is made of dry grass and moss, cemented or bound together with spiders' webs and garnished with wing cases and sometimes lichen, and lined with roots, hair, and feathers, one of these materials often being exclusively employed. The second species is the Redbreasted Flycatcher (M. parva), a bird that breeds no nearer to our area than Germany. It builds its beautiful little cup-shaped nest in a very similar situation to that of the preceding species, forming it externally of moss garnished with a few bits of lichen or one or two small feathers, and lining it 
with dry grass and hair. Some of the nests of the tropical species are extremely pretty little structures. The favourite breeding places of these birds in the tropics are amongst the dense masses of forest drift that accumulate in the clumps of bamboo, or in the drooping branches of low trees, or in the tufts of moss and the various vines or creepers that hang from the trees. Of the nest of an Australian species, the Frillnecked Flycatcher (Arses candidor), Mr D. Le Souëf writes as follows: "Their beautiful open nest has the appearance of a hanging basket, and is fastened between two upright hanging vines by cobwebs. The interior is composed of fine dark-coloured rootlets, and the exterior of small light-coloured twigs, rather loosely put together, and ornamented on the outside with green lichen, the whole being lightly covered with cobweb." This nest swung in the vines about thirty feet from the ground. Another and much more open and flat type of nest is made also by an Australian species, the Yellow-breasted Flycatcher (Macharirhynchus flaviventer). A nest of this bird built in the fork of a slender projecting branch about fourteen feet from the ground is a shallow structure composed externally of twigs bound together in places by cobwebs, the latter also being used to secure the nest to the supporting branches, and lined exclusively with curly vine tendrils. The depth of the egg cavity in this nest is only half an inch, and the complete diameter of the entire structure 
but three and a quarter inches. Yet another Australian species, the Broad-billed Flycatcher (Myiagra latirostris), makes an open nest often in a mangrove tree overhanging a deep stream. In some genera the architecture is remarkably uniform. Thus the Fan-tailed Flycatchers (Rhipidura) are distributed over the Oriental and Australian regions in a large number of species. The nests are delicate little cups, saddled on to horizontal branches (often dead boughs in very exposed situations). The external materials, which are closely interwoven or felted, and bound together with spiders' webs, the latter in some cases covering the outside of the nest, consist of various fibres and dead grass leaves, the lining of finer grasses and fibres. Then in the genera Zeocephus and Hypothymis we have cup-shaped nests of moss felted together with spiders' webs, and lined with fibres of different fine kinds, and placed in forking branches in the lower growths of vegetation in forests. In Mluscicapula the nest is sometimes very slight, composed of roots, and lined with broad leaves. In Terpsiphone the nest is often delicately fashioned of moss lined with hair, and placed in some low fork of a small tree in the densest parts of the tropical forests.

Many of the nests of the Swallows (Hirundinidx) are shallow, open, and saucer-shaped, composed of mud, straws, and lined with grass, feathers, and so forth, but as they are invariably more or less concealed in covered sites, it will not be necessary to 
describe them in the present chapter. We therefore pass on to the Tyrant Birds (Tyrannidx), another family of birds strictly confined to the New World, many members of which construct the open type of nest, either placed amongst vertical growing twigs and branches, or slung hammock-wise from some horizontal or drooping forking limb. The chief materials employed by these birds are twigs, fibres, grass, moss, wool, hair, and lichens, cob-webs being used for binding purposes. As this family contains some four hundred species, distributed over nearly the whole of America, and especially abundant in the tropics, a vast amount of variation in the architecture is presented, in order to bring the nest into harmony with an equally extensive diversity of conditions. It would therefore be impossible with the space at our disposal here even to describe the salient characteristics of such a large assemblage of nests. Our next family, also confined to the Neotropical region, contains the Chatterers (Cotingidx), in which there are several very distinct types of architecture. Some of these have already been described, as, for instance, that of Rupicola (conf. p. 103); others come into the class of domed nests dealt with in a future chapter, whilst others yet again are open and cup-shaped, and must be included in our present division. These latter are placed in the forks of trees, and formed of moss and lichens. Passing over the Pittas with their domed globular nests, we reach yet another great 
family of South American birds, the Wood-hewers (Dendrocolaptidx). In no other family do we find a greater diversity of architecture, the most striking examples, however, belonging to such types that will require consideration elsewhere. The nests, however, of the Ant Thrushes (Formicariidæ) are generally of an open type. This group is also peculiar to the same region. They place their nests in trees and bushes. These nests are shallow saucer rather than cupshaped in form, and composed of grasses, fibres, moss, roots, wool, and hair. Lastly, we may allude to the family of Wren-like birds (Pteroptochidæ), chiefly confined to the temperate regions of South America, in which the architecture presents not a little diversity, although the group is such a small one, numbering no more than about a score of species. Some of these birds nest in burrows, others make domed nests of grass, whilst certain species construct an open nest composed chiefly of sticks.

The length of the present chapter bears significant testimony to the prevalence of the open or cup-shaped style of architecture amongst birds. If the number and variety of species building these open nests can be taken as any indication, we are, I think, fairly justified in coming to the conclusion that such a type is the most natural style of architecture in the entire avine class; and also that all divergence from that specially normal type has been caused by a vast variety of exceptional circumstances and conditions 
under which the reproduction of the affected species is conducted, the most important of which is most probably the concealment of showy or conspicuous plumage, the elusion of certain enemies, and adaptation to certain climates. Unfortunately in a vast number of instances, especially amongst the tropical species (notably those in South America), the habits of these open nest-building species are nearly if not quite unknown, as are likewise the nests themselves of not a few, so that we are as yet quite unable to comprehend the philosophy of their nidification-the relation between the open nest and the conditions of existence of its feathered architect. In a great many cases (in fact we may safely say in the majority) these open nests belong to the largest and most powerful of avine forms - to species that require no special protection, well able to defend their nests from ordinary enemies, or that derive their safety by building in societies, or in very inaccessible situations, such as in marshes or deep trackless forests; or yet again (more especially in tropical countries) by placing their homes in isolated trees or groves, which predatory creatures are not likely to visit under ordinary circumstances. Then, on the other hand, many of these open nest-builders, especially the weaker, smaller, and least aggressive species, take great pains to conceal them in a variety of ways, one of the most remarkable being that of mimicry, or assimilating the outer materials with surrounding objects. I have pointed 
out a great many of these instances, one of the most interesting and illustrative being the nest of the Common Chaffinch. Other instances may be found in such species as the Minivets (Campephagidæ), the nest of one of these birds found in China (the Pericrocotus griseigularis of Gould) being a small cup made of a certain filiform lichen, a few pine needles, and a flat lichen with finely scalloped edges, redidish brown underneath, with hairy black roots. The nest is completely plastered outside, and partly inside with this latter material, only a bit or two of moss being added, and has in consequence a peculiar black and green appearance. The whole is cemented together with cob-webs, and placed on the branch of a pine tree, where it is in perfect harmony with surrounding objects. Then we might mention as an instance the nest of Tharrhaleus jerdoni, a species breeding in Kashmir. A nest of this bird placed on a pollard birch tree about eight feet from the ground was made of moss, birch bark, reed stalks, and lined with hair and a few feathers. Its external mosaic of bits of birch bark, with which it was completely covered, made it exactly resemble the adjoining bough, and rendered it "very difficult to discover" (Ibis, 1898, p. 27). The nests of the Humming-birds supply us with many more interesting examples, as we have already noted. One of the most remarkable of these is furnished by the nest of a Humming-bird (Orthorhynchus cristatus) called in Barbados the " Doctor Bird." Col. 
Feilden discovered a nest of this species fastened to the edge of a leaf of a prickly pear, and was so completely deceived by its general resemblance to the fruit growing on the same bush that he could scarcely believe it was not a "pear," his attention being attracted in the first instance by seeing a female crouching apparently upon the top of one. Various other instances belonging to different families remain to be described in future pages. Another equally significant fact in the philosophy of these open nests is that the majority of them are made by species in which the female (or both male and female) are dull in colour, whilst the eggs are generally spotted, very exceptionally white and devoid of markings. In such cases where the eggs are of pale and conspicuous tints, we find that the female is protectively coloured as she broods over them, or when left unguarded in the nest during her absence, she carefully covers them with bits of vegetation or down until she returns. 
CHAPTER VI

DOMED AND ROOFED NESTS 



\section{DOMED AND ROOFED NESTS}

Nest of the Hammer-head-Domed Nests of the Rails-Of certain SwiftsOf various Parrots-Of the Lark-heeled Cuckoos-Nests of the Broad-billsOf the Lyre Birds-Domed type a dominant one in the Order Passeriformes-Of the Magpies-Of certain Starlings-Of the Meadow Starling-Of the Weaverbirds-Domed nests of certain Tanagers-Of the Sugar Birds-Of certain Sparrows-Other domed-building Finches-Of the Bush Larks-Of certain American Wood Warblers-Of the Sun Birds-Nests of the Sun Birds resembling those of the Social Spiders-Nests of the Flower-peckers-Of certain TitmiceOf the American Bush Tits-Of the Hill Tits-Of the Rock Nuthatches-Of the "Palm Sparrow "-Of the Willow Warblers-Of the Fantail Warblers-Of the Dippers-Of Origma rubricata-Of the Wrens-Of the Timeliïææ-Of various Pomatorhini-Of various species of Pellorneum-Triple types of nestNests of certain Flycatchers-Of various Swallows-Of certain Tyrant BirdsOf certain Chatterers-Of the Pittas-Of various Wood Hewers-Of the Oven Bird-Of certain species of Pteroptochidæ-General Remarks.

In the present chapter we are introduced to a much more complicated style of architecture than any that we have hitherto had to consider. Not that this domed-roofed type of nest is any indication of greater intelligence; it can only be regarded as another of the many methods that birds adopt for safety, a mere divergence or variation in the one grand utilitarian plan of avine architecture. In our review of these domed and roofed nests we shall again find it most convenient to confine ourselves to a taxonomic arrangement.

It is a somewhat remarkable fact that we have no instance of a web-footed bird building a domed or 
roofed nest, and it is not until we reach the order Pelargiformes, containing the Herons, Storks, and so forth, that an example of such a type of architecture occurs. Even then this is the work of a species that can only be regarded as a most aberrant member of the order. This bird is the curious Hammer-head (Scopus umbretta), an inhabitant of most parts of Africa south of the Sahara. Although but the size of a Raven, it makes an enormous nest six feet in diameter, which may either be placed on a ledge of rock or in the branches of a tree. In form it is dome-shaped or roofed, and is made principally of sticks, although dry grass and reeds form a minor portion of the materials. The entrance hole is at the side, the most concealed side being selected. This nest is said to contain no less than three chambers, each with an entrance so small that the owner can only enter with difficulty. The innermost chamber is said to be reserved for the eggs and purposes of nidification; the central one is a kind of playing place for the young birds when sufficiently matured; whilst the front one is used as a look-out station by the parent birds. It should be stated, however, that the Messrs Woodward, in describing a nest of this species found on a ledge of a cliff overhanging a river in Zululand, do not make any allusion to these three internal apartments, but merely remark that the only way to get at the four white eggs it contained was to remove the roof. Domed and roofed nests are found in no 
other group or order of aquatic birds with the one solitary exception of the Rails (Ralliformes). In this order, as we have already seen, the normal type of nest is an open one, but in a few exceptional cases a domed nest is made. One of these domed nest-building Rails is the Porzana cinereiceps, of Lawrence, an American species. Mr Charles Richmond met with this bird breeding commonly in the plantations on the Escondido river, in Central America, and states that the nest is placed in grass about a foot from the ground. He describes the nest as almost globular in shape with a small entrance in the side, and made of dry grass, lined with a broad-leaved grass.

There are a few builders of domed or roofed nests amongst the Coraciiformes. These belong to the family of Swifts (Cypselidæ). We have already had occasion to describe certain nests of these birds in our chapter on the covered or concealed type. The majority of these birds appear to conceal their nests in rocks, caves, hollow trees or buildings, still there are certain forms associated under the generic term Panyptila, which construct tubular or purse-shaped structures. A species inhabiting Guatemala is said to form a tubular nest of seeds, each one stuck together with the parents' saliva, which latter is also employed to attach the structure to a rock. Another of these birds, the Cayenne Swift ( $P$. cayanensis), is said to build a long purse-like nest. Singularly enough we have the domed type of nest occasionally 
occurring in the Parrots (Psittaciformes), and also as exceptionally, or even still more so, in the Cucloos (Cuculiformes). There are certain Parrots which are said to build globular nests, placing them amongst tall grass. So far as is known, the only domed nestbuilders amongst the Cuckoos are the Lark-heeled Cuckoos belonging to the genus Centropus. These birds frequent well-wooded districts in the Old World tropics, and usually place their nests in some thornbearing bush or tree, but in other cases select a site amongst herbage on the ground. The nest of Burchell's Larked-heeled Cucloo (Centropus burchelli), according to observations furnished to $\mathrm{Mr}$ Guy Marshall, by Mr Darling, who met with this species breeding in Mashonaland, is placed in a low thorn bush about six feet from the ground, and made of dry grass. It is rather roughly constructed, domed in shape, with a large entrance hole at the side pointing away from the prevailing winds. Of the Black-breasted Larked-heeled Cuckoo (C. nigrorufus), Mr Darling states that he took a nest in the long thick grass in a vlei, so cunningly concealed, that had not the parent bird flown out he would never have discovered it. This nest was "woven out of the living grass, so that it kept green all the time, and when I stood only a couple of yards away it was impossible to discern the nest. This was situated about two feet from the ground, domed, and with a small aperture at the side, the grass being very finely and carefully 
woven in small plaits or wisps and not in single blades, and the tops protruding freely for some distance above the nest" (Ibis, 1900, p. 253). Another species, the well-known Indian "Crow Pheasant" (C. rufipennis), makes a nest like an enormous ball of twigs and grass, lined with grass and leaves with an entrance at the side. The purse-shaped nests of the Broad-bills (Eurylæmi), a small order of tropical species ranging over India, Burma, Malaya, and Java, are usually suspended from the points of tapering branches, especially from bamboos. Here may be mentioned another aberrant group, the Lyre-birds, raised to the dignity of an order (Menuræ) by some systematists, yet only allowed family rank (Menuridæ) by others. So far as is known, the domed type of nest prevails in this group. This nest of Menura superba is built near to or on the ground, at the base of a rock or tree, and is made of closely woven fibres and roots, and lined with feathers. This central nest appears to be surrounded by a mass of sticks, grass, moss, and leaves, an opening in the side affording means of entrance and exit. The nest of another species, Menura alberti, is made on a similar plan, but the materials are almost entirely composed of long twigs and thin sticks.

The domed and roofed type of nest is a very dominant one in the architecture of the Passeriformes. Indeed, with the few exceptions which we have just noticed, this domed or roofed procreant 
cradle is practically a peculiar feature of the order. It is, however, by no means confined to any group or section of the Passeres, but has been adopted by an immense variety of forms, probably from similar motives. Neither can it, in many cases, be regarded as typical, for it is found to occur in a most irregular manner, even in genera where another type of architecture is the prevailing feature. We shall also find that in shape and materials these domed and roofed homes present a very great amount of diversity, as they also do in the situations they are made to occupy.

Beginning with the Crows (Corvidæ), as we did in our review of the open nest type of the Passeres, we find that the Magpies (Pica) are the only species that construct a domed, or rather in their case, a "roofed" nest. The nest of the Common Magpie $(P$. caudata $)$ may be taken as the most familiar example. This handsome bird is still a common and widely distributed one in the British Islands, and its bulky nest is one of the most familiar bird homes in the woodland districts. Some of these nests become quite historic, being tenanted year by year, added to or repaired each season, and reaching a very large size as each season's work accumulates. The nest of the Magpie may be found in almost every kind of forest tree, whilst tall thorn bushes, hedges, and isolated trees in the fields or open are frequently selected. The height at which it is placed is equally variable; it may be built in the tops of the loftiest 


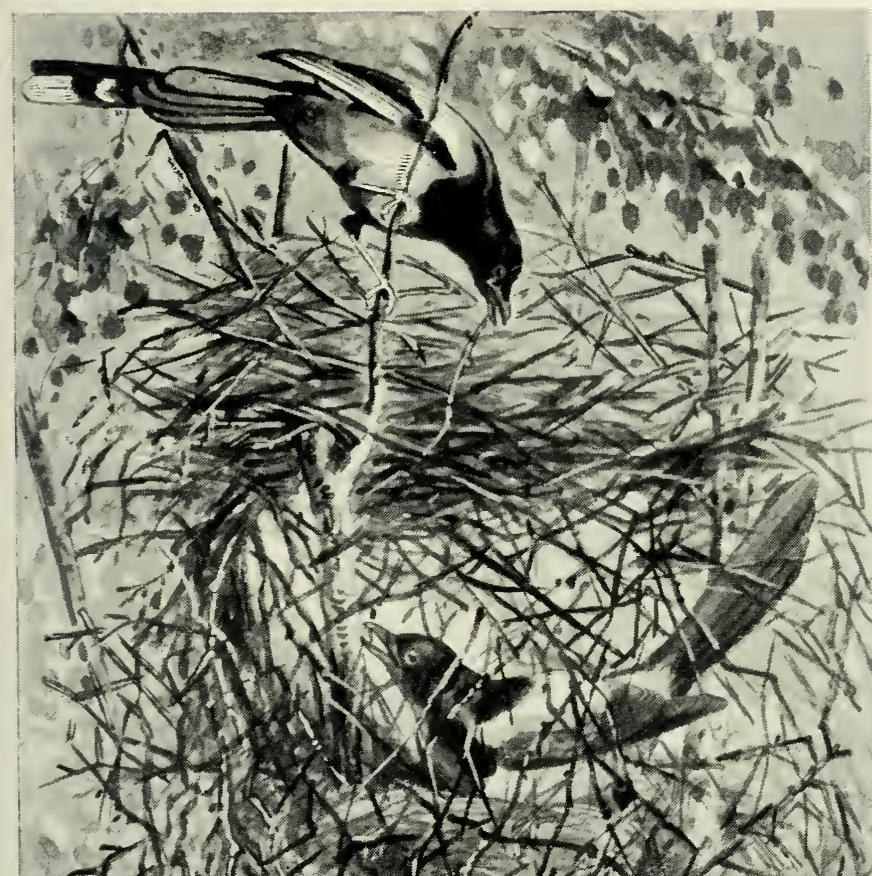

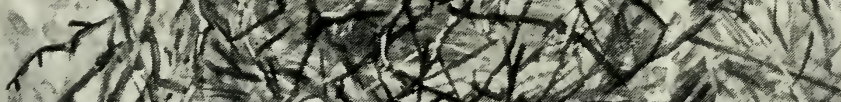

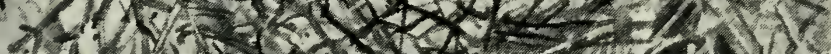

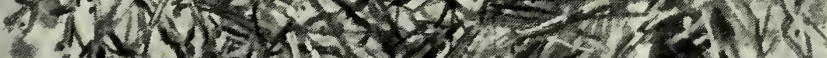

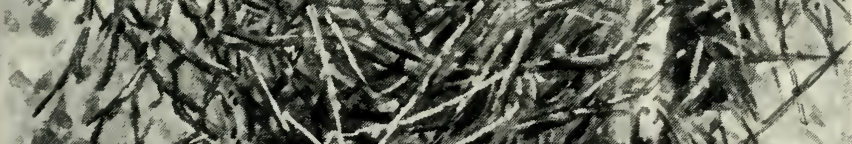

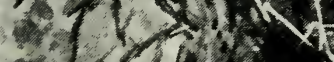

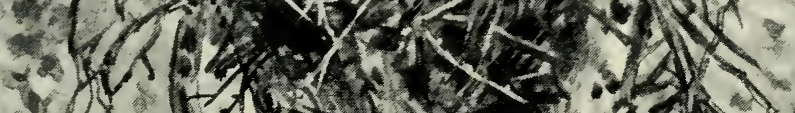
7. l. 

trees, or in lower sites no more than six or eight feet from the ground. It is a large and bulky structure, often a conspicuous object for a mile or more, and when finished is completely covered in with a dome or roof. The outer part of the nest is first formed of sticks, which are cemented together with lumps of clay or mud. Then follows a substantial lining of the latter materials. After this is completed, the huge dome is built over, dead thorn branches being generally selected, a well-disguised or masked hole or passage being left on the side, near the top or rim of the nest cavity, for ingress. Very often the nest is left at this stage for a day or so to allow the mud to dry, and finally a thick lining of fibrous roots is added. Possibly some of the allied species may use grass for a lining, but in our islands roots seem to be invariably used.

There are no domed nest-builders, so far as is known, amongst the Birds of Paradise, but the type is again forthcoming in the Starlings (Sturnidæ). Many of the more typical species of Starlings build in covered sites or conceal their nests in holes of walls, rocks, and trees, but some of the less familiar and tropical forms construct globular homes. Some of these are pendulous, and will be described in the following chapter. Passing over the Drongos with their open nests, and the Orioles, in which they are also open but slung hammock-wise, we reach the American family of Hang-nests (Icteridæ). Some of 
these birds, as we have already seen, build open cup-shaped nests; many of the others have a pendulous cradle, whilst in others it is domed. As an instance of the latter, we may mention the nest of the well-known Meadow Starling (Sturnella magna), which builds a globular nest of grass, placing it amongst vegetation on the ground.

Some of the most remarkable of these domed nest-builders are to be found amongst the very aptly named Weaver-birds (Ploceidæ) or Weaver Finches, a group (containing some 250 species) which is essentially a feature of the bird-life of the Ethiopian region, although represented in the Oriental and Australian regions, but not in America. With these birds weaving is little less than a mania, even certain species when caged apparently deriving great pleasure from twisting strings and fibres about their prison bars, and as exponents of the art they are certainly unrivalled in the avine world. Some of the curious cradles they so dexterously put together fall more naturally into our division devoted to pendulous nests, but a few of them require consideration here. The nest of the Blue-breasted Waxbill (Estrilda angolensis), a species breeding in Mashonaland, is a domed structure, with an entrance at the side, made of dry grass with no special lining. This is often built in a mimosa bush. A very interesting feature about the nidification of this bird is (as was, I believe, first recorded by $\mathrm{Mr}$ Guy Mar- 
shall) that the nest is almost invariably placed near or almost touching one or more of the hanging nests of a powerful social wasp (Belenogaster rufipennis), as though the little weaver regarded the insect in the light of a protector from certain enemies. It is still more remarkable that the same habit has been observed in South America (conf. p. 267). Another Weaver (Spermestes nana), known in Madagascar as the "Dwarf Rice-bird," builds one of the simpler types of "woven" nests, placing it almost anywhere like our own House Sparrow, in thatch or trees, or even in the deserted nests of other birds. Coming within the present division, however, of domed or roofed nests, is one of the most wonderful structures in the entire series of avine architecture. This is the home (or rather village would, perhaps, be the better term) of the Sociable Weaver-bird (Philhetarus socius), another African species. It is the habit of these little birds to live in communities, and to make what we may call co-operative dwellings, many pairs gathering the materials and constructing a huge dome or mushroom-shaped structure amongst the branches of a camel-thorn or other suitable tree. Travellers have often mistaken these nests for the grass-roofed huts of the natives, a pardonable blunder, when we are assured that many of them contain more than a cartload of grass, and accommodate from one hundred to three hundred pairs of birds! The under surface of this structure is nearly flat, and is full of 
holes, in which the Weaver-birds lay their eggs and rear their young. These republican nests are permanent dwelling-places, used year after year for the same purpose, and added to or repaired as circumstances demand. Some of the Oxbirds (Textor) make very similar structures, but as these birds do not appear ever to live in such large communities, their nests are much smaller, made of sticks and grass, amongst which in holes the ordinary grass nest of each pair is placed. The permanency of their occupation, however, is the same as the preceding. The domed or globular grass or reed formed nests of certain Weavers in the genera Euplectes and Ploceus might be mentioned as further examples of the leastor non-pendulous types. Some of these are generally attached to one or more reed stems hanging over water, whilst certain species of Foudia build their pear-shaped or oval and roofed grass and fibre-woven nests amongst the slender drooping twigs of tamarind trees or mimosas. We had occasion briefly to allude to the open nests of the Tanagers (Tanagridæ). Exceptionally, however, a domed or roofed type is found, as, for instance, that of the Central American Arremon aurantiirostris. The nest of this species is described by Mr Richmond as being very bulky and slightly raised from the ground. It is made on a base of dead leaves, plant stems and similar dry materials being the chief ones employed, whilst the whole structure is roofed over and covered with 
living ferns and mosses which most effectually conceal it from view.

Passing notice may be given to the nests of the Sugar-birds (Cærebidæ). These are somewhat loosely formed structures formed of dry grass, roots, fibres, feathers and vegetable downs, etc., domed in form, and in some cases with a projecting porch. It will also be necessary to revert to the architecture of the Finches. As we have already seen, the usual type in this family is open and cup-shaped, but in some species a domed type is adopted. Some of the special instances of this domed type also illustrate in a remarkable manner the wonderful adaptability displayed by birds in constructing their procreant cradles. The domed nest-builders in the Finch family include the Sparrows, and our own familiar House Sparrow (Passer domesticus) furnishes one of the most interesting examples. This bird-a past master of the art of making itself at home-has two very distinct types of nest, an open one, when built in a hole, a domed one when placed in trees or ivy, and so forth. This latter nest is most skilfully made, and is generally a somewhat loose globe about the size of a man's head formed of grass, straws, plant stems, etc., warmly lined with wool, hair, feathers, and a variety of other soft material. Incidentally, I may mention that House Sparrows, during the present December (1900) have been lining their nests under my eaves with the dry silky flowers of pampas grass. 
These domed nests are in use almost all the year round, brood after brood being reared in them, and they are also used as roosting-places during the colder months. So intricately are they woven that the discovery of the entrance hole is impossible. Another dome-building Finch is the West Indian Phonipara zena, which places its grass-formed nests (very similar to that of the Willow Wren) in the tufted head of spines on the top of a pine-apple; another the Central American Embernagra striaticeps, which forms a bulky roofed nest of dry leaves and stalks lined with grass in a fan palm leaf a few feet from the ground.

The Larks (Alaudidæ) are another group of open cup-shaped nest-builders, but as already shown there are certain exceptions even here. The Bush Larks (Mirafra) are like the other species terrestrial in their nidification, but form their grass-made nests on a domed model, concealing them amongst herbage. The same remarks may be said to apply to the Wood Warblers (Mniotiltidæ), some of the species (Siurus) arching over their nests, or even constructing domed nests, as in the case of the Yellow-bird (Dendraca capitalis).

In the nests of the Sun-birds (Nectariniidæ) we are introduced to a type of architecture thoroughly characteristic of the present division of domed or roofed abodes. These nests, however, present a considerable amount of variation in their model, ranging from the open cup-shaped type of birds in the genera 
Arachnothera and Æthopyga through the hooded or porched types to that of the globular one. Many writers consider these nests to belong to the pendulous type of avine architecture, but in my views of the definition of a penduline cradle they certainly do not present the peculiarities of it (conf. p. 253). The usual sites for the nests of the Sun-birds are the extremities of slender branches, several twigs often being utilised for support, or the under surface of large broad leaves and fern fronds. Single trees on open plains are selected by many species; others prefer forest or clearings. As a rule, these nests are neatly made, and the materials consist of dry grasses, mosses, fibres, roots and spiders' webs, lichens, cocoons, bits of bark or even paper forming a garniture when such is employed, whilst the linings may consist of hair, feathers and vegetable downs. Not the least interesting fact about many of the nests of the Sun-birds is the manner which they are made to resemble surrounding objects. A detailed description of one or two nests may now be given. The Madagascar Sunbird (Nectarinia notata), as if in imitation of its own favourite attitude of suspending itself from the twigs like a Titmouse, hangs its nest from the drooping branch of some mimosa tree. In shape it is something like a bag or pocket with an opening in the side or front. It is made of fine roots, dry leaves and stems of creeping plants, and lined with the softest spiders' webs. Another species (Cinnyris aldabrensis) 
peculiar to Aldabra Island suspends its nest from the branches of a mangrove or other bush near the shore, or even from a stalk of grass or euphorbia, hanging in the chasms of the coral rocks. $\mathrm{Dr}$ Abbot has recorded his observations of the nest-building of this species as follows: "The nest is neatly constructed of fibres of bark, generally mangrove. The female selects a suitable hanging leaf or branch, and attaches some fibres of bark firmly to it; other fibres are then attached to this until an oval mass is formed; this is then opened out by the bird entering her head and then her body into the mass. More material is now added to the outside, the bird occasionally entering the cavity and enlarging it by kicking and fluttering; finally the inside is lined with feathers. The construction of the nest occupies about eight days" (Proc. U.S. Nat. Mus. xviii. p. 536). Another remarkably pretty nest is made by the Cinnyris habessinicus, which is also hung from a drooping branch, and is purse or pocket shaped, with a protecting hood, or porch over the entrance. A nest obtained by $\mathrm{Mr}$ Lort Phillips, in Somaliland, was composed entirely of spiders' webs garnished all over with small empty cocoons. Another species, the Yellow-breasted Sun-bird (C. jugularis), breeding in the Philippine Islands, makes a similarly porched nest, the hooded entrance being on the side, composed of fibres, dry grass, and leaves, cemented together with spiders' webs, and lined with finer 



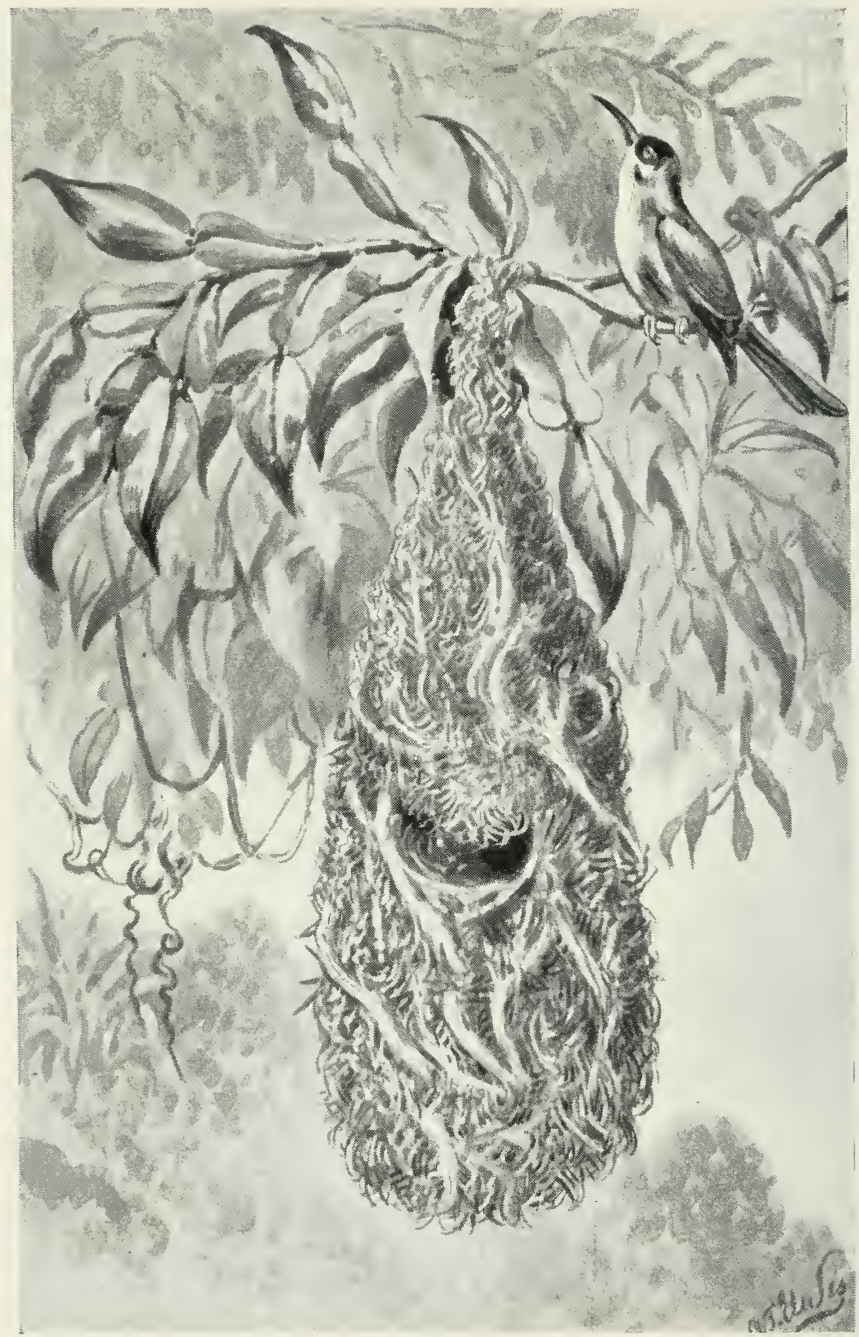

NEST OF MAGNIFICENT SUN BIRD (ÆTHOPYGA MAGNIFICA). 
grass and vegetable down. The Magnificent Sun-bird (Ethopyga magnifica) ${ }^{1}$ of the same locality, builds a nest on the same hooded plan, of fine grass and roots, palm fibres, and bits of dead leaves, bound together with webs, and lined with dead flowers of various grasses and seeds. The nest of the White-bellied Sun-bird (ZE. bella) also from these islands, is, however, a much longer structure, although porched in the same way, with a pendent mass of material hanging from the bottom. Other species in this genus are very fond of attaching their nests to tall fronds of bracken and ferns. Some of these nests are pearshaped, others are oval, and both types want the hood or porch, such a common feature in the more typical species. The nest of the Indian Ethopyga ignicauda is often attached to a bracken frond, and is made of vegetable down, and bits of green moss bound together with webs and a few long strips of grass, the latter being wound round the nest and utilised to bind or fasten it to the supporting frond. The entrance is near the top, and the whole structure, only four or five inches in length, looks like an unusually full-shaped pear. The nest of the allied Ethopyga dabryi is oval in shape, with an entrance near the middle, also hung to a bracken frond, the latter being interwoven with the roof material, the whole being formed of vegetable down and long strips of fine dead grass. I have already alluded to the

${ }^{1}$ Unfortunately made to appear in the illustration pendulous. 
wonderful manner in which some of the nests of the Sun-birds are made to resemble or harmonise in colour with surrounding objects, but I may be forgiven for quoting a very remarkable instance recorded by $\mathrm{Mr}$ Marshall in the Zoologist (1898). His observations concern the nests of three South African species of Sun-birds-Cinnyris gutturalis, C. chalybæus, and Anthodiæta collaris-which appear to be constructed specially to resemble certain nests of the social spiders (Stegodyphus). He writes:- "I have watched the construction in the case of these three species, and the nests are all built in a practically similar manner. No attempt is made at concealment, and they hang suspended from the outermost twigs of bushes on low trees at no great distance from the ground-positions which are equally affected by the social spiders. The ground-work of the dome-shaped nest, with its small porch, is composed of interwoven grass, and the exterior is covered with leaves, twigs, etc., bound on with cobwebs, so that the structure, when finished, has a generally unkempt appearance eminently suggestive of the abode of Stegodyphus. Indeed, I have been deceived myself in this respect more than once. In Natal I have observed $A$. collaris and C. chalybaus collecting webs from the snares of the large Nephile; but a pair of $C$. gutturalis, which built within a few feet of the door of one of my huts on the Umfali River, used only the webs of Stegodyphus." Lastly, we may mention that the nests of the Sun-birds 
forming the genus $Æ$ Ethopyga frequently so closely resemble masses of dead leaves and other forest refuse or débris, amongst which they are placed, that their discovery is most difficult. The South African Nectarinia famosa furnishes another example.

As we have already seen, the nests of some of the Flower-peckers (Dicæidæ) are open and cup-shaped, but the normal type in this small family is very similar to the domed or roofed cradles of the Sunbirds, and attached to drooping branches or to the stems of big leaves. A Burmese species, Dicæum cruentatum, forms a lovely little nest about the same size and shape as a Goose's egg, made of the finest vegetable fibres, with a small entrance on the side. Another, dwelling in the Philippine Islands, the Dicæum cinereigulare, forms a bag-shaped nest of green moss, cemented with webs and lined with down from young fern fronds, fastening it to the slender twigs of some tree. There are also pendulous nests in this family, as will be described in the following chapter (conf. p. 256). Then amongst the Titmice (Paridæ) we have some very beautiful examples of domed architecture. Some of these birds build thoroughly typical pendulous nests, and must be reserved for our closing chapter, but the domed cradle builders have two very characteristic representatives in the British avifauna. The Long-tailed Titmice (Acredula) build exquisitely beautiful nests. None of these is handsomer than that of the British 
Long-tailed Tit (A. rosea). This beautiful example of avine architecture is placed in bushes, hedges, thickets or trees, often those of an evergreen character, and may be as low as five or as many as fifty feet from the ground. So elaborately is it made that nearly a fortnight is taken up in its construction. It is globular in shape, with an entrance hole on one side near the top. The outer materials are chiefly green moss and variously coloured lichens (the tint varying a good deal with the situation) cemented and felted together with spiders' webs and often bits of wool; the lining is chiefly a large quantity of feathers and some hair. The general substance of the nest very closely resembles that of the Chaffinch's cradle, and the outside is usually made to resemble surrounding objects in tint, with a view to its concealment. Some nests are studded all over with small, empty cocoons; others with bits of grey, or green, or goldenyellow lichen, others with cobwebs, and so forth. I have seen a nest of this bird with a kind of flap over the entrance hole which had to be raised each time the little owners entered or left their ball-like home. I should say that the birds build upwards, and gradually encircle themselves with the outer shell. The other British example is the nest of the Great Titmouse (Parus major). This is exceptionally interesting, because the Great Titmouse generally makes an open, cup-shaped nest in a hole, but sometimes it selects a deserted home of a Crow or a Magpie, or the old drey 


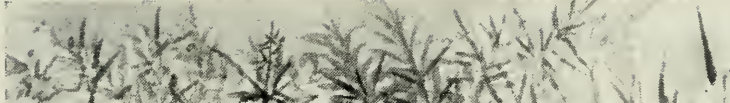
n.t.

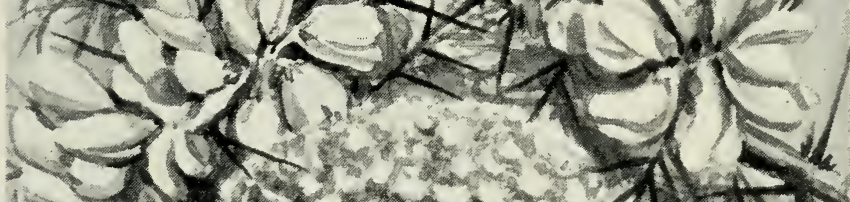

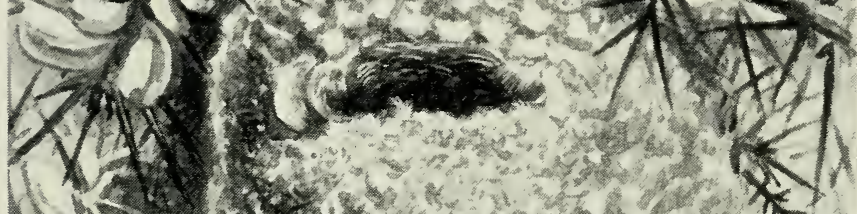
-

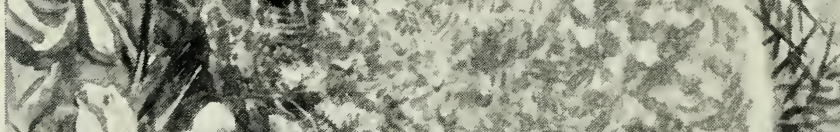
120 (1) 

of a squirrel, or even builds in some crevice amongst the sticks beneath a nest of a rook. In these cases it forms a perfectly globular nest, generally of green moss and warmly lined with feathers. The American Bush Tits (Psaltriparus) also malke domed nests. That of the Lead-coloured Bush Tit (P. plumbeus), first discovered by Lieutenant Benson in Southern Arizona, an account of which was recorded by Bendire in the Proceedings of the U.S. National Museum (1887, pp. $557,558)$, is described as more or less gourd-like in form, and woven into and supported by small twigs and branches of oak and mesquite trees. The entrance is on the side near the top. The whole nest is about the size of that of our own Long-tailed Tit. Externally it is made of dry curled-up leaves of the white sage, vegetable down, spiders' webs, bits of moss and lichens, and thickly lined with soft, small feathers. Some of the Hill Tits (Liotrichidx) build cradles very similar in type to those of the Goldcrests. That, for instance, made by Yuhina pallida, a Chinese species, is described by Mr De La Touche as a cradle of moss and moss roots, with an inner cup or lining of fibres and fine roots. The entrance is at either end of the nest. This cradle or hammock-like nest is generally suspended under a moss grown branch of a palm or other tree, or even from the bamboo thatch under the eaves of a shed. A nest of an Indian species, Yuhina nigrimentum, is very similar, and described by $\mathrm{Mr}$ Stuart Baker as being built between two long pendent 
masses of lichen hanging from the underside of a branch, the two ends of the cradle being prolonged and interwoven with the drooping tree moss. It was made almost entirely of moss roots, with a few small bits of dead moss bound together with cobwebs and lined with the very finest stems of grasses and one flower head of the same. Then, again, the nests of the Rock Nuthatches are very interesting. The nest of the Syrian Rock Nuthatch (Sitta syriaca), for instance, is attached to rocks and domed, or rather semi-globular, like that of the House Martin, with a long spout-like entrance about an inch in diameter. The external part of this nest is made of mud, the interior being lined with a large quantity of felted hair. It is very strongly and solidly built, time increasing its stability, for in some cases at least it is used for the same purpose year after year.

Passing on to the Waxwings (Ampelide), we have already seen that the normal type of nest is open and cup-shaped, but the home of one of the more aberrant members of the family is not only a very curious one, but owing to its shape requires notice here. This is the nest of the so-called "Palm Sparrow" (Dulus dominicus), a species inhabiting San Domingo, and to which island it is apparently confined. Several pairs of these birds build in company, forming a kind of co-operative nest, like some of the Weaver Finches already described. These nests are described by $\mathrm{Dr}$ Christy as quite an armful of twigs interwoven into a 
compact mass in the head or crown of a palm, or on the cluster of berries just below it. In this ball of sticks there are usually three or four nests, which are merely burrows into the main mass of sticks, lined at the end with finer twigs.

I have already had occasion to deal at some length with the nests of the Warblers (Sylviinæ), a group which presents considerable diversity in its architecture even in the open or cup-shaped type. We have now to consider the domed or roofed nests made by other species included in this sub-family. To British ornithologists the most familiar examples of these are furnished by the Willow Warblers (Phylloscopus). These little birds construct domed or semi-domed nests, placing them amongst herbage on the ground or amongst vegetation a little distance above it. Some of the species, as for instance the British Willow Wren ( $P$. trochilus) and the Chiff-chaff ( $P$. mufus), make their nests of dry grass, scraps of moss, dead leaves and roots, and line them with quantities of feathers and a little hair. Others, like the equally well-known English Wood Wren ( $P$. sibilatrix), make a similar half-globular nest, but do not use any feathers in the lining, only a small quantity of hair. But even more interesting are the wonderful little homes of the Fantail Warblers (Cisticola). These species build globular nests amongst long grass, and possess the curious habit of sewing together the tall stems of herbage into a canopy above them. It must be admitted, however, that some of 
these Fantails display more skill in this tent-making process than others. One of the most famous is the South European species Cisticola cursitans; another, the Ground Fantail (C. terrestris) of Mashonaland. These birds make beautiful nests of vegetable down and spiders' webs, forming them into bag- or pocketlike structures attached at the sides to tall stems of grass, which latter are eventually drawn together by a series of knotted fibres into a sheltering roof. The Grey-backed Fantail (C.subruficapilla), another Mashonaland species, is said to breed amongst small bushes growing on termite heaps, and to make a domed and slightly-porched nest of grass and webs, lining it with white cotton down. The extraordinary variation in the eggs of some of these Fantails is not the least interesting portion of their nidification. There are several very distinct types in the eggs of the European species-white or blue, spotted with rufous, and sometimes blue or white, without any markings at all. Some of the species in more or less closely allied genera, such as the Australian Chthonicola, Sphenæacus, Dasyornis, and the more aberrant Malurus, also build domed nests, but the limits of my space prevent more detailed allusion to them here.

So far as is known, none of the typical Thrushes (Turdinæ) builds a domed nest, but the aberrant Dippers (Cinclidx) are famous for this type of architecture. The Dippers, although a small group, are 
very widely distributed, being found in the mountainous parts of the Palæarctic region and in the Rocky Mountains and Andes in the New World. They are dwellers on the banks of swift-flowing rivers and streams, and all seem to possess the habit of making large globular nests, which are often placed so near to or even beneath cascades and running water, that the outer materials are kept in a moist and green condition. The nest of the British Dipper (Cinclus aquaticus) may be taken as thoroughly typical of all the rest. The favourite site for the nest is in some crevice of the rocks on the side of a gorge under a bridge, in the masonry of a sluice or weir (the latter situations being capital examples of adaptability), or amongst the exposed roots of a tree. The external materials of this globular nest (which in some cases may be as many as eighteen inches in length) consist principally of green moss (in many cases sphagnum is used), which harmonises in tint with surrounding objects, strengthened here and there with grass stems, especially round the circular entrance hole. Inside this ball of moss another and a cup-shaped nest is formed, consisting of dry grass, roots, and fine twigs, and finally lined with quantities of dead leaves arranged in a series of layers. Dippers are much attached to certain nesting spots, and build year after year in one situation, if they are left undisturbed especially. I might also mention that an Australian bird (Origma rubricata), certainly not very closely related to the 
Dippers, nests in a very similar manner, placing its domed nest in a suitable nook on the banks of the rocky streams and gullies that it frequents.

Very similar nest-makers are the Wrens (Troglodytidæ), although their globular homes must be taken in the sense of an analogy rather than an affinity, for these birds cannot be regarded as very close relatives of the Dippers. As already pointed out, the domed type of nest is not absolutely universal in this family, but the normal style of architecture is a globular one, and that is all that need concern us in the present chapter. Beginning with the most familiar species, we have the pretty globular nest of the Common Wren (Troglodytes parvulus). Although this is always constructed on the same general plan, there is a very large range of variation in the general shape and the materials employed, due to local conditions of site and so forth. The situations for it vary considerably also. Among the more frequent may be mentioned bushes, brambles, ivy, overhanging banks, amongst the exposed roots of trees, and in stumps in hedges. Less usual situa. tions are amongst thatch, in hay- and wood-stacks, or the extremity of some long pendent branch of an evergreen tree. The Wren is another of those species that takes great pains to conceal its nest by closely assimilating it with surrounding objects, hence the great variety of the external materials of its cradle. According to circumstances, therefore, the outer 
materials may consist of moss, dead fronds of ferns, dry leaves and grass, and lichens. The lining is not so variable, and usually consists of green moss, hair, and feathers. The entrance to this ball-like nest is generally on the front near the top, less frequently on the side, and almost invariably it is bound round with straws or dry grass stalks, twigs, or even roots, thus rendering secure and strong that part of the structure subject to the greatest amount of wear. Some of the most beautiful nests of the Wren that I have ever seen were made externally of fern fronds, or of greenest moss studded with bits of lichen and cob-web. The nests of some of the exotic members of this family are equally pretty. That of the Pnoepyga pusilla, a species found in India and China, has been most fully described by Messrs Stuart Baker, and La Touche; and from those naturalists' accounts I draw the following particulars. This Wren builds its nest amongst mosses hanging from trees and rocks, masses of orchids and other parasitic plants, clumps of ferns, and so forth. Two distinct types of nest are made by this species. An example of one of these was placed inside a large tuft of brilliant green moss growing from the trunk of a big tree in an evergreen forest. The bird in the first place seemed to have attached some of the loose lower ends of the hanging moss fibres to rough projections on the bark of the tree, forming a sort of loop beside it. Then more and more of the living growing moss was worked into this 
loop, until a firm foundation had been made for the quantities of fine black moss roots which formed the inner structure and lining. No entrance hole was required, the birds passing in and out between the moss clump and the tree trunk. On other occasions a certain amount of added moss is worked into the growing mass, until a sufficiently large bag with a side entrance has been made, which is lined with fibres and fine brown grass stems. An example of the other type of nest was wedged under a mass of yellow-flowered orchid, and rested upon a small stump jutting from the fallen tree trunk, which was almost concealed by dense masses of ferns, mosses, and other vegetable parasites. This nest was globular, made of the brightest and freshest moss, and lined with the finest roots of the same. The leaves and flowers of the orchid drooped over and concealed the entrance, whilst the green moss of which it was made exactly resembled the other moss growing in clumps all around it. This ball-like nest was about four inches high, three inches in diameter, and the entrance hole about an inch wide. A more open nest is made by the Indian Elachura haplonota. One of the nests of this new species (closely allied to the much more widely dispersed E. punctata) was placed on a heap of dead leaves, broken twigs, and branches in a hollow below a fallen tree, and was supported on each side by a broken branch. It was largely composed of dead leaves, skeleton leaves, cemented together with coarse 
fern-roots, a few bents, and one or two twigs, the lining consisting of skeleton leaves alone. Mr Baker, the discoverer of the species, describes this nest as a deep cup with the back wall much prolonged, though not sufficient to form a roof or porch. Lastly, I may remark that some other species of Wrens form purselike nests, with a long passage of woven materials for an entrance.

The next family with which we are concerned in the present chapter is that ill-defined and ill-assorted heterogeneous assemblage vaguely termed Timeliidæ. As we have already seen, the nests of birds provisionally included in this ornithological refuse heap present an immense amount of variation. Domed, or globular, or roofed structures largely prevail, but limits of space will only permit of a few of them being noticed here. Some of the most interesting of these nests are made by the species included in the genus Pomatorhinus. Some of the Australian members of it make huge domed nests of twigs with a spout-like entrance, lined with feathers and placed at the extremity of branches. Various other species, found in India, make completely or nearly globular nests. Thus the nest of Pomatorhinus phayrii is a globular structure formed of bamboo leaves, more or less mixed with bracken and fern fronds and grass, the latter material also forming the lining. Contrary to the usual custom of these Pomatorhini, which generally build on or near to the ground, this bird places its nest from four to seven feet above 
it in dense bushes, clusters of bamboo and so forth. Then again the nest of Gampsorhynchus rufulus is a massive and nearly globular structure formed of bamboo leaves and lined with fern roots, narrow strips of bark and grass. Again, various species of Pellorneum make equally massive nests of very similar materials, some being more neatly put together than others. In some of these nests the entrance is near the top, in others near the middle, or even quite close to the bottom. The majority of these birds nest on the ground, but exceptionally a species places its home in clusters of bamboo or in tangled masses of plants and creepers. Another species, also an Indian one, the Drymocataphus tickelli, makes a rather different type of nest, more in the shape of a deep cup with one side prolonged and arched over into a sort of hood, placed either on the ground or low down in bamboo clusters and dense bushes. The materials consist of bamboo leaves, soft sun-grass, dead leaves, and fern fronds. As previously mentioned, some of these Timeline birds display an exceptional amount of adaptability in forming their nests, in certain instances no fewer than three types of nest. In one of these, Stachyrhis assimilis, when it builds under shelter sufficient to cover the nest completely, the cradle is cup-shaped (as so often happens in a great many remotely allied species); when in more open sites it is formed on a semi-domed model; whilst on other occasions it assumes the completely globular 
model. The materials in each type consist of bamboo leaves either entire or shredded, and sometimes a lining of fine grass is added. Then again, Stachyrhidopsis rufifrons (another Indian species) builds two distinct types of nest; one a globular one, the other shaped like " an egg placed on its larger end, with the extremity cut off in a rather slanting direction" (Stuart Baker). These nests were either placed in bamboo clumps, or in masses of twigs on the outside of them, or in very dense bushes, and were made of shreds of sun-grass, in one case mixed with bits of bamboo leaves, and lined with fine grass and bamboo roots. We still find the domed type of nest prevailing in such genera as Timelia, Mixornis, Drymocataphus, and Pellorneum.

We have already had occasion to describe various nests of the Flycatchers (Muscicapidæ), the birds presenting considerable diversity in their domestie arrangements, even so far as they are known. As previously shown, we have the covered or concealed type of nest, as well as the open cup-shaped one, whilst more exceptionally domed or roofed structures occur. As, however, the nests of a very large number of the three hundred species or thereabouts of which the present family is composed are absolutely unknown, it is impossible in the present state of our knowledge to give a comprehensive review of their architecture. Even the very limits or composition of the family are as yet in an ill-defined condition, 
and are likely to remain so until a knowledge of the external characters of many "Flycatchers" is supplemented by a wider range of anatomical facts than is now at the service of ornithologists. Many of the tropical species are adepts at concealing their cupshaped nests in the crevices of moss-draped trees and rocks and banks, skilfully assimilating them, in not a few cases, with surrounding objects. Others build partially domed nests in holes under banks, the shape of the cradle conforming to that of the aperture in which the pretty home is placed, often so filling it that merely the round entrance is visible. Another, an Indian species, Anthipes leucops, builds a globular nest of grass leaves, and a few dead bamboo leaves, lined with grass stems, placed amongst upright forks in bushes, or masses of creeping plants, or roots.

Much more is known concerning the nesting arrangements of the Swallows (Hirundinidæ). These birds build their nests far more frequently in open and exposed situations, where they are comparatively easily detected, although very often they are difficult of access. We have already made a brief allusion to some of the species making open nests (although these are generally in concealed or covered sites), it now becomes necessary to describe a selection from the various types of domed or roofed nests made by others. Beginning with the best known, we cannot do better than examine the procreant cradle of our own familiar House Martin 
(Chelidon urbica). The nest of the bird furnishes another very interesting example of a changed method of building within historic time. Before the dawn of human architecture in England this Martin attached its nests to rocks, and possibly to big trees, but when masonry appeared the bird gradually took possession of the sites with which we are all so familiar to-day. House Martins now nest indiscriminately upon cliffs and buildings, when on the latter some spot with a projecting ledge or cornice being selected similar to the sites chosen on cliffs where a natural prominence furnishes the all-necessary protection. The nest is somewhat like a half basin in shape, more conical in some than in others, the rather wide entrance hole generally being close to the rim, between it and the sheltering projection above, and either at the front or on one side. The shell of the nest is made of little pellets of mud, built on piece by piece sometimes with bits of straw intermixed to give it better adhesive properties. The interior of this mud shell is then lined with dry grass and feathers. The House Martin generally begins at the bottom of the cup, working upwards and outwards towards the sheltering prominence, plastering on each little ball of mud either whilst clinging outside or standing inside the structure. These birds are gregarious, and in some places every available bit of wall or cliff is occupied by a nest. Rows of these may often be seen under copings or eaves, but on cliffs they are of course placed less regularly, 
although I have seen clusters of several nests, each attached to the one adjoining. House Martins are also much attached to their breeding places, and yearly return to their old nests, after their migrational journeys of thousands of miles and an absence of quite six months. Far away in India a Martin (Chelidon cashmeriensis), closely allied to our own, makes a nest on a very similar plan, attaching it to cliffs under the little projections. It is made externally of mud and bits of moss, and lined with grass stems and feathers. Another Eastern species of Martin (C. blakistoni), found in Japan, was thought by $\mathrm{Mr}$ Jouy to make its nest largely of saliva when breeding in the volcanic region of Fuji-Yama, at an altitude above the limits of forest growth where no mud could be obtained. Many of these birds that were shot in this region had their mouths full of fine scorix dust, which when mixed with saliva evidently became a substitute for mud. These Martins were breeding in considerable numbers on the sides of an inaccessible cliff or chasm on this mountain. An interesting instance of the intelligence often displayed by Swallows in nest-building has been recorded by $\mathrm{Mr}$ F. Lewis (Nature, 1886, p. 265). This relates to the "Bungalow "Swallow (Hirundo javanica), so named because of the frequency with which it breeds in houses. A pair of these birds made a nest on the top of a hanging lamp, taking care to build the domed cradle over the pulleys by which the lamp was lowered 
for lighting, so that the chains could travel over the enclosed wheels without damaging the nest. Although this lamp was in use each night the birds successfully reared their brood, after which the nest was removed owing to the inconvenience caused by the feathered usurpers. Some of the typical Swallows (Hirundo) differ very remarkably in their nest-model from the swallow of the British Islands. One of these, the Striped Swallow (H. striolata), a resident in Formosa, makes a retort-shaped nest of mud, attaching it to walls. The Chinese show this little bird every consideration and encouragement, and never allow the nests that it makes in their houses to be disturbed or robbed. In India this species, according to the observations of Mr Stuart Baker, does not make a retortshaped nest, but one more after the model of the English Swallow, attaching it to cliffs under a little projection. The retort-shaped type is by no means an uncommon one in the present family, in widely separated parts of the world. Thus in Australia we have the Fairy Martin ( $H$. ariel) attaching its flaskshaped nests to cliffs. These are made of mud or clay externally, and lined with soft materials. The length of the entrance spout appears to be subject to considerable variation in length, ranging from six to ten inches. Then in America we have the Rufousnecked Swallow ( $H$. fulva), building a similar flaskshaped structure, but the spout is shorter and more open. Numbers of these nests are often placed as 
close together as possible on some suitable cliff-a spot where an overhanging ledge furnishes the required shelter from above. Another American species, the Chestnut-bellied Swallow (H.erythrogaster), makes a nest of mud in the form of an inverted cone, the side nearest to the rock to which it is affixed being more or less flat. Incidentally I may mention that various species of Swallows breed in the disused nest of the Oven-bird, forming a bed for their eggs with dry grass and feathers, but whether this indicates a change in the nest-building methods of these annexing species it is of course impossible to say. We might almost presume that these birds have relinquished the habit of forming a mud shell or outer nest when they discovered that these mud "ovens" saved them the trouble of making one for themselves. A full description of the Oven-bird's curious nest will shortly be given (conf. p. 244).

The open type of nests of the Tyrant Birds (Tyrannida) has already been described, but we have now to deal with the various domed nests made by other species in this family. A description of one or two of these must suffice. Mr Richmond has recorded (Proceedings U.S. National Museum, xvi. p. 504) a most interesting experience of how he found his first nest of the Tyrant Bird named Todirostrum cinereum, by seeing the little owner of it (after a spirited attack upon an intruding species of Wood-hewer) disappear into what he had supposed to be an accidental tuft of 
dead grass and leaves. This nest he found to be a very compact structure with a hidden entrance in the side just large enough to admit the bird. All the nests of this species found subsequently by him were built in exposed situations, and resembled bunches of drift grass. Another species, breeding in Brazil, and locally known as the "Ferreirinho," or Little Smith ( $T$. maculatum), builds a similarly domed nest. One of these has been most carefully described by $\mathrm{Dr}$ Goeldi, to whom we are indebted for the following particulars. It was built near the extremity of a short branch of an "abin" tree about twenty-three feet from the ground, somewhat well concealed in the central part of the crown, and is described as a baglike structure with an entrance hole in the side, the latter being small and circular, and provided with a sort of porch or protecting roof, as we have already seen is a feature in the nests of some Sun-birds. The principal material of which the nest is made is the fibres of palm-tree leaves and bits of straw. Many of these fibres hang down in a loose and slovenly manner far below the bulk of the nest, whilst the upper part of the structure, including the portion connecting it to the branch, is similarly prolonged into a horn-like mass. Possibly the very carelessness of its construction forms one of its best safeguards, as it might readily be taken for a mere lodgment of rubbish amongst the clustering leaves in which it has been so cunningly placed. 
As already indicated, the Chatterers (Cotingidæ) build several types of nest, concealed, open or cupshaped, and as we have now to repeat, domed or roofed. Here, again, we are confronted with such a small amount of material that a fairly exhaustive review of the architecture of these birds is at present impossible, and with nothing of special interest to record, we must, with this brief allusion, pass on to our next family of domed nest-builders. This includes those gaudily arrayed Wren-shaped ground birds the Pittas (Pittidæ). The Pittas (an Old World group) are mostly ground builders, as might naturally be inferred from their eminently terrestrial habits, and construct globular nests of twigs, roots, fibres, in some cases cemented with mud, and lined with grass and moss.

We now reach a specially interesting family of birds, the Wood-hewers (Dendrocolaptidx). This family is entirely confined to the Neotropical region, and presents, so far as it is known, a singularly large amount of variation in its architecture. Amongst the most remarkable nest-builders in this family (indeed we might say with equal truth throughout the entire avine kingdom) are the Oven-birds (Funarius). Perhaps the species whose nest is best known is the Red Oven-bird (Funarius rufus). Possibly because the nest is such an elaborate structure, and formed of material that requires some time to harden, the birds begin building it months before it is required for its principal purpose, the rearing of the young. This 
building goes on more or less intermittently from autumn onwards through the winter, as the weather may be favourable for the task. The birds, curiously enough, seem to take little or no pains to conceal their conspicuous nest, placing it indiscriminately on the tops of fences, on masses of rock, amongst trellis work fastened to houses, or even on some exception. ally large cactus, in bushes, or on broad branches of trees. Several nests are occasionally made close together. The nest or "oven" is nearly globular in shape, strong and massive, and made of clay or mud mixed with bits of straw, hair, and fibres. The walls of this mud nest are perhaps an inch in thickness, and when thoroughly baked by the fierce sub-tropical sun become almost as hard as a brick. The whole structure is still further strengthened by peculiarities of its design, consisting of a central wall or partition which rises from the bottom of the nest and reaches nearly to the top of the dome, thus dividing the interior into two chambers. This party wall curves inwards from the entrance nearly to the back, thus leaving a narrow passage into the inner chamber, where the nest is completed by a bed of soft dry grass. The "oven" is about twelve inches in diameter, and often weighs as much as ten pounds. Notwithstanding the elaborate character of these nests, the birds are said to make a new one each season, sometimes doing so on the top of the previous one. Both sexes appear to join in building 
these curious nests. The deserted "ovens," as we have lately pointed out, are used by a variety of other birds for nesting purposes.

Some of the other nests made by the Wood-hewers are little less extraordinary. Not a few of the most curious are made by certain members of the genus Synallaxis. One of these, Synallaxis phryganophila, makes a nest of sticks about twelve inches deep, and from the top to the bottom of this a tubular passage is constructed, similar to a rain-pipe along the wall of a house, and then passing outside slopes upward, and finally terminates several feet from the actual nest. I ought to add that this curious passage is made of fine twigs dexterously interlaced. A Yucatan species, S. erythrothorax, makes an enormous nest of sticks, and varying in size from that of a small pumpkin to that of a barrel. So numerous are these nests in some localities that upwards of two hundred of them have been counted on trees standing within a radius of twenty rods. Sometimes a single tree contains half a dozen nests; whilst occasionally, as was observed by $\mathrm{Mr}$ Burrows, the nests of several species crowd each other out of shape, so closely are they made on the same bush. Another of these species of Synallaxis weaves a small straight tube out of grass open at both ends, the aperture being only large enough to admit a single finger, the parent bird having to pass right through this singular nest 
when once she had entered it, owing to the impossibility of turning round. One other species scoops out a circular hollow in the ground, and over this builds a dome of finely woven grass. Still another of these birds, the Synallaxis albescens, builds a domed nest with a passage leading out of the top, made of sticks and lined with wool. In building this curious dwelling, the large cup-shaped nest is made first, which is then roofed over, and the tubular passage added.

Synallaxis pudica builds its nest in a bush from three to five feet from the ground. This resembles a retort in shape, having a bowl with a neck at the top slanting downward. It is made of small thorny sticks closely laced together, the neck or entrance being built out and downward until it is below the level of the body of the nest. In some cases, as was remarked by $\mathrm{Mr}$ Richmond, this covered way is not very well defined, being lost in the mass of sticks, and so compactly is the whole structure put together that it is no easy matter to open it barehanded.

Some of the marsh frequenting species attach their spherical or oval-domed nests to reeds. Some of these are a combination of dry grass and clay, so cleverly put together as to be impervious to wet, almost indestructible, and light as baskets. Another type of nest is found in the genus Phacellodomus. One species, P. striaticollis, places its nest in a 
sloping position on a tree or bush often over water, making it of twigs, and lining it with hair, roots, and feathers. It resembles a wide-mouthed bottle in shape, and consists of two separate chambers, an inner and an outer one. Then in the genus Homorus we are introduced to another model, the Homorus lophotis, making a big nest, in shape resembling a gigantic flask. This is also placed in a horizontal position amongst the lower spreading branches of trees. Another member of this genus, Homorus gutturalis, forms a monstrous domed or roofed nest of sticks, so big, that if the dome were removed, a condor (one of the largest of known birds) could incubate her eggs and rear her young in it. Lastly, we may mention one example from yet another genus of these remarkable architects. This is the Pracellodomus sibilatrix, which builds so huge a nest, at the extremity of a horizontal branch ten or fifteen feet from the ground, that its weight when completed bends the branch down to within a few feet of the earth.

Our last instances of domed nest-builders are drawn from the small group of South American Wren-like birds associated in the family Pteroptochidæ. But little appears to have been recorded respecting the nidification of these somewhat isolated and aberrant species; but some of them are known to build domed nests of grass and fibres, others breed in burrows, whilst some make an open type of nest with sticks. 
As we remarked at the beginning of the present chapter, the domed or roofed type of nest is an especial feature in the architecture of Passerine birds. These are mostly small and comparatively weak and defenceless species, and unquestionably adopt this style of nest as a safeguard from the exceptionally numerous enemies that surround them, especially in tropical countries. To a much smaller extent they may be formed on this model for the purpose of shielding their contents either from cold (as in the case of some of the northern ranging species), or from the torrential deluges of rain that are such a feature of tropical latitudes. In a great many cases it will have been remarked that the protection derived from these bag-like nests is still further ensured by the peculiarities of the situations that have been selected for them, such as at the extremities of drooping slender branches, often above water, where naught but winged enemies could reach them. In like manner we have often seen how cunningly they have been concealed amongst surrounding vegetation, or made to resemble objects near them. Another fact worthy of repetition here is the frequency with which a species has occasionally adopted a domed type of nest when built in an exceptional position. Lastly, we have to call attention to the fact that the eggs of these domed or roofed nestbuilders are, in a very large number of cases, white, or of one tint, or rarely spotted to any great extent, 
as is the case with birds breeding in open nests; whilst in a similarly large number of instances these domed nests are made by species remarkable for the showy colours of their plumage. How far, however, this is cause or effect it is impossible in the present state of our knowledge to suggest. 
CHAPTER VII

\section{PENDULOUS NESTS}





\section{PENDULOUS NESTS}

Erroneous opinions respecting Pendulous Nests-Definition of Pendulous Nests-Rarity of this type in Avine Architecture-Variation in shape of Nest in same species-Nests of the Penduline Tits-Of various Flower-peckers-Of certain Honey-eaters-Of various species of Gerygone-Of the Glossy Starlings-Of the Weaver-birds-Of the Indian Weaver-bird-Extraordinary Nest of this species-Of the Yellow-crowned Weaver-Various shapes of Weaverbirds' Nests-Method of building adopted by Weaver-birds-Weaver-birds a striking feature of Eastern Bird Life-Nests of the Hang-nests-Shape and dimensions of Nests-Changes in materials used according to locality occupied by species-Nest of Baltimore Oriole-Reason displayed by Birds in Nestbuilding-Most typical Pendulous Nests-Of various Cassiques-Nests of the Cassiques a feature in tropical American scenery-The Cow Birds-Parasites - Various facts relating to Pendulous Nests-Enemies to Birds and EggsResumé of previous chapters and conclusion.

IT is somewhat remarkable how the term "pendulous" or "penduline" is applied to such a large number of nests that have little or no claim, strictly speaking, to be described as such. Not a few of the nests included in our previous chapters have quite erroneously been classed as pendulous by various writers. We may allude specially to the nests of certain Humming-birds, Sunbirds and Tyrant-birds to illustrate our remarks, and here insist that a hanging or suspended nest is by no means necessarily a "pendulous" one. Nests built at the extremity of slender and often drooping branches, or attached to fern fronds and broad ribbon-like leaves, cannot accurately be described as pendulous. My de- 
finition of a "pendulous" nest is one that may either hang loosely by a woven rope of varying length and not supported from below, or in any other manner; or by having the upper material of the nest itself attached in one or more places to the branch which carries it, the nest, however, swinging completely free. This type of nest is by no means a common one. Indeed, it is noteworthy in how very few families these pendulous nests are found, and I may also add that they are almost exclusively confined to species dwelling in tropical countries. To my mind they represent the most skilful limits to which birds have developed the nest-building art. Not that they should be regarded as any more wonderful in their construction than the various other types of avine nests (for they are but representatives of the same great utilitarian plan), but they are the highest development of an architecture that has progressed along certain lines-a type that is possibly a development from, or even an improvement upon, the one that has for its examples nests suspended from the extremities of drooping branches, so many of which have been described in the previous chapter. Possibly these pendulous nests appeal more to our admiration than those of any other birds when we bear in mind how skilful must the little architect be that can construct or weave, first a swinging rope or cord, and then a more or less elaborate domed cradle at the extremity of it, absolutely in mid-air, often over water, and 
swayed to and fro by every breeze! Lastly, I may state that the considerable amount of variation in the shape of these pendulous nests belonging to the same species is a feature of exceptional interest. We will now proceed to a description of some of these pendulous nests.

Perhaps it may be as well to deal with those that are least pendulous first, those that may be described as a sort of compromise between nests hanging from the extremities of twigs and with which they are interwoven, and those that are suspended in the more typical pensile manner. Examples of these nests are furnished by the Penduline Tits (Egithalus), included in the family Paridæ. One of these birds is found in various parts of Southern Europe, the Penduline Titmouse (Egithalus pendulinus), probably the only instance of a typical pendulous nest-builder throughout the Palæarctic region, the other members of the genus being found in warmer localities. A favourite situation for the nest of this species is the extremity of some slender drooping branch, at varying heights from the earth, and not unfrequently over water. The nest is hung from the branch with woven camels' or other hair. In shape it is more or less globular, something like that of the Long-tailed Tit, but the entrance consists of a kind of tube extending a little way beyond the side. The materials consist of cotton down and hair very closely felted together. Some of the nests of this bird that I have examined are decidedly pear. 
shaped, the stalk forming the attachment to the supporting branch. Another species, the Crowned Tit (Egithalus coronatus), makes a somewhat bootshaped structure of similar materials, the entrance hole being in the "ankle" portion, and the whole suspended from the "heel." In some parts of Asia Minor nests of the typical Penduline Tit have been found made entirely from the wool and hair of sheep and camels.

Instances of this particular type of pendulous nest are also furnished by some of the Flower-peckers (Dicæidæ). Some of the nests of these birds have already been described in the previous chapter, but a thoroughly pendulous one must find a place here. This is the beautiful cradle of the Australian Flowerpecker (Dicaum hirundinaceum). It is said generally to be built amongst the branches at the top of a tree, hung or suspended from a more or less horizontal twig, either of the tree itself or some parasite plant. It is a bag or purse-shaped globular structure with a side entrance near the top, the upper portion of the nest being woven round the supporting branch. The material is almost entirely composed of the white cotton-like down of certain seeds. Another of these strictly pendulous nests is made by the Thick-billed Flower-pecker (Piprisoma agile). This bird suspends its tiny nest from some twig, the latter passing through the upper portion of it like a beam or rafter. This, again, is mostly made of down and spiders' 
webs mixed with a few fibres, the latter lending the whole structure a brown appearance. It is, of course, purse-shaped; and Mr Jesse records that another of its peculiarities is "that it can be rolled up and unrolled again without losing its shape." Perhaps the nests of no other family form such a connecting link between hanging domed nests and those of a strictly pendulous character, some of them being exceptionally puzzling as to which division they most correctly belong. Some nests of the Honey-eaters (Meliphagidæ) rank next in this peculiarity, the open cradle, for instance, of the Lanceolate Honey-eater (Plectorhynchus lanceolatus) being attached at each extremity of the rim to the supporting twig; vegetable down and grass are the principal materials of this hammock-like abode.

Other examples of pendulous nests are furnished by the Goldcrest-like little birds of the genus Gerygone, associated by some systematists with the Flycatchers, by others with the Warblers. They are peculiar to the Australian region. From particulars published by Mr D. Le Souëf, I have drawn the following information relating to the Masked Gerygone (G.personata). This bird lives in the dense scrub, and suspends its dome-shaped nest from the extremity of a thin branch or a palm leaf. It has a porch at the entrance, more prominent in some nests than in others. It is composed of fine fibres of grass; and to the tapering beard-like lower portion the dried 
excreta of wood-loving caterpillars are attached, whilst small portions of the same material are often studded over the exterior of the nest itself, as well as cob-webs; the lining is formed of the fine browncoloured down off the reeds of scrub plants, together with a good deal of cob-web. The nest itself, exclusive of the "beard" or pendent, is about five inches in length, the tapering portion below about three inches. A very interesting circumstance was observed by the above named gentleman in connection with the nest of this bird. That was, that it always seemed to build its nest in close proximity to a wasps' nest, from within a few inches to four feet away-a peculiarity already remarked of some other birds (conf. p. 224). More information relating to the architecture of another of these birds has been published by Mr Alfred North. This relates to the Great-billed Gerygone (G. magnirostris). This species generally builds its nest in low trees overhanging a river or a creek, but one nest was discovered in a shaddock tree in a garden. It is a long pendent structure, varying from sixteen to twenty-four inches in length, usually attached to the drooping end of a nearly leafless twig. The end of this twig is first covered with an irregular layer of material between two and three inches in diameter, and from nine to twelve inches in length, before the actual nest is commenced. This is domed with a projecting porch over the entrance, whilst the lower portion of the nest terminates in a straggling beard 
about five inches in length. The nest is made of shreds of bark, cocoanut fibre, dry grass and weeds, skeletons of leaves, and the silk-like coverings of spiders' nests-the whole matted together and more resembling a hanging mass of débris left by the floods than a nest. The lining consists of feathers. The dome of the nest is about seven inches in length and five inches in breadth. It may be of interest to state that these birds are very frequently selected to play the part of foster parents to various species of Cucloos. Mention might here also be made of the apparently pendulous nest of the Glossy Starling (Calornis metallica). This species is said to be very common in the north-east coast districts of Australia, building their nests on the tallest trees available in the scrub, forest country, or mangroves. These birds very closely resemble our own Starling in their habits, living in flocks and breeding in societies. Mr D. Le Souef remarks that when a large colony are nesting on one tree the noise they make is considerable, the birds looking like a swarm of bees circling round the top. The same nest trees are used year after year; and sometimes one tree will contain just upon three hundred nests. These nests are suspended from the thin branches which sometimes break with their weight. These are described as bulky hanging structures, nearly circular, measuring about seven inches in diameter, the nest cavity about four and a half inches. They are chiefly composed of dark-coloured 
curly vine tendrils, lined with finer light-coloured fibres from the palm trees.

We now arrive at the most typical of these pendulous nests, those to be considered first being made by various species of Weaver-birds (Ploceidæ). The nests of some of these birds have already been described-globular or domed structures, but nonpendulous-the nests of the hanging type are even still more remarkable. These nests, although made on a very uniform plan, present not a little diversity in shape and general appearance. A very typical example of these pendulous nests is made by the Indian Weaver-bird (Ploceus baya). After having selected a suitable branch (usually of a tar tree) the bird begins to weave from it a rope or string of tendrils and fibres, from the end of which is ultimately formed the globular nest chamber, lined with grass, which is succeeded by an open woven tube, several inches in length, serving for the entrance. A most extraordinary nest of this species has been recorded by $\mathrm{Mr}$ W. Jesse (Ibis, 1897, p. 558). This nest, better described as a collection of nests, is made up of no fewer than seven distinct nest chambers, one placed below the other. These nests appear to have been added to the structure year by year, as the lowest was composed of new grass, the material of the others getting older and older, the top one apparently being so timeworn that it was a wonder it had not given way under the unusual strain. 


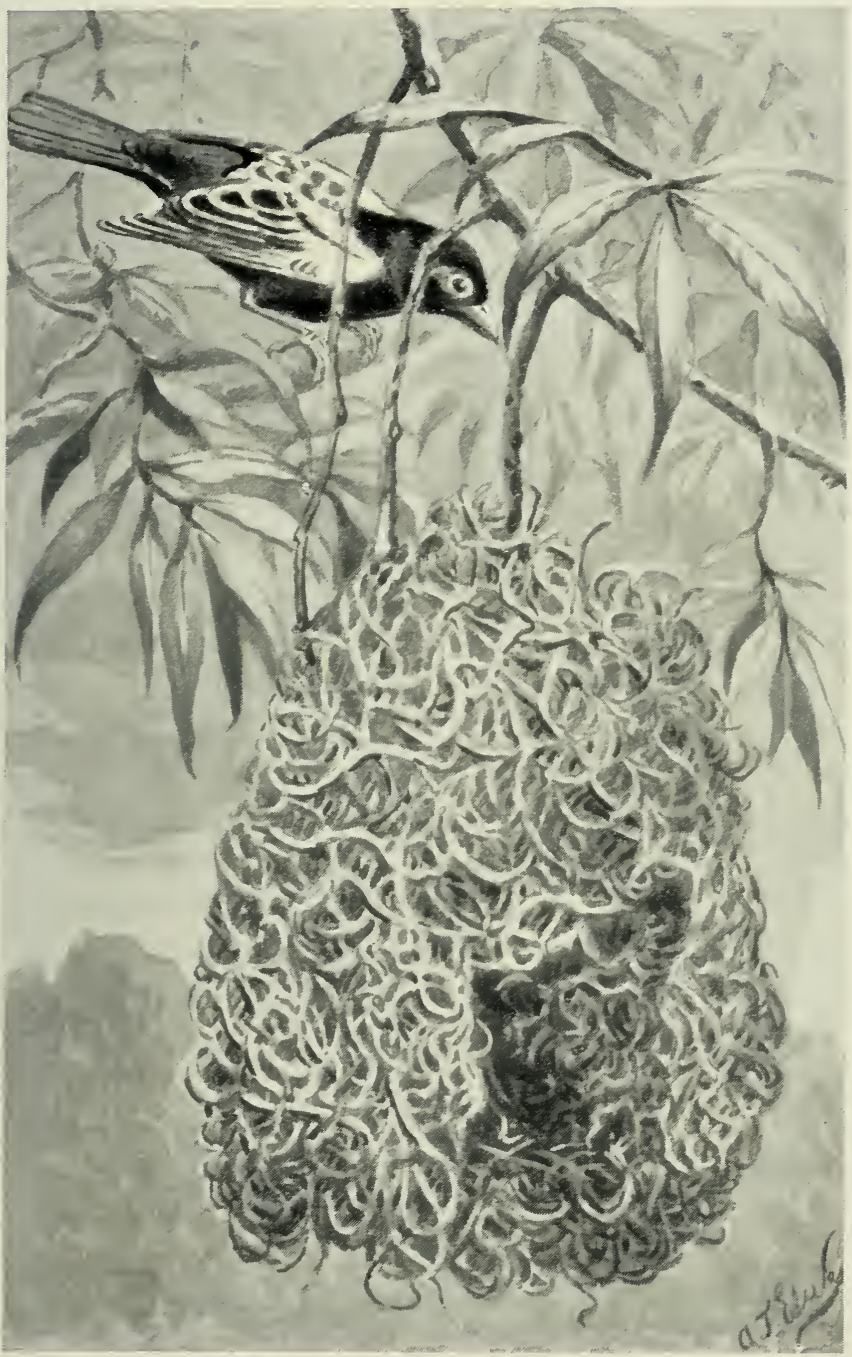



Three out of the seven chambers were found to be in actual use, each containing eggs. Another species, the Yellow-crowned Weaver ( $P$. spilonotus), inhabiting Africa, builds a nearly globular nest, attached by two woven ropes to the supporting branch, with an entrance either on the side or near the bottom. To this nest no special entrance tube appears ever to be attached. Some other species belonging to the genus Hyphantornis exhibit a considerable amount of ingenuity in the construction of their nests. These are retort-shaped, and are suspended with the short neck downwards, and from a casual examination might be considered most unsafe receptacles for eggs and young birds. But closer inspection will reveal the curious fact that across the entrance to the bulb-like chamber a safety wall or guard has been woven, several inches in height, thus insuring absolute safety for the contents. Other nests made on the same inverted retort plan or model are made by the Pensile Weavers peculiar to Madagascar. These nests are about twelve inches in length, the entrance tube being about four inches in diameter. All the Weaver-birds work at their nests in a very similar manner. Nlany of the species are gregarious, or, at least, social, during the breeding season, and numbers of nests may frequently be seen swinging in company from the same trees, and even occasionally one nest will be actually suspended from another. Weaver-birds are one of the most striking features in 
the bird-life of the East, and in some countries (as, for instance, in Burma) there are few thatched houses, as $\mathrm{Mr}$. Oates informs us, without a number of their inverted flask-like and spouted nests suspended from the eaves, the birds caring little for the near approach of the human owners. I may also state that the chief materials generally employed by these wonderful little birds are fibres, strips of various leaves, and a variety of narrow stiff and elastic grasses.

Our last examples of these pendulous nests are furnished by a family of birds not inappropriately named Hang-nests (Icteridæ), confined to America, and most abundant in the tropical portions of that vast region. These birds are the makers of the most pronounced type of pendulous nest, some of the structures they weave being of a most extraordinary description. Some of these wonderful avine cradles measure nearly six feet in length, the greater part of this, of course, being occupied by the supporting woven cord or tube. They vary considerably in shape, some being nearly globular, others of almost every description of bottle or flask shape. The materials consist of wiry grasses, dry roots, hairs and fibres, lichens and slender mosses. Many species breeding in the more populated districts have readily availed themselves of such articles as twine and worsted. This variation of material in some cases has a very perceptible effect upon the appearance of the nests of the same species. Apropos of this 
fact, $\mathrm{Dr}$ Goeldi has made the following observations, which I herewith quote from the Ibis (1897, pp. 364, 365):- "Just as the material used by Cassicus persicus for its nest in Bahia (and southwards) is different from that used by the same bird in Para, the material employed by Ostinops decumanus in these two countries respectively is also different. I have stated that in Southern Brazil Ostinops uses exclusively the Barba da velho (Tillandsia usneoides), and that these southern, nests are of a greyish colour. On the Amazon the material employed by this bird is composed of -(1) a black hairy substance, very like horsehair or delicate and elongated roots [which botanical researches in the Para Museum prove to be a most interesting lichen, but of which it is not yet possible to ascertain the exact systematic name]; (2) of the dry and tender roots of certain orchids of a yellowish colour. As the proportions of both substances is almost as two to one, and the black rootlike lichen is largely predominant, the general aspect of these northern nest-bags is of a blackish colour, contrasting in a striking manner with the greyish Tillandsia-structures of Southern Brazil." We thus see how a species may change its nest material with the change of vegetation in different latitudes - a phenomenon of which vast numbers of other instances might have been given, and of which not a few have already been indicated in the present volume. But to return to the nests of these Icterine 
birds. Certain of the species in the present family construct nests of a somewhat intermediate type, like those of the Penduline Tits and the Honey-eaters. Of these mention may be made of the following. The Baltimore Oriole (Icterus galbula), a common summer migrant to many parts of the United States, makes a deep bag or pocket-like nest, which is hung pendulously to the extremity of a suitable branch, the rim of the structure generally being caught or interwoven in one or two places to the supporting twigs. The bird commences operations, according to that accurate observer, Wilson, by fastening strong strips of hemp or flax fibre round the two forks of a twig sufficiently wide apart for the purpose, and with these and other materials, such as tow and wool, it weaves it into a kind of strong cloth-like substance, which is fastened into a pocket-like nest, the latter being lined with a variety of soft material, and finally finished with a layer of horse-hair. Considerable variation in the neatness and fabrication of the nests of these birds has often been remarked, the least elaborate and skilfully made cradles most probably being the work of young and inexperienced individuals. This undoubted fact in the nest-building of other species has already been noticed in the opening chapter (conf. p. 15). Other species of Orioles belonging to the same genus or closely allied genera make very similar structures. Perhaps the nests of no other birds exhibit so much evidence of construc- 
tive adaptability as do those of the American Orioles. A long and observant familiarity with these nests prompted the illustrious Wilson to proclaim that they " exhibit not only art in the construction, but judgment in adapting their fabrications so judiciously to their particular situations. If the actions of birds proceeded, as some would have us believe, from the mere impulses of that thing called instinct, individuals of the same species would uniformly build their nests in the same manner, wherever they might happen to fix it; but it is evident from those just mentioned, and from a thousand such circumstances, that they reason, à priori, from cause to consequence, persistently managing with a constant eye to future necessity and convenience." The belief in instinct, however, like many another popular superstition and prejudice, dies hard, and is still very generally invoked as an explanation of many of the wonders associated with avine architecture.

The most typical pendulous nest-builders are the Cassiques (Cassicus, etc.). These birds are inhabitants of tropical America, where they form a very prominent and characteristic feature in the ornithology of that region. Their nests are very curious and interesting structures, and may best be described as elongated bags or pockets suspended by woven cords of various lengths and thicknesses. These wonderful hanging nests-a type of architecture in which the art of suspension reaches its climax-are one of the 
most characteristic features of tropical river scenery in Amazonia and Guiana, where single trees are often draped, with numbers of them hanging from the extremities of the highest branches in situations practically inaccessible to all but winged enemies. These birds are in many cases not only gregarious, but remarkably familiar, showing little fear of man and often breeding in very populous places (such as by the side of a much frequented road), like the Rook and some other species in our own islands. One of the most interesting of these nests is made by a Brazilian Cassique (Ostinops decumanus). Some of these are suspended by an exceptionally long woven cord, this and the bag of the nest itself measuring quite six feet in length! The nests of other species, such as that of Cassicus persicus, are much shorter and more cylindrical, although made on precisely the same model, a deep bag with a comparatively small horseshoe shaped entrance at the top. The materials of these pendulous nests vary considerably according to the locality, as we have just seen, but in every case long dry fibres and thread-like roots are the principal. These are woven together with great skill into fabrics of exceptional strength, the females alone being the architects apparently in every species. The observations of $\mathrm{Dr}$ Goeldi (whose biological observations in Amazonia are of the greatest interest and value, and which I hope may receive a better reception next time than they got from certain stupid and ignorant 
reviewers when placed before an English public in his book entitled Aves de Brazil) confirm the widely prevailing and popular belief in Brazil and Guiana that these Cassiques choose such trees for their colonies which are also occupied by wasps and their nests. The natives of these regions say that the Cassiques when threatened by an invading carnivorous animal or even by man fly intentionally against the wasp's nest in order to direct the irritation of these insect allies against the intruder, and literally to "bring a hornets' nest about his ears," as the old saying has it! This habit, however, is by no means confined to the Cassiques, and I have had occasion to allude to it several times elsewhere in the present volume. I may also mention in connection with these Cassiques that at least one of the Cow-birds (Cassidrix oryzivora) is parasitic on them, a fact which was first made known by $\mathrm{Dr}$ Goeldi, who has most conclusively shown that its eggs are habitually laid in the hanging bag-like nest of Ostinops decumanus.

As we have seen in the preceding pages, a vast number of birds are at great pains to conceal their nests from view, not only by hiding them in a great variety of situations, but by assimilating them with surrounding objects both in colour and in form. But with the builders of the most typical pendulous nests no attempt is ever made to conceal them. They hang at the extremity of branches in full view of all, and it would seem that in many cases the birds sought 
to encourage discovery rather than to evade it. Some of the birds, however, building the more intermediate types of pendulous nest, take pains to hide their nests amongst the leaves at the extremities of drooping branches; others make their homes resemble drift or masses of rubbish lodged in the trees. The safety of the truly pendulous nest, however, does not depend in any way upon its concealment, that safety is derived from the peculiarities of the position in which it is placed, at the extremities of slender branches.

As we have already seen, this situation is selected for the nest by a great number of species breeding in the warmest regions of the earth. These regions abound in the most deadly enemies to birds and eggs, and it is only reasonable to expect that the most elaborate methods are there pursued in order to defeat them. Some of the most dreaded of these enemies are monkeys, lizards and snakes, but even these agile creatures are absolutely baffled in their attempts to reach nests suspended so airily, brooding parent and precious eggs swinging in safety far from the ground or over deep waters, which such creatures specially avoid.

Our review of avine architecture is now brought to a close. All things considered, it may be regarded as reasonably complete. It is, of course, impossible to deal with the nidification of some twelve thousand species of birds, even if the nests or methods of 
reproduction were all known. There are, however, a great many birds whose nests still remain absolutely unknown, or, at least, have never been described by any competent naturalist. The bulk of these belong to species peculiar to the South American continent, a region exceptionally rich in bird life, and as equally poor in working naturalists. Then, again, it would be quite unnecessary to describe more than one nest in many groups, that of one being almost an exact replica of another. Broadly speaking, every special type of architecture has been described, and each has been fairly well, in some cases exceptionally well, illustrated by numbers of examples; whilst every opportunity has been taken to touch lightly upon the philosophic side of the subject. More than this could not be attempted in a little work, which, besides being a pioneer, standing practically alone at the threshold of an almost neglected science, makes no more ambitious pretension than to introduce the reader to the very fascinating study of Birds' Nests.

In our wide review of avine reproduction, we com. menced with the consideration of those birds that either make no provision for their eggs or young, the absolutely nestless that seek the bare earth for a cradle, or those that annex the deserted cast-off home of some more industrious, shall I say, more provident species? Or yet again the parasites, the birds that shirk every parental duty and leave their egg to be hatched and their young fostered by another 
and a stranger species. From these we have passed to those birds that make the crudest nest forms, and through them have reached such species that hide their homes away in concealed or covered sites. Our next division has included the builders of the open type of nest, a type that is not only extremely common, but adopted by the members of almost every great group in the avine kingdom. Passing on we reach the more complicated type of a domed or roofed nest, in which we may fairly assume that the architectural skill of birds has attained to a very high level; and that, in my own opinion, reaches its absolute climax in the builders of pendulous nests which have formed the subject of our closing chapter.

I may conclude the present volume by quoting some very beautiful lines on a Peacock's feather, the sentiments of which as aptly apply to the Nests of Birds :-

In Nature's workshop but a shaving,

Of her poem but a word,

But a tint brushed from her palette,

This feather of a bird !

Yet set it in the sun glance,

Display it in the shine,

Take graver's lense, explore it,

Note filament and line,

Mark amethyst to sapphire,

And sapphire to gold,

And gold to emerald changing

The archetype unfold!

Tone, tint, thread, tissue, texture,

Through every atom scan, 
Conforming still, developing,

Obedient to plan.

This but to form a pattern

On the garment of a bird ! What then must be the poem, This but its lightest word! Sit before it ; ponder o'er it, 'Twill thy mind advantage more Than a treatise, than a sermon, Than a library of lore. 



\section{INDEX}

A

Аввот, Dr, 222

Acæna affinis, IOI

Accentor, Iro

Accentors, I ro

Accentor, Hedge, 26

Accipitrinæ, I60

Acredula, I2I, I86, 225

Acredula rosea, 226

Acrocephalus, I9r

Acrocephalus arundinaceus, I9I

Aëdon, I92

Egithalus, 186, 255

Agithalus coronatus, 256

Egithalus pendulinus, 255

Ethopyga, 225

Ethopyga bella, 223

Ethopyga dabryi, 223

Athopyga ignicauda, 223

Ethopyga longirostros, 185

Etbopyga magnifica, 223

Aix, 124

Alaudidæ, 220

Albatrosses, I4I

Albatross, Great, I4I

Albatross, Sooty, I 42

Alcidæ, 97, 108

Alcedinidæe, 93

Alcedo ispida, 93

Alcurus striatus, I96

Allen, 5

Allen's Humming-bird, 167

Ampelidæ, I87, 228

Ampelis garrulus, 187

Anatidæ, I24

Anis, 69

Annexers, 46

Anous stolidus, 79

Anseres, 82
Anser cinereus, 138

Anseriformes, 81, 138, 152

Anserinæ, 82

Anthipes leucops, $23^{8}$

Anthodiæta collaris, 224

Anthus obscurus, II3

Anthus pratensis, I I 2

Anthus rufulus, 183

Aptenodytes tæniata, 76

Aquila, 159

Arachnothera, I94, 221

Aramidæ, I 54

Ardea cinerea, 144

Ardea garzetta, I44

Ardea purpurea, I43

Aritaná, I78

Arremon alurantiirostris, 218

Arses candidor, 200

Athene glaux, I08

Athene noctua, 108

Auks, 45. See Guillemot and Razor-bill

Auk, Little, 108

Aves de Brazil, by Dr Goeldi, 267

Avocet, 74

Azorella selago, IOI, I07, I42

B

BADGER, 96

Baker, S., I97, 227, 233, 235 237, $24 \mathrm{I}$

Baldamus, Dr, 57,69

Barba da velho, 263

Barbet, I I9

Basilinna xantusi, $\mathrm{I} 64$

Battye, I39

Bee-eater, Common, 94, 95

Bee-eaters, 94, I3I

S

273 
Belenogaster rufipennis, 2 I7

Bendire, Major, 58, 227

- Captain, 96

Benson, Lieutenant, 227

Birds, their taste for the beautiful, 7 ; their intelligence as compared with their instinct, pp. 9 to 18,50 ; their other faculties, I9; their adaptability, 80 ; their power of mimicry, 204

Birds, Annexers, 46

Birds, British Museum Calalogue of, 126

Bird, Doctor, 205

Birds, Frigate, $1_{48}^{8}$

Birds, Game, 72

Bird, Humming, 7, 25, I6I, I62, r67, 168

Birds, Mound, I26, 132

Bird, Oil, I03, 104

Birds of Paradise, 174,215

Birds, Parasite, 52

Birds of Prey, 47

Bird, Tailor, 23

Birds, Tropic, 43, 148

Birds, Tyrant, $7 \mathbf{x}$

Birds, Web-footed, 209

Birds, Wren-like, 203

Bitterns, I44, I 45

Bittern, American, I45

Bittern, Little, I45

Blackbird, $16,46,55,188$, 195

Blackcap, 26, 190

Black Woodpecker, 49

Boletus, I66

Botaurus lentiginosus, I 45

Botaurus minutus, $\mathbf{r} 45$

Bower-Birds, 7, I76

Bower-bird, Great, I76

British avifauna, 225

British Birds, a History of, by C. Dixon, 189

Broad-bills, 213

Bucerotidæ, II7

Bucorvus abyssinicus, 118

Buffel-headed Duck, 82

Bulbuls, 196, 198

Bulbul, Blyth's, 197

Bulbul, Finch-billed, 197

Bulbul, Olive, 198
Bulbul, Striated Green, I96

Bullfinch, 62, 180, 182

Bulweria columbina, 108

Bunting, 29, 46, 125, 180,182

Bunting, House, II2

Bunting, Snow, 32, II 3 , II 4

Burchell's Lark-heeled Cuckoo, 212

Burrowing Owl, 95, 97

Burrows, 246

Bush-Tit, 2.27

Bustards, 73

Bustard-quail, Indian, 73

Bustard-quail, Little, 73

Buteo brachyurus, 49

Buteoninæ, 159

Buzzards, 48, 67, 159

Buzzard, Honey, 48

\section{C}

CEREBIDE, I78, 219

Calornis metallica, 259

Calypte costæ, 164

Campephagidæ, 198, 205

Cape Wagtail, 32

Capitonidæ, II9

Caprimulgi, 68

Carpodacus, 182

Carythocichla striata, I96

Cassicus, 265

Cassicus persicus, 263, 266

Cassidrix oryzivora, 267

Cassiques, 265, 267

Cassique, Brazilian, 266

Cassowaries, 42, 65

Cat-bird, 192

Catharista atrata $(=$ American Black Vulture), 43

Catheturus cathami, I28

Centropus, 69, 212

Centropus burchelli, 2 I2

Centropus nigrorufus, 212

Centropus rufipennis, 213

Centropus toulou, 69

Cephallepis delalandi, 165

Certhiidæ, 184

Chaffinch, 6, 14, 16, 18, 24, 30, 64, I80, I8r, I9I, 205

Chaffinch, Common, 180 
Charadriidæ, 74

Charadriiformes, 43,73

Charito netta, 124

Chat, I09, I IO, I32, I 88

Chatterers, 202, 244

Chelidon blakistoni, 2.40

Chelidon cashmeriensis, 240

Chelidon urbica, 239

Chiffchaff, 63, 64, 229

Chlamydodera nuchalis, 176

Chleophaga melanoptera, Iog

Chough, 62, 64, 102, 133

Christy, Dr, 7I, 228

Chthonicola, 230

Ciconia alba, 146

Ciconia nigra, I47

Ciconiidæ, 146

Cinclidæ, I92, 230

Cinclus aquaticus, $23 \mathrm{I}$

Cinnyris aldabrensis, 222

Cinnyris chalybæus, 224

Cinnyris gutturalis, 224

Cinnyris habessinicus, 222

Cinnyris jugularis, 222

Circus æruginosus, 160

Circus cineraceus, I6r

Circus cyaneus, 160

Cisticola, 194, 229

Cisticola cursitans, 230

Cisticola subruficapilla, 230

Cisticola terrestris, 230

Clangula, 124

Coccothraustes, 182

Coccyzus americanus, 68

Coccyzus erythrophthalmus, 68

Coccyzus glandarius, 54

Cock of the Rock, 103

Cockatoo, Australian, II9

Coffin-Bird, 32

Colies, 169

Coliidæ, 169

Collocalia, IO4

Collocalia esculenta, ro4

Columba livia, 102

Columbiformes, 69

Colymbidæ, 75

Cometes sparganurus, 166

Conurus, 95

Coots, 27, 55, I54, 157

Coot, Giant, 155

Coracias caudatus, 120
Coracias garrulus, 95

Coracidæ, 120

Coraciiformes, 68, 16I, 2 II

Cormorants, $1_{3}, I_{4} 8, I_{50}, I_{5}$, I6I

Corvidæ, 17I, 2I 4

Corvus corax, I7I

Corvus fuigelegus, I7I

Corvus monedula, I02

Cotingidæ, 202, 244

Coua, 69

Coucal, 69

Coues, Dr, g6

Courser, 43,74

Cow-bird, 54, 58, 267

Crake, Corn, 140,156

Crakes, I 54

Cranes, $75,153,154$

Crane, Common, 153

Crane, Demoiselle, 153

Craspedophora, I75

Craspedophora alberti, $\mathbf{1 7 5}$

Crawston's "Ostrich Farming in California," 65

Creepers, 184

Crex pratensis, 156

Crossbills, 180, 181

Crotophaga, 69

Crow, $47,48,49,50,54,62,63$, I22, I23, I7I, 173, 174, 214, 226

Crow Pheasant, Indian, 213

Crypturi, 66

Cuckoo, 52, 57, 68, 212, 259

Cuckoo, Black-billed, 68

Cuckoo, Black-breast Lark-heeled, 212

Cuckoo, Common, 54

Cuckoo, Great Spotted, 54

Cuckoo, Lark-heeled, 69, 212

Cuckoo, North American, 69

Cuckoo, Yellow-billed, 68

Cuculiformes, 68, 212

Cuculus canorus, 54

Curassows, 72, 73, I39

Curlews, 74

Curlew, Stone, 44, 73

Cygninæ, 82

Cyornis, 123

Cypselidæ, 2II

Cypselus Melba, ro6 


\section{D}

Dacelo, 93

Daption capense, 77

Darter, I48, I 5 I

Darling, 2 I2

Darwin, Charles, 7

Dasyornis, 230

Davidson, J., I23, 127

De Laland's Plover-crest, $\mathbf{x}_{5}$

De IAa Touche, 227, 233

Dendræeca capitalis, I84, 220

Dendrochelidon, I68

Dendrocitta, $\mathbf{1 7 2}$

Dendrocolaptidæ, 92, 203, 244

Descent of Man, Darwin's, 7

Dicæidæ, 225, 256

Dicæipæ, I85

Dicæum cinereigulare, 225

Dicæum cruentatum, 225

Dicæum hirundinaceım, 256

Dicæum minimum, I86

Dicruridæ, 176

Diomedea chionoptera, I4 I

Dipper, 25, 192, 230

Dipper, British, 23I

Diver, 75

Dixon, Charles, Story of Birds, $5,28,169$

Dotterel, 74

Dove-cote Pigeon, 30

Dove, Ring, $24,47,48,49,50,64$

Dove, Rock, 102

Dromadidæe, 75

Drongos, 176, 215

Drymocataphus tickelli, 236

Ducks, $22,27,30,33,82,83,84$, I24

Duck, Buffel-headed, 82, I24

Duck, Eider 32, 55, 83

Duck, Golden-eyed, 82, I24

Duck, Mandarin, I24

Duck, Tufted, 55

Luck, Wood, I24

Dulus dominicus, 228

E

EAGLE, $13,67,158$

Eagle, American Bald, 159
Eagle, American Harpy, I59

Eagle, Sea, I 59

Eagle, Pallas' Sea, I 59

Eagle, Short-toed, 48

Egrets, I44

Egret, Little, I44

Eider, 32, 55, 83

Elachura haplonota, 234

Elachura punctata, 234

Emberiza, I25

Emberiza saharæ, II2

Embernagra striaticeps, Central American, 220

Emerson, Otto, 167

Emus, 42, 65

Endyptes chrysocome, 77

Erithacus luscinia, 125

Erithacus rubecula, I25

Estrilda angolensis, 2 r6

Eulipoa wallacii, 127

Euplectes, 218

Eurylæmi, 213

\section{F}

FALCON, 27, 48, 66

Falcon, Iceland Jer, 48

Falcon, Jer, 66

Falcon, Peregrine, 66

Falcon, Red-legged, 48

Falconiformes, I 57

Fantails, 229, 230

Fantail, Grey-backed, 230

Fantail, Ground, 230

Feilden, Colonel, 205

Ferreirinho, 243

Fiery Topaz, 166

Finches, 26, 179, 219. See Goldfinch, Chaffinch, Bullfinch, \&c.

Finches, Weaver, 2x6

Finfoots, I 54 , I 56

Flamingoes, 81,152

Flower-peckers, 185, 225, 256

Flower-pecker, Australian, 256

Flower-pecker, Thick-billed, 256

Flycatchers, I 22, I32, I99, 237, 257

Flycatchers, Broad-billed, 20I

Flycatchers, Fan-tailed, 201

Flycatcher, Frill-necked, 200 
Flycatcher, Pied, 122, 134

Flycatcher, Red-breasted, 199

Flycatcher, Spotted, 30, 3I, I34, 199

Flycatcher, Yellow-breasted, 200

Formicariidæ, 203

Foudia, 218

Fowl, Spur, 73

Fratercula arctica, 97

Fratercula corniculata, 108

Fregatid $\boldsymbol{x}$, I5I

Frigate Birds, I 48 , I 5 I

Frilled Coquette, $16_{3}$

Fringilla cælebs, 180

Fringilla carduelis, I8I

Fringillidæ, I79

Frogmouths, 68

Fulica gigantea, I 55

Fulica leucoptera, 155

Fulmar Petrel, 22, 43, 78

Funarius, 244

Funarius rufus, $2+4$

\section{G}

GALBULIDÆ, 94

Galliformes, 72, I30, I38, I 40

Gallinules, I 54

Gallinula chloropus, ${ }_{5} 6$

Galloperdix, 73

Game-Birds, 72

Gampsorhynchus rufulus, 236

Gannets, I48, I 50

Garrulax, I94

Garrulus glandarius, 173

Garrulax gularis, 195

Gecinus viridis, I 15

Geese, 82, 84, 109

Geococcyx, 69

Geophaps, 70

Geronticus hagedash, I 46

Gerygone, 257

Gerygone, Great-billed, 258

Gerygone magnirostris, 258

Gerygone, Masked, 257

Gerygone personata, 257

Goatsuckers, 45, 68

Godwit, 74

Goeldi, Dr, 92, 178, 243, 263, 266, 267
Goldcrests, 186,227

Goldcrest, British, 186

Goldfinch, 16, 180, I8I

Golden eyes, 82, 124

Goosanders, 124

Goose, Grey-lag, I38

Gorse, ${ }^{6} 67$

Gould, 6

Gould's Manucode, I7t

Grackles, I78

Grackle, Purple, 5 I

Grallina australis, I72

Grant (G. L.), I2

Grebes, 27

Grebe, Little, 33

Greenlets, 187

Greenlet, Yellow-throated, 188

Grosbeaks, 180, 182

Grouse, Sand, 7I

Gruiformes, 75, I53

Grus cinerea, 153

Grus virgo, 153

Grypus nævius, 166

Guacharo, 103, 104

Guans, 72, I39

Guide, Honey, II 9

Guillemot, 45

Gull, 26, 43, 44, 55, 78, 79

Gull, Black-headed, 80

Gull, Bonaparte's, 80, I40

Gull, Glaucous, 79

Gull, Herring, 74, 79

Gymnomystax melanicterus, 178

Gypaetus barbatus, $15^{8}$

Gyps fulvus, $\mathbf{I}_{57}$

\section{$\mathrm{H}$}

HALIAËTUS, I59

Haliaëtus leucocephalus, ${ }_{5} 59$

Haliaëtus leucoryphus, $x_{59}$

Haliastur indus, 159

Hall, R., I00, 107, I4I

Halobæna cærulea, Ior

Hammer-head, I 47,2 I0

Hangnests, American, 14, 215, 262

Hanthixus flavescens, 197

Harriers, I6o

Harrier, Hen, 160, I6I 
Harrier, Marsh, 160

Harrier, Montagus, I6I

Hawfinches, 180,182

Hawk, 49, 67, 160

Hawk, Cooper's, 49

Hawk, Short-tailed, 49

Hawk, Sparrow, 27, 47

Hedge Accentor, 26

Heliornithidæe, 156

Hermits, ${ }^{6} 6$

Hermit, Pygmy, 16 5

Heron, $13,27,29,49, x_{43}, x_{45}, 2$ ro

Heron, Cattle, I 44

Heron, Common, $\mathrm{r}_{44}$

Heron, Night, 144

Heron, Purple, I43

Heron, Squacco, $\mathrm{I}_{44}$

Herring-Gull, 74

Hill Stars, 166

Hill Tits, 227

Hirundinidæ, 201, 238

Hirundo, 241

Hirundo ariel, 241

Hirundo erythrogaster, 2.42

Hirundo fulva, $24 \mathrm{r}$

Hirundo hyperythra, 106

Hirundo javanica, 240

Hirundo rustica, 107

Hirundo smithi, r12

Hirundo striolata, 24I

Hoatzin, 72, 73, 139

Hobby, 47

Hobby, Orange-legged, 48

Homes without Hands, by J. G. Woods, 4,30

Homorus, 248

Homorus gutturalis, 248

Homorus lophotis, 248

Honey-eaters, 184, 257, 264

Honey-eater, Banded, 184

Honey-eater, Graceful, 185

Honey-eater, Lanceolate, 257

Honey-eater, Yellow-spotted, 185

Honey Guide, II9

Hoopoe, 32, I19, I 20

Hornbills, $117,118,120,131$

Hornbill, Ground, 118

House-Martin, II, 25, 52, 238 et seq.

House Sparrow, 12, 30, 31, 50, 51, $55,123,219$

Hudson, 54
Hume, 168

Humming-Birds, 7, 25, 16r, 162, $167,168,205,253$

Humming-bird, Allen's, 167

Humming-bird, Calliope, 164

Humming-bird, Circe, 154

Humming-bird, Costa's, I64

Humming-birds, Hermit, 165

Humming-bird, Long-tailed, 167

Humming-bird, Saw-billed, 166

Humming-bird, Xantus's, 164

Hylocharis sapphirina, 165

Hyphantornis, 261

Hypolais, I9I

Hypolais icterina, IgI

Hypothymis, 201

\section{I}

IACHE latirostris, I6+

Ibididæ, $\mathrm{I}_{45}$

Ibis, 1892,104

I897, I78, rog

- 197

1897,260

1897,263

$1898,123,205$

I900, $213,100,107$

- 92

Ibis, $143, \mathbf{1} 45, \mathbf{x} 46$

Ibis, Hagedash, 146

Icteridæ, I4, 54, 21 5, 262

Icterus galbula, 264

Impennes, 76

Iole, 198

Iole virescens, 198

Irby, 95

Iynginæ, 117

\section{I}

JACAMAR, 94, 130

Jacana, 73, 74

Jackdaw, r2, 22, 27, 62, 64, 102, 108, I12.

Jay, $26,50,63,64,173,174$

Jay, Common, 173

Jesse, W., 257, 260

Jouy, 240 


\section{K}

KESTREL, 27, 47

Kidder, Dr, 76, IOI, 142

Kingfisher, 26, 27, 93, 94, 131, I33

Kingfisher, Laughing, 93

Kite, 48, 67, I59

Kite, Brahaminy, I59

Kittiwake, 80

Kiwis, 42, 65

L

LÄMMERGEYER, $15^{8}$

Lane, Ambrose, I55

Laniidæ, 187

Lapwing, 44, 74

Laridæ, 79

Lariformes, 78,138

Larks, 183,220

Lark, Bush, 220

Lark, Magpie, I72

Larus argentatus, 80

Larus glaucus, 79

Larus philadelphia, 80, 140

Larus ridibundus, 80

Lawrence, 2 II

Leisure Hour, 16

Le Souëf, D., I19, I74, 175, I84, $200,257,258,259$

Lewis, F., I86, 240

Limpkins, $\mathbf{I}_{54}$

Linnets, I8r

Linota flamistris, I8I

Liotrichidæ, 227

Lipoa ocellata, 128

Lochmias nematura, 92

Locustella luscinioides, IgI

Locustella nævia, Igc

Lophornis magnificus, 163

Lort Phillips, 222

Lory, Crimson-winged, II9

Loxia, I8I

Lyre-birds, 213

\section{M}

MACHÆRIRHYNCHUS flaviventer, 200

Macropteryx, I68
Magpies, 26, 47, 48, 49, 50, 54, $63,64,122,123,171,214$, 226

Magpie, Common, 214

Majaqueus æquinoctialis, 10

Maleos, 126, I29

Malurus, 230

Mandarin Duck, 124

Manucodia gouldi, I74

Marshall, Guy, 216, 224

- Observations of Mr Darling to, 212

Martin, 55, 112, 238, et seq.

Martin, Fairy, 24I

Martin, House, II, 25, 52, 238, 239,240

Martin, Sand, 26, 90, 91, 94, 98

Magacephalon maleo, 129

Megapodes, 72, 73

Megapodiidæ, 126

Megapodius cumingi, I27

Megapodius duperreyi, I27

Megapodius eremita, 127.

Megapodius macgillivrayi, 127

Megapodius nicobariensis, 127

Meliphagidæe, 184, 257

Mellisuga minima, 166

Menura alberti, 2I3

Menura superba, 213

Menuræ, 2I 3

Menuridæ, 2I3

Mergansers, 82, 124

Merganser, Hooded, 124

Mergus, I 24

Mergulus alle, 108

Merlin, 67

Meropidæ, 94

Merops apiaster, 94

Merrill, Dr, I64

Merula vulgaris, 188

Microglossus aterrimus, II9

Milvinæ, 159

Mimidæ, 192

Mimus carolinensis, 192

Mimus polyglottus, 192

Minivets, 205

Minoteltidæ, 184

Mirafra, 183, 220

Misselthrush, 32

Mniotiltidæ, 220

Mocking-bird, 192, 193 
Molobrus badius, $5+$

— pecoris, $54-58$ refaxillaris, 54

Monticola, Iro

Moorhen, $\mathrm{r}_{3}, 27,33,55, \mathrm{r}_{54}, \mathrm{r}_{5} 6$, 157

Motacillidæe, $\mathrm{rI} 2, \mathrm{I}_{3} 3$

Mound Birds, r26, r3o, 132

Mound Bird, Nicobar, 127

Muscicapa atricapilla, I22

Muscicapa grisola, I99

Muscicapa parva, I99

Muscicapidæ, 199, 237

Muscicapula, 201

Myiagra latriostris, $20 \mathrm{r}$

Myzomela pectoralis, 184

$\mathrm{N}$

Nature, (1886), 240

- (r888), r2, 13

Nectarinia famosa, 225

Nectarinia notata, 22I

Nectariniidæ, 185,220

Nephile, 224

Nests, preservation of, 33 ; mudmade, 143, I7I, 214, 244, \&c.

Nicobar Mound Bird, 127

Nightingale, 125, r $_{34}$

Nightjiar, 45, 64

Nightjar, Owlet, 68

Noddy, 79

North, Alfred, $25^{8}$

Nucifraga, 173

Nucifraga caryocatactes, 173

Nutcrackers, $x_{73}, x_{74}$

Nutcracker, Common, 173

Nuthatches, 122

Nuthatch, Common, 122

Nuthatches, Rock, 228

Nuthatch, Syrian Rock, 228

Nycticorax griseus, 144

\section{$\mathrm{O}$}

OATES, 262

Oceanites oceanicus, I07

Oegotheles, 68
Oestrelata parvirostris, 78

Oil Bird, ro3, ro 4

Opisthocomus hoazin, 139

Oreotrochilus, 166

Origma rubricata, 23I

Orioles, 177, 184, 186, 187, 215, 264

Oriole, Baltimore, 264

Oriolus galbula, 177

Oriole, Golden, 177

Oriolidæ, 177

Orthorhynchus cristatus, 205

Orthotomus, 193

Orthotomus longicaudas, 193

Osprey, 5I, r6r

Ossifraga gigantea, 77

Ostinops decumanus, 263, 266, 267

Ostrich, 42, 65, 7r

Ostrich Farming in California, by Crawston, 65

Otididæ, 73

Ouzels, 189

Oven-bird, 92, 242, 244

Oven-bird, Red, 244

Owl, 47, 49, 67, ro8

Owl, American Barred, 49

Owl, Burrowing, 95, 97

Owl, Eagle, 49, 67

Owl, Hawk, 49

Owl, Little, ro8

Owl, Long-eared, 49

Owl, Saw-whet, 49

Owl, Scops, r23

Owl, Screech, 49

Owl, Snowy, 67

Owl, Southern Little, I08

Owl, Tawny, 49

Owl, Tengmalm's, 49

Owlet Nightjar, 68

Oxbirds, 218

Oyster-catcher, 74

\section{p}

PALAMEDEÆ, 8r

Palamedea cornuta, r 39

Pandioninæ, $\mathrm{r} 5 \mathrm{r}$

Panurus biarmicus, 186

Panyptila, 2II

Panyptila cayanensis, 2 II

Paradise, Birds of, 174,215 
Paradiseidæ, I74

Parasites, 52

Paridæ, 75, I2I, I86, 225, 255

Parrakeets, 95

- South American, II9

Parrot, 27, 68, 109, II9, I31, 212

Partridge, 55, 72

Parus major, 50, I2I, 226

Passeres, 65, 90, 109, 123, 124, I69, 249

Passer domesticus, , I23, 219

Passer montanus, I23

Passer rutilans, I23

Passer salicicola, $5^{\mathrm{I}}$

Passeriformes, 169, 213

Pastor roseus, III

Pediophili, 7I

Pelargiformes, I43, 210

Pelecanidæ, I5I

Pelecaniformes, 148

Pelicans, I48, I5I

Pellorneum, 236

Penguins, 76

Penguin, Rock-hopper, 77

Penguin of Tristan d'Acunha, I3

Peregrine Falcon, 66

Pericrocotus griseigularis, 205

Petrels, 45, 77, 99, IO7, I3I, I4I

Petrel, Bulwer's, 45, I08

Petrel, Cape, 77, I03

Petrel, Fork-tailed, 45, 99, 100

Petrel, Fulmar, 22, 43, 78

Petrel, Giant, 77

Petrel, Spectacled, Ioo

Petrel, Stormy, 99, 100, I08

Petrel, Wilson's, 45, I07

Petronia stulta, 9I

Phæthontidæ, 43

Phaëthornis, I65

Phaëthornis pygmæus, 165

Phacellodomus, 247

Phacellodomus, striaticollis, 247

Phalacrocoracidæ, 150

Phalacrocorax carbo, I 50

Phalacrocorax graculus, 103

Phalarope, 74

Pheasant, 55,72

Philhetærus socius, 217

Phillips, Lort, 222

Phœenicopteri, 8I

Phœnicopteridæ, I 52
Phoniparazena, West Indian, 220

Phylloscopus, 229

Phylloscopus occipitalis, I23

Phylloscopus rufus, 229

Phylloscopus sibilatrix, 229

Phylloscopus trochilus, 229

Pica, $2 \mathrm{I}_{4}$

Pica caudata, 2I4

Picarian Species, 27

Picidæ, II5, II7

Pies, I 72

Pigeon, 62, 69, 70, I03

Pigeon, Dove-cote, 30

Pigeon, Ground, 70

Pinicola, 182

Pipits, II2, 183

Pipit, Indian, 183

Pipit, Meadow, II2

Pipit, Rock, II3

Piprisoma agile, $25^{6}$

Pittas, 202, 244

Pittidæ, 244

Plantain-Eaters, 68

Plataleidæ, I 45

Plectorhynchus lanceolatus, 257

Plectrophenax nivalis, II 3

Ploceidæ, 178, 216, 260

Ploceus, 2I 8

Ploceus baya, 260

Ploceus spilonotus, 26I

Plotidæ, $\mathbf{r}_{5} \mathrm{I}$

Plover, 29, 43, 73, 74

Plover, Crab, 73, 74

Plover, Ringed, 43, 74

Plover-crest, De Laland's, 165

Pnoepyga pusilla, 233

Pochard, 55

Podargidæ, 68

Pomatorhinus, 235

Pomatorhinus phayrii, 235

Porzana cinereiceps, 2II

Pracellodomus sibilatrix, 248

Pratincola rubetra, 189

Pratincole, 43, 74

Presidente da porcaria, 92

Prionopidæ, I72

Prions, IOI

Procellaria leachi, 99, 100

Procellaria pelagica, 99, 100

Procellariiformes, 77, 99, I4I

Progne, I 20 
Psaltriparus, 227

Psaltriparus plumbeus, 227

Psittaciformes, 68, I19, 212

Psophiidæ, 154

Pteroptochidæ, 93, 203, 248

Ptilotis gracilis, 185

Ptilotis notata, 185

Ptilonarhynchinæ, 176

Ptistes coccineopterus, II9

Puffin, 22, 43, 45, 97, 98, I 33

Puffin, Common, 97

Puffin, Horned, ro8.

Puffinus, IOI

Puffinus anglorum, Ior

Pyrrhocorax graculus, I02

Pycnonotidæ, 196

\section{Q}

Quall, Indian Bustard, 73

Quail, Little Bustard, 73

Quelch, J. J., I39

\section{R}

RAILS, 154, 156, I60, 21 I

Ralliformes, 154, 2 II

Ramsay, Dr, 128

Raptores, 27

- Green lining of their nest, $16 \mathrm{r}$

Ratitæ, 42, 65, I32. See Rheas, Cassowaries, Emus, Kiwis, Ostriches

Raven, 48, I7 I

Razor-bill, 45

Redpole, 26, 180

Red-throated Sapphire, 165

Redstart, I1O, I23, 188

Redwing, 29

Regulinæ, 186

Regulus cristatus, 186

Rennie, 4

Rhamphastidæ, 118

Rheas, 42, 65

Rice-bird, Dwarf, 217

Richmond, Charles, 211, 218, 242, 247

Ridgway, 162

Rifle-birds, 175
Rifle-bird, Prince Albert's, 175

Ring-Dove, 24

Ring Ouzel, 125

Rissa tridactylus, 80

Robin, 31, 46, 125, 134

Roller, 95, 120, $1_{3}{ }^{1}$

Rook, 48, 50, 5I, 63, I22, I7I, 266

Rose-finches, 180,182

Rose-coloured Starling, or Pastor, III

Ruby-throat, 163

Rupicola, 103

Ruticilla, I I0

SAND-GROUSE, 7I

Sandpipers, 29, 50, 73, 74

Sandpiper, Green, 50, 75

Sandpiper, Wood, 50, 75

Sand-Martin, 26, 32, 90, 91, .94, 98

Sapphire, Red-throated, 165

Sappho Comet, $\mathbf{1 6 6}$

Saxicola ænanthe, rog

Saxicola deserti, rog

Saxicola pileata, rog

Sclerurus umbretta, 93

Scops scops, 123

Scopus umbretta, 147,210

Screamers, 8I, 139

Sea-Eagle, 159

Sea-Eagle, Pallas', 159

Seebohm, 144, 193

Selasphorus alleni, 167

Shag, 103, 151

Shearwater, 45 , I0 I

Shearwater, Manx, IoI

Sheathbill, 73

Sheldrake, 83

Sheldrake, Ruddy, 83

Shrikes, 187

Shrikes, Cuckoo, 198

Siphia, I23

Sitta cæsia, 122

Sitta syriaca, 228

Sittinæ, 122

Siurus, 220

Siurus auricapillus, 184

Skuas, 70 
Smew, 82, 124

Smith, Little, $2+3$

Snake-Birds, I $_{5}$ I

Snipe, 74

Snow-Bunting, 32, II 3, I I4

Sophodytes, 124

Sparrows, 112, 123, 219

Sparrow-Hawk, 27

Sparrow, House, 12, 30, 3I, 50, $51,55,123,219$

Sparrow, Mountain, I23

Sparrow, Palm, 228

Sparrow, Rock, 9I

Sparrow, Spanish, 5 I

Sparrow, Tree, 123

Speotyto cunicularia, 96

Spermestes nana, 217

Sphenæacus, 230

Spizixus canifrons, 197

Spoonbills, 145

Spotted Fly-catcher, 30, 31, 134, I99

Spur Fowl, 73

Squirrel, 47, 49, 96, 122, 227

Stachyrhidopsis, 196

Stachyrhidopsis rufifrons, 237

Stachyrhis, 196

Stachyrhis assimilis, 236

Stactocichla merulina, 195

Starling, I2, 27, 46, 51, 55, I08, I23, 215,259

Starling, Glossy, 259

Starling, Meadow, 216

Starling, Rose-coloured, III

Steatornis caripensis, Io3

Stegodyphus, 224

Stellula calliope, 164

Stercorariidæ, 79

Stevenson, 55

Stilt, 74

Stilt, Black-winged, 75

Stork, 51, 143, 146, 210

Stork, Black, I47

Stork, White, 146

Story of Birds, by C. Dixon, 28, 169

Streets, Dr, 149

Striges, 67

Sturnella magna, 216

Sturnidæ, III, 215

Sugar-birds, 178, 219

Sula bassana, 149
Sula cyanops, $5_{50}$

Sula piscator, 149

Sulidæ, I 48

Sun-birds, 185, 194, 220, 22I, et seq., 243, 253

Sun-bird, Madagascar, 22 I

Sun-bird, Magnificent, 223

Sun-bird, White-bellied, 223

Sun-bird, Yellow-breasted, 222

Swallows, 12, 25, 50, 106, 120, 201, 238,241

Swallow, British, 107

Swallow, Bungalow, 240

Swallow, Chestnut-bellied, 242

Swallow, Rufous-necked, 24I

Swallow, South African, II2

Swallow, Striped, 24I

Swan, 22, 27, 82, I 39

Swan, Bewick's, 139

Swift, 24, 25, I04, I06, II2, I62, I68, 2 I

Swift, Alpine, 106

Swift, Cayenne, 2r r

Swifts, Tree, 168

Sylvia atricapilla, Igo

Sylvia orphea, I9o

Sylviinæ, 190, 194, 229

Synallaxis, 246

Synallaxis albescens, 247

Synallaxis erythrothorax, 246

Synallaxis phryganophila, 246

Synallaxis pudica, 247

\section{T}

TACHYCINCTA, 50

Tachycincta albiventris, 120

Tailor-Bird, 23, 193, 194

Tailor-bird, Indian, 193

Tanagers, 178,218

Tanagridæ, 178,218

Tanysiptera sylvia, 93

Telegallus fuscirostris, $\mathbf{2} 28$

Tern, $44,64,78$

Tern, Common, 44

Tern, Lesser, 44

Terpsiphone, 20I

Textor, 218

Thalurania glaucopis, 165

Tharrhaleus jerdoni, 205 
Thrasaëtus, 159

Thrush, 178, 188, 192, 230

Thrushes, Ant, 203

Thrush, Golden-crowned, $x 84$

Thrush, Laughing, 194

Thrush, Indian Laughing, I95

Thrush, Rock, I Io, 188

Thrush, Song, I6, I7, 29, 46, 50, r89

Tichodroma muraria, $x$ ro

Tillandsia usneoides, 263

Timeliidæ, I93, 235

Timelines, r93, 235, et seq.

Tinamous, 66

Tit, Bearded, I86

Tit, Bush, 227

Tit, Crowned, 256

Tit, Lead-coloured Bush, 227

Tit, Long-tailed, 255

Tits, Penduline, $255,256,264$

Titmice, 3I, I2I, I86, 225

Titmouse, Bearded, 186

Titmouse, Great, 50, I21, 226

Titmouse, Long-tailed, 6, 8, I6, I8, 25, 64, 225, 227

Titmouse, Penduline, 25, 255

Todidæ, 94

Todirostrum cinereum, 242

Todirostrum maculatum, 243

Tody, 94

Topaza pyra, 166

Toucans, Ir8, r 31

Touche, De La, 227, 233

Tristam, Canon, II 2

Tristan d'Acunha, Penguin of, $x_{3}$

Trochalopterum, I94

Trochalopterum virgatum, I94

Trochilidæ, I62

Trochilus colubris, I63

Trochilus polytmus, 167

Troglodytidæe, 192, 232

Troglodytes furvus, 32

Troglodytes parvulus, 232

Trogons, II8, I 31

Trogonidæ, 118

Trunipeters, I54

Turdidæ, 109, 188

Turdinæ, 188,230

Turdus musicus, I89

Turkeys, Brush, I26, 128

Turnix dussumieri, 73
Turnix tanki, 73

Turnstone, 74

Twite, I25, I8I

Tyrannidæe, 202, 242

Tyrant Birds, 71, 202, 242, 253

Tyrannus dominicensis, $7 \mathbf{I}$

UPUPIDE, II9

VIEILLOT, 49

Vireos, 187

Vireo flavifrons, 188

Vireonidæ, 187

Vultures, 43, 67, I57. See American Black Vultures, 43

Vulture, American Black, 43

Vulture, Bearded, 48, $15^{8}$

Vulture, Egyptian, 48, I57

Vulture, Griffon, I57

Vultur monachus, I 58

Vulture, Old World Black, I 58

Vulture, Turkey, 49

\section{W}

WAGTAIL, 30, 3I, II 3,183

Wagtail, Cape, 32

Wagtail, Pied, 183

Wagtail, Yellow, ${ }^{8} 8$

Wall Creeper, I Io

Wallace, Dr, Theory of Birds' Nests, 4

Wallace, Dr, 22, 24, 28, I29, I30

Wallace, Alfred Russell, 9, r 8

Warblers, I88, I90, 229, 257

Warblers, Fantail, 229

Warbler, Garden, 26

Warbler Grasshopper, r9o

Warbler, Icterine, I9I

Warbler, Marsh, 26, 190

Warbler, Orphean, I90

Warbler, Reed, 26, I9I

Warbler, Rufous, I92

Warbler, Savi's, I91

Warbler, Tree, 26, I9I 
Warblers, Willow, 229

Warblers, Wood, I83, 220

Waxbill, Blue-breasted, 216

Waxwings, 187,228

Waxwing, Bohemian, 187

Weavers, Pensile, 26r

Weaver, Yellow-crowned, 26r

Weaver-birds, $178,216,260$

Weaver-bird, Indian, 260

Weaver-bird, Sociable, 217

Weaver Finches, 216

Whale-birds, IOI

Wheatear, I09

Wheatear, Common, I Io

Wheatear, Desert, ro9

Whinchat, 189

White-eyes, 185, 186, 187

Whitethroat, 26, 190

Willow-Wren, 26, 29, 36, 63, 64, 229

Wilson, 264, 265

Woodcock, 75

Wood-hewers, 202, 242, 244, 246

Wood Nymph, Brazilian, 165

Woodpeckers, 27, 49, 55, II 5, I2O, I22, 131, I33
Wood pecker, Black, 49

Woodpecker, Green, II 5, II 7

Woods, J. G., Homes without Hands, 4, 30

Woodward, Messrs, 2 Io

Wood-Wren, 29, 63, 64, 229

Wren, $17,22,24,32,33,74$, I92, $232,233,235$

Wren, Common, 232

Wren, Willow, 26, 29, 36, 63, 64, 229

Wren, Wood, 29, 63, 64, 229

Wrynecks, II7

\section{Y}

YELLOW-BIRD, 184,220

Yuhina nigrimentuın, 227

Yuhina pallida, 227

\section{Z}

ZEOCEPHUS, 201

Zoologist, The (1898), p. 224

Zosteropidæ, 185 





\section{UNIVERSITY OF CALIFORNIA LIBRARY}

\section{Los Angeles}

This book is DUE on the last date stamped below.

SEP 18 1973

Biomed HANGE t1B 1981

JAN 11 RECD

Biomed MAR 161981

MAR 16 RECí

Form L9-40m-5,'67 (H2161s8) 4939 


\section{${ }_{3}|||||||||||||||||||||||||||| \mid$}


